\title{
From setting limits to shaping practices : trust and accountability in health care for older people
}

Citation for published version (APA):

Moust-Ubachs, J. (2011). From setting limits to shaping practices : trust and accountability in health care for older people. [Doctoral Thesis, Maastricht University]. Maastricht University. https://doi.org/10.26481/dis.20110325jm

Document status and date:

Published: 01/01/2011

DOI:

10.26481/dis.20110325jm

Document Version:

Publisher's PDF, also known as Version of record

\section{Please check the document version of this publication:}

- A submitted manuscript is the version of the article upon submission and before peer-review. There can be important differences between the submitted version and the official published version of record.

People interested in the research are advised to contact the author for the final version of the publication, or visit the DOI to the publisher's website.

- The final author version and the galley proof are versions of the publication after peer review.

- The final published version features the final layout of the paper including the volume, issue and page numbers.

Link to publication

\footnotetext{
General rights rights.

- You may freely distribute the URL identifying the publication in the public portal. please follow below link for the End User Agreement:

www.umlib.nl/taverne-license

Take down policy

If you believe that this document breaches copyright please contact us at:

repository@maastrichtuniversity.nl

providing details and we will investigate your claim.
}

Copyright and moral rights for the publications made accessible in the public portal are retained by the authors and/or other copyright owners and it is a condition of accessing publications that users recognise and abide by the legal requirements associated with these

- Users may download and print one copy of any publication from the public portal for the purpose of private study or research.

- You may not further distribute the material or use it for any profit-making activity or commercial gain

If the publication is distributed under the terms of Article $25 \mathrm{fa}$ of the Dutch Copyright Act, indicated by the "Taverne" license above, 




\section{FROM SETTING LIMITS TO SHAPING PRACTICES}

Trust and accountability in health care for older people 
(c) Josy Ubachs-Moust, Maastricht 2010

ISBN 978-90-5335-357-8

Cover design by Nikki Vermeulen, Ridderprint BV

Printed by Ridderprint BV, Ridderkerk, the Netherlands 


\section{FROM SETTING LIMITS TO SHAPING PRACTICES}

Trust and accountability in health care for older people

\section{PROEFSCHRIFT}

ter verkrijging van de graad van doctor aan de Universiteit Maastricht, op gezag van de Rector Magnificus, Prof. mr. G.P.M.F. Mols volgens het besluit van het College van Decanen, in het openbaar te verdedigen op vrijdag 25 maart 2011 om 14:00 uur

door Josy Ubachs-Moust 


\section{Promotores}

Prof. dr. R. Vos

Prof. dr. R. ter Meulen, Bristol, United Kingdom

Co-promotor

Dr. R. Houtepen

Beoordelingscommissie

Prof. dr. F.C.B. van Wijmen (voorzitter)

Dr. R. Dillmann (Zaans Medisch Centrum, Zaandam)

Dr. J.F.B.M. Fiolet (UMC+, Maastricht)

Prof. dr. G.I.J.M. Kempen

Prof. dr. D.L. Willems (AMC, UvA, Amsterdam) 
Aan Iwan

Aan Kes en Dex Aan papa en mama 



\section{Contents}

\section{FROM SETTING LIMITS TO SHAPING PRACTICES}

$\begin{array}{ll}\text { Introduction } & 15\end{array}$

$\begin{array}{ll}\text { References } & 21\end{array}$

$\begin{array}{ll}\text { Chapter } 1 & 23\end{array}$

Age And Age-Based-Rationing In The Medical Decision-Making Process For Older People-A Qualitative Study Of Experts' Views And Perspectives

1.1 Introduction 24

1.2 Methods $\quad 26$

$\begin{array}{ll}1.3 \text { Results } & 27\end{array}$

$\begin{array}{ll}1.4 \text { Discussion } & 35\end{array}$

$\begin{array}{ll}\text { References } & 38\end{array}$

Chapter 2

Informed Consent, Communication And Value Judgments In Medical Care For Older Patients-A Qualitative Study

2.1 Introduction 42

2.2 Methods 43

2.3 Results 46

2.4 Discussion $\quad 51$

References $\quad 55$

Chapter 3

Value Judgments In The Decision-Making Process For The Elderly Patient

$\begin{array}{ll}3.1 \text { Introduction } & 60\end{array}$

3.2 Methods $\quad 60$

3.3 Results 62

3.4 Discussion $\quad 66$

$\begin{array}{ll}\text { Acknowledgments } & 68\end{array}$

$\begin{array}{ll}\text { References } & 68\end{array}$ 
Chapter 4

Trust In Medical Decision-Making Concerning Older People:

The Views Of Key Professionals In The Dutch Health Care Practice

4.1 Introduction

$\begin{array}{ll}4.2 \text { Methods } & 73\end{array}$

$\begin{array}{ll}4.3 \text { Results } & 75\end{array}$

4.5 Conclusion $\quad 87$

Acknowledgements $\quad 88$

$\begin{array}{ll}\text { References } & 88\end{array}$

$\begin{array}{ll}\text { Chapter } 5 & 91\end{array}$

New Views On Medical Professionalism:

Building Medical Practices In Health Care Delivery For Older People

5.1 Introduction 92

5.2 The medical profession in a changing society 92

$\begin{array}{ll}5.3 \text { Building a new medical practice } & 97\end{array}$

5.4 Concluding remarks 105

$\begin{array}{ll}\text { Acknowledgments } & 105\end{array}$

$\begin{array}{ll}\text { References } & 105\end{array}$

$\begin{array}{ll}\text { Chapter } 6 & 107\end{array}$

Shaping Trust And Accountability In Health Care Delivery For Older People: Giving Voice To The Elderly

$\begin{array}{ll}6.1 \text { Introduction } & 108\end{array}$

$\begin{array}{ll}6.2 \text { Trust and accountability } & 108\end{array}$

6.3 Tying together professionalism, trust and accountability 118

$\begin{array}{ll}\text { Acknowledgments } & 122\end{array}$

$\begin{array}{ll}\text { References } & 123\end{array}$

$\begin{array}{ll}\text { Epilogue } & 125\end{array}$

$\begin{array}{ll}\text { References } & 129\end{array}$

$\begin{array}{ll}\text { Summary } & 131\end{array}$

$\begin{array}{ll}\text { Samenvatting } & 135\end{array}$ 
Dankwoord

Curriculum Vitae 




of the Google search machine, I hit upon two types of images of this group of citizens. On the one hand images of frail, sick and needy older people are listed, while at the other hand I came across pictures of laughing older people, projecting an active life style, looking healthy and happy. Thus, two opposite types of older people are represented, classifying older people in two extreme categories. However, is that really all there is to it? Is society only capable of viewing the elderly as either full of life and taking care of themselves or as needy and depressed, requiring care in various ways? What do these images tell us about the way society approaches this group and what is the impact of this perspective on the way older people are approached and treated in health care? What matters here is that age is a characteristic that can easily be determined and thus can provide clear-cut boundaries in legal, societal and medical arrangements. At the same time, however, age is in many respects a poor indicator. It does not provide information on how this person views the stage of life he or she is in, about his wishes and desires. It only tells us something about how many years he or she has lived.

In the 1980's three ethicists, Daniels, Harris, and Callahan, set the lead in the ethical debate on the role of age in medical decision-making (Callahan, 1987; Daniels, 1985; Harris, 1985). They presented a bold and uneasy proposal: older people have had the opportunity to benefit from their life and all the facilities and arrangements provided by society in education, health care, and work to realize their potential. Therefore, under conditions of scarcity, it would be ethically legitimate to give priority to medical treatments for younger people. The central focus in their analysis is whether it can be justified to ration care based on age. Harris' theory is developed on the basis of the notion of intergenerational justice. This is the idea that future or present younger generations may hold legitimate claims against the increasing older generation, to take a step back in receiving curative treatments, especially expensive ones. Callahan and Daniels propose, under conditions of medical scarcity, to focus on care instead of cure treatments in taking care of older people. They state that society can only keep providing adequate long-term care when limits are set regarding the access to acute care services for older people.

This ethical issue of 'age-based-rationing' has kept raising an emotional and provocative societal debate. Ethicists crowded together, as well as medical professionals and their organizations, resulting in a lot of commotion. However, the discussion as raised by these ethicists eventually slipped away for various reasons. First, these proposals are based on a certain normative world-view, which outside of this circle was quickly perceived as unfair and unethical (Churchill, 2005; Giordano, 2005; Hackler \& Micah Hester, 2005; Loewy, 2005; Rivlin, 2000; Springer Loewy, 2005). In addition, these proposals were considered unfeasible on a policy level. For example, in one of the most talked-about reports in the Netherlands on the possibilities for prioritizing and rationing in health care in the 1980's, age is quickly and expressly dismissed (Commissie Keuzen in de Zorg, 1991). Furthermore, some considered the proposal as de facto irrelevant. Young, for example, dismisses the ethical focus on age-based-rationing with one stroke of the pen, arguing that the notion of age-based-rationing has become unsustainable and unethical as there is increasing evidence that clinical outcomes for older people, are in no way inferior to those for younger people (Young, 2006). Here, Young discusses in fact the heart of the matter: the problem is not poor outcomes for older people, but increasing good outcomes. Finally, medical professionals were simply not interested in basing their treatment decisions on this kind of criterion, (e.g. Choo, 1994; Hunt, 1993; The Lancet, 1993). Doctors like to think that they 
only take medical decisions based on an assessment of the prognosis and the options for one specific patient.

Beyond the rationing debate, reasons for discussing the role of age in medical decisionmaking are also found. Interestingly enough, Callahan's contribution to the rationing discussion already covered some of these reasons. In his book Setting Limits, he discusses setting limits by way of rationing cure treatments above a certain age and he presents a proposal for limiting the continuous extension of life (Callahan, 1987). Callahan made an effort to broaden the debate regarding financial and societal resources provided to the various age groups in society, by addressing fundamental questions about the meaning of old age, the social position of older people in modern western societies, and the needs for long-term care. In this way, he questioned social views on the goals of medicine and health care.

It is intriguing to see how Callahan's proposal, although being encountered with major ethical and social opposition, actually addresses fundamental issues regarding the demographic change in our populations and the growing needs for health and social care, which are becoming more urgent. At the background of these issues different views on a good old age and on good care play their part, resulting in different answers to the questions of what a good society is obligated to provide for older people, to what the rights of older people in the context of health care pertain, and what the preconditions are for dealing with older people in a decent manner.

Some of the authors in the debate specifically emphasize a broader context outside rationing and beyond the discussion of medical scarcity. According to these authors, the position of older people in society is often perceived with distrust and hostility. In our society, old age and the elderly are often viewed in a negative way. The ultimate form of this negative perception of old age is ageism, conceived as the systematic stereotyping of and discrimination against older people, because of their age (Cole, 1986). As Murray argues, we are inclined to think of the lives of the aged among us as having less value than the lives of younger people. Older people retire from productive participation in the community's economic life and spend their remaining years in leisurely pastimes of no genuine significance (Murray, 1991). Although opponents of ageism have a strong case as it is unjust to discriminate people because of their (old) age, Cole urges us to be sceptical at the same time. Scepticism is required towards the liberal assumption that underlies anti-ageism, namely that age is irrelevant, that old people differ from young people only in their chronological age (Cole, 1986), which does not do justice to reality. In general, older people's perspective on life, the goals they want to achieve, and their relationships with relatives and friends have changed as they have grown older, and are usually different from the perspectives of younger people (Agich, 2003).

Furthermore, according to some authors, when the limits of someone's life come into view, questions on the meaning of life and the meaning of old age as a specific period in life come into play (Moody, 1986; Murray, 1991). According to Moody, it seems certain on demographic grounds alone that more and more people will be confronted with the 'limit situation' of old age in which the whole of life itself may be put into question (Moody, 1986). For example, the well-known example of the life boat, in which there is only one place left. Instinctively, it is often suggested, we feel the older person should give up his place to save the younger person, who still has many years left and thus is given the opportunity to make something out of his life, as the older person already has had his chance. However, according to Moody, through biomedical technology all possible 
efforts are spent to keep elderly patients alive as long as possible. Thanks to the triumphs of public health and general affluence, an increasing proportion of the population will experience the last stage of life-old age- as progressively drained of specific meaning. At the moment when the meaning of old age vanishes, we find that huge economic resources are spent to prolong lives deprived of any purpose. This paradox becomes apparent to anyone who works among the elderly in our society (Moody, 1986). As ageism may result in under treatment of older people, anti-ageism and the denial of a specific meaning of old age may result in the opposite that is over treatment of older people, in the sense that life is prolonged beyond meaning. Gerontologists and physicians have always upheld the motto 'adding life to years, and not merely years to life', but this may sound as wishful thinking in the light of Moody's observations.

Both discussions on ageism and the meaning of old age are thus permeated with values. Ageism is mainly concerned with discriminative judgments concerning the value of older people for society. The discussion on the meaning of old age, although not based on a discriminative foundation, touches upon certain prejudices regarding older people as well. Consequently, society is imbued with conscious and unconscious value judgments concerning older people and old age. Professionals working in health care cannot stand aside in this debate, as they are part of society. It would be naive to expect, that for physicians these values do not influence their attitude towards older people and their care.

Parallel to the debate on the role of age in medical decision-making, a new type of vocabulary has developed concentrating on issues like quality of life, good care and appropriate care. Outcome criteria for medical interventions are drawn wider. By now, quality of life is a standard indicator for the outcome of treatments, especially in the long run (Daatland, 2005; Testa \& Simonson, 1996). In these discussions, a different note is struck: a note of warning. Instead of concentrating on the role of age, should we not focus on issues such as good care and quality of life? In these debates a central focus is provided by the question whether sometimes medical treatments do more harm than good. For example, when treatments will not result in a full recovery of health or when there are serious sideeffects of the proposed treatment. This is, however, a difficult question to answer. The issue of quality of life is meant to be helpful in formulating a response to this dilemma. This raises the issue of how to define beneficence in the assessment of medical treatment. This issue includes discussions on the goals of medical care and on the limits of life-extending treatments (Musschenga, 1987, 1997). In the Netherlands the discussion on quality of life has resulted in the launch of the Leyden Academy on Vitality and Ageing. It is the first institute in the Netherlands to train pioneers in implementing excellence to advance the quality of life of older people, including the very old ( 85 years and older). The Academy trains young medical doctors and ambitious professionals to become pioneers in implementing excellence to advance the quality of life of older people (www.leydenacademy.nl).

However, will the debate on quality of life and what it means to provide 'good' care to older people be enough to counterbalance the impact of ageism, and in relation with it, be able to prevent over and under treatment of older people?

We are confronted with a paradox, we prolong lives without valuing the years added, in the care for older people, as Moody suggests (Moody, 1986). If we want to try to answer the question what it means to provide 'good' care to older people, we should be aware that the care for older people is affected by both types of attitudes. On the one side there are ageist attitudes, which may lead to under treatment of older people, while on the other side, anti-ageist considerations have the risk of over treatment. In both cases the 
wishes and desires of the individual patient and quality of life considerations are overlooked. Thus, there are many reasons to discuss the role of old age in medical decisionmaking and the various types of value laden arguments, hidden or not, that play a role in the decision process as part of quality of life and quality of care considerations.

In sum, the debate on the role of age focused on three issues. First, it centred on the role of scarcity in the provision of care for older people. Second, the influence and consequences of the meaning of old age and ageism in society in the care for older people were discussed. And third, the question was asked, what does it mean to provide good care to older people?

This thesis aims to reflect on the way these issues shape medical practice and on the considerations and preconditions to ensure that such shaping takes place in a legitimate and productive way. This means it is not a normative study on whether it is ethically justified or not to use age as a criterion for medical decision-making. Instead, we focus on what the exact role is of these value judgments in the decision-making process concerning older people. The various aspects of the debate on the role of age in medical decision-making as discussed here, are the basis for this thesis and for answering this question. Recalling the discussion of Callahan's proposal at the beginning of this Introduction, it is our purpose in this thesis not to set limits, but to promote elderly sensitive medicine, including awareness that more health care is not always better. Also, we want to place our discussion on the societal level, but without the attention to set limits. In terms of shaping health care practices we believe it is not preferable to impose the outcomes of ethical and social debate on medical professionals. Instead, the practice and views of these professionals should thoroughly be taken into account. Therefore, we studied both decision-making practices in the care for older people and the reasons given for these decisions. We believe the main ethical and social question is whether doctors can be trusted to make such decisions, and whether their accounts can stand the test of scrutiny. Subsequently, we want to develop a framework based on accountability and trust in the care for older people.

\section{Outline of the book}

In this thesis, the issues identified above will be further analyzed, resulting in two main subjects: trust in doctors and accountability of doctors both specifically regarding the role of value judgments in the decision process in the care for older people. The coordinating question concerns whether and how the public can trust physicians in the care for older patients and how a more accountable medical practice concerning older patients can be reached. We divided this question into six sub questions, which are separately addressed in the chapters.

In Chapter 1, we take a closer look at the debate on the role of age as it has resulted in two established views on medical decision-making for older people. First, age-basedrationing is generally rejected as a tool in deciding what care to provide to older people. Secondly, age can only be accepted as part of a strictly medical-technical approach of decision-making in health care. Physicians should only be allowed to use it as a strictly medical criterion. In this chapter, we address the uncertainties and questions surrounding these views, including what is a medical or clinical criterion and how can age be part of a strictly medical-technical assessment. More specifically, we are interested in what these views mean for the role of value judgments regarding old age. We performed interviews with key professionals in clinical practice and policy-making in health care. The views of these professionals raise concerns about how patients and society should (re)consider 
their trust in physicians. We therefore need a closer look at medical practice.

In Chapter 2, we focus on the interaction between physician and older patients. Our goal is to present arguments to reconsider the role of age and ageist arguments in the communication between physician and older patient. We will do so by first identifying the various patterns in the way this communication process is structured. Second, we will perform a comparative analysis of the identified patterns, trying to explicate the most significant ways how the value laden use of age enters the process of decision-making and delivery of care in the setting of the relationship of the physician and the older patient. Third, we will then discuss the presented results in terms of the informative and deliberative models of the physician-patient relationship as identified by Emanuel and Emanuel (Emanuel \& Emanuel, 1992), which present different ways of connecting medical facts and values and shaping distinct roles for the physician and patient in health care. In this way we hope to contribute to the normative debate on the role of age in clinical communication and decision-making. We propose transparency in the criteria and arguments influencing the communication and decision-making process regarding older patients. Thus, trust in the medical profession regarding the care of older people will be enhanced.

Subsequently, in Chapter 3 we investigate how exactly age influences the decision-making process in medical care. To explore the normative argumentation in the decisions regarding an older patient we make use of the argumentation model advanced by Toulmin (Toulmin, 1958). Our results in this chapter show the pervasive character of age related value judgments. They influence the physician's decision in several ways and at several points in the decision-making process. Since age plays such an important, yet hidden role in the medical decision-making process, we return to the question what is needed to improve the physician-patient relationship and to create trust.

Chapter 4 deals with the issue of public trust in decisions made by individual physicians, concerning older people, as perceived by various key professionals. While trust is a basic element in our health care service, it is at the same time a difficult phenomenon to conceptualize. This paper tries to contribute to a better understanding of what trust in medical practice entails, and what are the necessary conditions for a society to put trust in the medical profession. We found roughly three categories of trust: distrust, trust and qualified trust. In each category, we found different reasons to give or withhold trust in doctors and different views on how far the discretionary power of doctors should go. In this chapter, we recommend promoting trust by addressing the criteria or limits brought forward in the qualified trust category.

In Chapter 5 and 6 then, we are able to address the research questions as presented above regarding accountability and trust in physicians concerning the care for older people. We therefore first take a closer look in Chapter 5 on what is discussed in the context of trust by medical professional organizations and link this to the elements needed for constructing an elderly focused practice. Subsequently in Chapter 6, we will provide a more detailed description of what we believe trust and accountability entail in the context of the care for older patients. We conceptualize this as building new practices, for we will present a set of important building blocks in the form of what medical professionals should do (Do's) and what they should not do (Don'ts). Via a theoretical discussion of the concepts of trust and accountability, we will finally present a new framework of accountability in the context of the care for older patients. 


\section{References}

Agich, G. J. (2003). Dependence and autonomy in old age. An ethical framework for long-term care (Second and revised edition ed.). Cambridge: Cambridge University Press.

Callahan, D. (1987). Setting limits: medical goals in an aging society. New York: Simon \& Schuster.

Choo, V. (1994). Gaps in UK research into elderly. The Lancet, 344, 745.

Churchill, L. R. (2005). Age-rationing in health care: flawed policy, personal virtue. Health Care Analysis, 13(2).

Cole, T. R. (1986). The 'Enlightened' View of Aging: Victoria Morality in a New Key. In T. R. Cole \& S. A. Gadow (Eds.), What Does It Mean to Grow Old? Reflections from the Humanities (pp. 115-130). Durham: Duke University Press.

Commissie Keuzen in de Zorg. (1991). Kiezen en delen. Rijswijk.

Daatland, S. O. (2005). Quality of life and ageing. In M. L. Johnson (Ed.), The Cambridge Handbook of Age and Ageing (pp. 371-377). Cambridge: Cambridge University Press.

Daniels, N. (1985). Just health care. Cambridge: Cambridge University Press.

Emanuel, E. J., \& Emanuel, L. L. (1992). Four Models of the Physician-Patient Relationship. Journal of the American Medical Association, 267(16), 2221-2226.

Giordano, S. (2005). Respect for Equality and the Treatment of the Elderly: Declarations of Human Rights and Age-Based Rationing. Cambridge Quarterly of Healthcare Ethics, 14, 83-92.

Hackler, C., \& Micah Hester, D. (2005). Age and the Allocation of Organs for Transplantation: A Case Study. Health Care Analysis, 13(2), 129-136.

Harris, J. (1985). The value of life. An introduction to medical ethics. London/New York: Routledge \& Kegan Paul.

Hunt, R. W. (1993). A critique of using age to ration health care. Journal of Medical Ethics, $19,19-23$.

Loewy, E. H. (2005). Age discrimination at its Best: Should Chronological Age be a Prime Factour in Medical Decision Making? Health Care Analysis, 13(2), 101-117.

Moody, H. R. (1986). The Meaning of Life and the Meaning of Old Age. In T. R. Cole \& S. A. Gadow (Eds.), What Does It Mean to Grow Old? Reflections from the Humanities (pp. 9-40). Durham: Duke University Press.

Murray, T. H. (1991). Meaning, Aging, and Public Policy. In R. H. Binstock \& S. G. Post (Eds.), Too Old for Health Care? Controversies in Medicine, Law, Economics, and Ethics (pp. 164-179). Baltimore and London: The John Hopkins University Press.

Musschenga, A. W. (1987). Kwaliteit van leven. Criterium voor medisch handelen? Baarn: Ambo.

Musschenga, A. W. (1997). The relation between concepts of quality-of-life, health and happiness. The Journal of Medicine and Philosophy, 22, 11-28.

Rivlin, M. (2000). Why the fair innings argument is not persuasive. BMC Medical Ethics, 1(1). Springer Loewy, R. (2005). Ageisms. Health Care Analysis, 13(2), 147-156.

Testa, M. A., \& Simonson, D. C. (1996). Assessment of quality-of-life outcomes. The New England Journal of Medicine, 334(13), 835-840.

The Lancet. (1993). Do doctors short-change old people? The Lancet, 342, 1-2.

Toulmin, S. E. (1958). The Uses of Argument. Cambridge: University Press.

www.leydenacademy.nl. Retrieved 15 March 2010

Young, J. (2006). Ageism in services for transient ischaemic attack and stroke. Could be cut 
by emulating succesful efforts against ageism in heart disease care. British Medical Journal, 333, 508-509. 


\title{
Chapter 1
}

Age And Age-Based-Rationing In The Medical Decision-Making Process For Older People A Qualitative Study Of Experts' Views And Perspectives

\author{
Josy Ubachs-Moust \\ Rob Houtepen \\ Wybo Dondorp \\ Ruud ter Meulen \\ Rein Vos
}




\subsection{Introduction}

ince the 1980's philosophers, ethicists, lawyers and medical professionals have fiercely debated the role of age in medical decision-making. The work by Callahan and Daniels started a discussion on rationing of health care on the basis of age as a possible solution to the increasing health care costs and growing scarcity in resources: the basic idea of their proposals is that it is ethically legitimate to provide health care to younger people at the expense of the elderly, although different arguments were used by these authors (Callahan, 1987, 1990; Daniels, 1985). Consequently, a fundamental debate arose on the central question whether it can be justified to limit the care to older people on the basis of their advanced age (Rivlin, 1999a). Various authors explicitly argued against age-based-rationing on various reasons, for example because of its supposed discriminative nature (e.g. Binstock \& Post, 1991; Choo, 1994; Rivlin, 1999b; Thomasma, 1991; Young, 2006), while some found multiple grounds in favor of using age as a criterion (Clarke, 2001; Maynard, 1996).

The outcome of this debate was ultimately twofold. The first outcome was the rejection of age-based-rationing as a tool in deciding what care to provide to older people on a policy level and in the consultation room, not only by philosophers and ethicists, but also by many medical professionals, including their representative organizations, as well as by society at large. In this respect renowned international organizations, such as the European Union (EU), the World Health Organization (WHO), and the United Nations (UN) have formally condemned any form of 'ageism', including ageism in health care provision (Giordano, 2005). The second outcome was that age itself is more broadly rejected as a standard for medical decision-making on the level of the physician-patient relationship. To ration on the basis of age alone came to be considered unfair to the individual who would be denied treatment, and damaging to the community because of the danger of disrupting solidarity in democratic societies (Loewy, 2005). Only when age can serve as a true medical criterion, physicians are allowed to use it as a criterion in the decision-making process concerning the care for older people (Vrakking et al., 2005). In this respect, it is acceptable that physicians are considering the fact that in general older people are more vulnerable than younger people that their bodies are not that strong anymore and that prognosis and prediction of risks are complicated by the time window of the years left in their life. However, these considerations can only be used in the context of the medical assessment of needs and interests of the elderly.

This view, that age may only play a role as part of a strictly technical assessment, implies that these subject matters have moved from the policy level to the level of the medical profession, since medical assessments should be left to the physician's discretion. The medical professional is supposed to use her medical expertise in dealing with this issue: in the process of collecting data about symptoms, signs and condition of the patient (anamnesis and physical examination), the construing of the (differential) diagnosis and further the provision of therapy or prevention, science and evidence based medical decision-making should be the goal of any physician. Only in this medical sense, age might become part of the various stages of medical decision-making. But, is it really as clear-cut? What does this mean in the practice of treating an older patient? The notion of age as a medical criterion is beset with uncertainties and difficulties, and continuously raises many questions and discussions. For example, what is a medical or clinical criterion and when is age part of a strictly technical assessment (Kilner, 1990)? When and how are value judgments made 
and how can these be accounted for (Hope, Sprigings, \& Crisp, 2002; Truog et al., 2006)? The view as formulated here suggests a specific conception of the medical decision-making process and the relationship between physician and older patient. In this view, the medical decision-making process takes place based on the scientific and objective knowledge the physician possesses. When reaching a decision a physician weighs this knowledge and makes an objective assessment regarding the patient's condition and prognosis. Age as a strictly medical criterion is part of such an objective judgment. It presumes that the physician has the necessary sources of objective evidence at his or her disposal to determine what the nature of a true medical age criterion is. It is viewed as part of a medical decision-making process, in which the physician reaches his decision based on objective medical evidence. This positivistic model of medical decision-making presumes that values only play a role through preferences and interests of the patient self, e.g. accepting or rejecting a certain therapeutic option by the patient. However, the underlying assumption is that specific age-related values and opinions are presumed to play no role in this process. The public trusts physicians to filter out ageist opinions at the gate and that age will henceforth only function as a sound, evidence based and technical variable. The physician then presents his or her findings and therapy and care proposals to the older patient and the patient gives his or her consent or not. In this sense, the move from the policy level to the level of the medical profession appears to be the end of the discussion on the role of age in medical decision-making: no age-based-rationing at the group level and age can only play a role as part of a purely technical assessment at the individual level. However, this picture is too smooth to be true. It does not do justice to the role of value judgments, or more specifically to the role of age as value laden criterion, in medical practice. Various studies show that age plays a role, and not only as a medical criterion, e.g. in organ transplantation (Stahl, Tramontano, Swan, \& Cohen, 2008), in quality of life considerations regarding older people on dialysis (Apostolou, 2007; Halvorsen et al., 2008), in the care for hospitalized patients for acute coronary syndrome and congestive heart failure (Osterwalder, Osswald, Buser, \& Pfisterer, 2001) and in the prescription of statins for the secondary prevention of ischaemic heart disease (Gnavni et al., 2007). Misconceptions regarding what older people can tolerate and what they are likely to gain from treatment still exist. As well as the misunderstanding by many healthcare professionals that older people are a more or less homogenous group (Health Council of the Netherlands, 1998). These studies show hat using age as a purely technical criterion in the decision-making process concerning older people might be not that self-evident.

Thus, the role of age in medical decision-making appears to be less decided than official policy statements, either at the government level or at the medical professional organizational level, suggest. In the original debate, the justifiability of age-based-rationing formed the central point, an issue that is currently much less discussed. But there is still a lot left requiring further investigation and discussion. It is no wonder that, despite the seemingly clear and unambiguous rejection of age-based-rationing, the topic continuously creeps up in the medical and ethical literature (e.g. Binstock, 2007; Bowling, 2007; Churchill, 2005; Giordano, 2005; Hackler \& Micah Hester, 2005; Harris, 2005; Kapp, 2002; Loewy, 2005; Nilstun \& Ohlsson, 1995; Springer Loewy, 2005; Werntoft E. \& Edberg, 2009; Yap \& Celi, 2007). Over viewing these studies, the interesting point is that they attempt to move beyond the straightaway acceptance or rejection of an age criterion, now focusing mostly on the consequences for medical practice and what it means to use age as a criterion. 
In this paper, we want to take a closer look at expert views on how age criteria play a role in the decision-making process concerning older patients. Interviews were performed with key professionals in clinical and societal decision-making. The focus of the study is their views on decision-making for older people in medical practice.

\subsection{Methods}

The aim of this study is to learn about respondents' views and experiences on the role of age and age-based-rationing in the decision-making process concerning older people. We are specifically interested in the views and opinions of various key professionals in clinical and societal decision-making. Such key professionals are found 'inside' medical practice, as well as 'outside' medical practice, like policy-makers, and researchers who are in a position to have a deep understanding of and insight into the health care system and the ways age enters the decision-making process concerning older people. Thus, we want to answer the central question: what views and opinions regarding age as a medical criterion and age-based-rationing are found in the decision-making process regarding older people, according to these experts?

\subsubsection{Design}

The present study has a qualitative design consisting of semi-structured in-depth interviews with 24 key professionals focusing on decision makers and those in line of professionally organizing or influencing the decision-making process on a national level in 2004. The interviews were analyzed qualitatively using grounded theory analysis.

\subsubsection{Sample and recruitment}

The first author (JU-M) conducted the semi-structured in-depth interviews on the role of age in medical decision-making on both the macro and micro level of health care. The respondents are key professionals in their fields of experience in the Dutch health care practice. They were selected to guarantee heterogeneity. Criteria used were, their field of work (for example as a geriatrician or lawyer in the area of health care), their experience in decision-making regarding older people on a macro level (for example as a policy maker in a hospital or at a Ministry), or micro level (physicians) and, if applicable, their position in the discussion on the role of age limits in health care decision-making. Because of the policy and professional practice oriented nature of the study, patients were not included, but two members of representative organizations were interviewed (see below). We focused on the views and opinions of physicians, decision makers and those trying to influence the decision-making process, regarding older people in general. Interviews were conducted with four physicians in the field of geriatric care (two oncologists and two geriatricians), seven policy makers on a national level at the Ministry of Health, Welfare and Sport, on a local level in hospital management, and at the National Institute for Public Health and the Environment, three scientific researchers in the field of health care, two bioethicists, two lawyers in the field of health care, two medical guideline developers, two health economists, and two relevant interest group representatives (one representative of an anti-age-discrimination organization, and one employee of a large union for older people). The interviews ranged in length from 45 to 60 minutes. All the interviews were conducted in Dutch. The questions were not disclosed to the respondents before the interview, except regarding two respondents who asked to receive a copy of the questions 
beforehand.

Each interview was recorded on tape and transcribed ad verbatim. After 24 interviews no new information or arguments were raised by interviewees (saturation point), subsequently no more interviews were conducted. For this paper, we made a selection of illustrative quotes from all respondents. We found this selection sufficient to provide the information needed in the light of the explorative nature of our study. In presenting the interview quotes we did some marginal editing (grammatical and linguistic errors), but we did not alter the content.

\subsubsection{Analysis}

Each interview transcript was first submitted to open coding by the first author (JU-M) and independently by one other researcher, varying per interview. During this process and subsequently the results were discussed in the research team (investigator triangulation). In this phase the interviews were read thoroughly and notes were written in the margin, to capture what was going on in the data (Polit \& Beck, 2004). Consensus on coding was reached by discussion between the researchers. In the next step, these codes were condensed in broader categories. In this phase, the quotes were divided in three categories: informed consent, views on justice and equality, and views on old age in medical decision-making or health care policy. The following phase of the analysis, known as selective coding, consisted of coding those data that are related to the central category, perspectives on the role of age and age-based-rationing (Polit \& Beck, 2004). We were interested in the arguments and views regarding the role of age as a criterion in the treatment of older patients. In this paper we will primarily focus on the views and perspectives on the role of age-based-rationing and age as a criterion as brought forward by our respondents.

\subsection{Results}

By way of an analysis of the interviews, we found that age intricately influences the decision-making process of the physician. We identified three major ways in which the various respondents discuss this issue. In the first section, we assembled quotes of respondents all explicitly addressing the question 'age as a criterion: yes or no?'. The second section focuses on age-based-rationing, which still appears to influence medical practice concerning older people. In the last section, the starting point for discussion is found in the rejection of age-based-rationing and the centre of attention is on alternatives to an age criterion.

\subsubsection{Age as a criterion: yes or no?}

In this section, we assembled quotes concerning the idea that age can only play a role in medical decision-making as part of a technical assessment. We found two categories of quotes concerning these issues, the first concerning views of respondents on age as a strictly technical criterion, and the second on age as a value driven criterion.

\section{Age as a strictly technical criterion}

It seems self-evident that age as such can provide medical reasons not to treat an older patient. Some of our respondents think that this notion requires no further justification.

Medically, there can be very good reasons to be rather reserved regarding treatments 
after a certain age. So, medically, if good medical assessments form the basis of these kinds of decisions, I do not find that hard to take. (BN4, 354-357)

Others subscribe to this notion, but are aware that outsiders might distrust the strictly mechanical, but hidden nature of the age criterion.

But age, no that is forbidden. But, imagine you are that 50 or 55 -year-old person, or that 40-year-old one with a high creatinine level. Gee, no, that is not allowed. And somebody of 70 years with a low creatinine level, oh well, that is okay. Then you have to say to yourself, is this really a medical criterion, what does that mean? Where is the line? And that is what makes choosing well, okay, not on the basis of age because that is taboo. But it is okay to use a creatinine level. And obviously that is a bit silly. (GE1, 84-90)

This respondent claims that age is a valid indicator for specific criteria such as a creatinine level, a kind of shorthand for a set of relevant medical criteria. But he complains that the discrete criteria are regarded as accepted, whereas the overall indicator is not.

This respondent also dug deeper into what age as a medical criterion can mean. One fundamental kind of doubt concerns the very concept of a strictly technical criterion, to be used by doctors.

But medical criteria, generally speaking, mean nothing. That is mere talk. (...) hot air that medical professionals use as a cover (...). But a lot are surrounded by chance. And as soon as you are surrounded by chance, age is a medical criterion just as any other (...). It is impossible to distinguish between them. (GE1, 296-306)

The respondent emphasizes the soft nature of the so-called medical criteria and interprets the reference to such criteria, including age, as an attempt by doctors to protect their professional sovereignty. Thus, the claim that age is a medical criterion would not be the end, but the start of a process of justification.

In addition, even medical arguments can be put forward against age as a proper medical criterion to limit care, as provided by one of the physician respondents.

Back to breast cancer. If you are saying, here is someone with an operable breast cancer and I will not treat her, because she is old, 80 years old. And I will be providing a suboptimal treatment, I am not able nor willing to monitor this rightly, because in the same line of reasoning that she will not be seeing a surgeon, she will also not be going to the hospital for some additional photo's. And so I will be finding out relatively late, that the pills I have given her are not working. And instead of being an operable problem, it is almost surely becoming a non-operable problem, that is to say the cancer will be growing through the skin and will fester, leak and smell. And then, well, the suffering has become a burden and she will be finally seeing a surgeon, who will not be able to do anything for her, or only with really extensive things (...). But the fact that she is still here with 80 years means that we seriously have to take into account that she will still be here when she is 85 . And something has to be done. (KP1, 62-75)

This respondent makes a strong plea against using an age criterion based on the fact that people who are presented with, for instance, cancer for the first time at a high age, means 
that we should realize that this person is very likely to live on for a few more years. The medical argument regarding the relative short life expectancy of older people may be based on incomplete information.

It is generally supposed that using age as a medical criterion will result in a limitation of care for older patients. However, sometimes using age as a criterion might have the opposite effect and actually broaden the spectrum of possible treatments.

Of course, age does play a role when making that choice (...). In that situation, age plays a reverse role when selecting patients. Sometimes age will then lead to a more intensive treatment than a younger patient would receive. (OI1, 53-59)

\section{Age as a value laden criterion}

In this category, we discuss quotes from respondents in which the focus lies on the issue of age as a criterion as such, leaving aside whether this can be qualified as a strictly technical medical criterion. These quotes do not refer to clinical criteria, but to normative and societal arguments. The near consensus in the literature that government directed agebased rationing has no legitimate basis, does not defer every respondent from advocating such a policy as a solution to scarcity problems. For example, in the following quote in which it is argued that within a scarcity context age is a convincing criterion.

Because at the same time you can say, well if there is something that is justified because it will hit us all, it is of course an age criterion. I mean, if it is possible to draw a line there on the basis of wise arguments, that vital older person already has had a lot of luck, because he is sitting there in front of you blooming with health at the age of 80. And I do not find it that hurtful, socially and morally, if you would deny that person a treatment. Purely based on calendar age, while you know that the biological age perhaps would predict a bigger success. (...) And within such a scarcity context and political will to explicate criteria, I think age is a very valid criterion, that is no problem. I mean, it will be difficult, and it is politically controversial and nothing will come about of that for the time being. But for myself, I consider this, yes, morally it does not make my hair stand on end. (BN4, 198-215)

Whereas the previous respondent phrases his position as a personal statement, others explicitly refer to arguments set out in the ethical literature, concerning the relevance of an age criterion, claiming these express shared intuitions.

Yes, I think ceteris paribus, all circumstances the same, older people have received more, fair innings, will be given less priority (...). I think this feeling is generally shared; I am not alone in this (...). And that is not discriminating but choosing. (GE1, 204-208)

The concept of a 'fair innings argument' refers to the justification that the British ethicist John Harris has given in favor of age rationing (Harris, 1985). But the appropriateness of such an argument depends on the role we allow financial issues to play in the decisions regarding the provision of care. One respondent argues in favor.

Regarding the relationship between age and medical success, I do not really see a difference between the medical context and the health economy or policy context. The point is whether indeed you believe that scarcity, money, can play a role in the 
context of limiting care. (...) But, right now this takes place implicitly and we should be making this more explicit. (BN4, 223-229)

Therefore, the argument is to recognize that scarcity issues are not external to medical decision-making and to make this more transparent. In addition to ethical reasons in favor of using an age criterion, ethical arguments were also provided against using age as a criterion. One respondent opposes from a societal perspective, invoking the social status of older people.

What you really are saying, is that you do not care about the health of people above that age, as it were. In other words, I mean, we give up on them, right. So, the psychology is, well, that is the abandoned group, we will not deal with them anymore. So, and that is actually the same, as a group of second-class citizens. You will then be distinguishing between the value of people in society and you are actually saying older people matter less than younger people do. (EJ1, 194-201)

But, apart from ethical reasons, arguments are also given on empirical grounds against using an age criterion.

So age can have a role, a function here and there, in diagnostics and regarding treatments. If you are able, supported by scientific research, to mark out purposeful care in a clear-cut way (...). But, so far, this kind of research has not been performed yet. In this kind of cost effectiveness research age criteria, are used as solid criteria while these are actually rather arbitrary. (KP2, 220-229)

Distinct from arguments whether age can be considered a proper medical criterion or not, there is a more general argument that older people should receive the best care available based on medical judgments made with an open mind. A physician referring to daily practice makes such a plea on grounds of good care against an age criterion.

And those are the things that every day when, since cancer is something of people of a high age, something like that comes to see us, every time we discuss, estimate what is the life-expectancy of this patient. Not assuming that it will be short just like that, but taking into account that this can be considerable and therefore something has to be done right away. But whatever you are going to do, how this will be tolerated by this particular patient. (KP1, 120-125)

Medical decision-making regarding older people in the view of this respondent is a delicate and nuanced process in which the understanding that this person may live longer than expected is balanced against the physical condition of the patient. In other words, in deciding what kind of action is needed, the question whether the patient will be able to handle it and not age per se must be addressed.

\subsubsection{Age-based-rationing in medical practice}

In this section we will discuss the views of respondents regarding the general consensus that strict age-based-rationing has no legitimate basis. Despite this clear-cut view, it appears that in medical practice age rationing still takes place. Normative age based arguments influence the physician's discretionary space. We identified two clusters of quotes 
dealing with the issue of how and where age-based-rationing takes place, which are presented below.

\section{Age-based-rationing and professional freedom}

First of all, it is argued, physicians are influenced by their own personal feelings in the decision-making process.

That is just the way it is. It all has to do with the personal choices we make. And these personal choices obviously have something to do with our background. But also with our own preferences. And also have something to do with knowledge or perhaps lack of knowledge. Experiences we have. And have also something to do, I think, with your own personal environment. (OI2, 33-38)

This personal factor is inevitable, as physicians need some freedom to individualize their decisions.

But, all the same, there always will be a certain decisional freedom, which has to be completed in the consultation room. Even if it is only the question whether a list of, at first sight, unambiguous criteria are applicable to a specific patient or not. (BN4, 128-131)

In this decisional space of freedom, physicians are also influenced by rationing arguments, although this need not be in the manner envisaged in policy discussions.

Doctors make choices themselves all the time. The moment they have to decide who am I going to treat now, while the whole intensive care unit is filled with patients, than they too will be balancing with which patient they will be achieving the most. In their own way, they are making a cost effectiveness analysis. Their costs at that moment, is their time. In fact, Florence Nightingale did the same on the battlefield. She would also be considering which soldier it would be best to help. And obviously, in essence these are all cost effectiveness considerations. (GE1, 40-47)

In addition, the way age criteria are used in medical professional guidelines can result in some form of age-based-rationing.

Regarding the guideline on stomach, you cannot say people over 50 should be given an endoscopy and under 50 not. Because one 50-year-old maybe much more vital than someone younger than him. There is always some clinical freedom, and that is left to the individual physician to judge. And I believe, that should stay that way.(...) That you will not be formulating this too precise. I mean, these studies in which age limits are used have to be described. In the recommendations to the guidelines, you can refer to these limits, but I think you have to implement them in a broad sense. (RO1, 305-315)

But the physician keeps his freedom to deviate from the directions in the guideline. In this way a physician can decide to ignore an age criterion and provide a treatment despite the guideline. Thus, all respondents in this category agree that there is a significant space for physicians to make a personal assessment, both guided by personal preferences and by 
considerations of practicality, concerning the relevance of the patient's age for decisionmaking.

\section{Rationing and the level of application}

The second category contains statements that address, given the fact that age-based-rationing still takes place, the issue at which level such rationing decisions should be made. Interestingly, these respondents ignore the government's statement that age-based-rationing has no legitimate basis. As in the previous category, respondents discussed how the practice of medical decision-making may de facto still be influenced by rationing arguments. In contrast, in this category, the justifiability of these kinds of decisions is taken for granted.

The first quote reveals the complicated nature of the question whether rationing decisions should be made on a macro, meso or micro level.

There also we know the official answer, which is macro. But in reality some decisions will be made on the micro level as well. It is like I was just saying; I think it is so much prettier if it can be done on a macro level, or meso by way of guidelines, as far as I am concerned. Because it is really better if this will not end up on the personal level, then it will not be damaging the physician-patient relationship and that is really better (...). So, I also think it is really attractive if you can say as a doctor, I am a champion for my patient, a patient advocate, and I will be doing everything what is in his interests. Beautiful. But this image is not right. So, I think that unfortunately the micro level cannot escape it (...). But it may be obvious that also on this level choices in the context of scarcity have to be made. There is no way of escaping it. (EJ3, 328-340)

This view argues that if rationing decisions have to be made, this should not take place at the micro level by individual physicians in face of individual patients, since this would jeopardize the physician-patient relationship. Simultaneously, this respondent who rejects rationing at the micro level believes it is inescapable.

In contrast, another respondent believes the micro level is the proper level for such decisions, because there they can explicitly be discussed with the patient.

As I already pointed out, on the micro level physician and patient always have to make good assessments on what misery to expect from this treatment, and what will be the profits. And I think, a lot of people, except those that are just really afraid to die, will give up on treatment every now and then (..). And I hope, on that micro level doctor and patient will be making these kinds of assessments more and more, together on good terms. (BN5, 597-609)

In the privacy and comfort of the relationship between physician and patient, both parties should try to openly discuss the costs and the results of the treatment.

Other respondents, however, fundamentally disagree with this reasoning.

Because if you will be leaving that to the doctor, you can expect a situation in which a physician is treating one patient, while he still has five other patients in the back of his head, because of the fear that his budget may be used completely. And that is something that would seriously affect the physician-patient relationship, if you will 
allow that to happen. (EJ1, 253-257)

If we will make physicians responsible for making rationing decisions in their consultation rooms, they will not be able to put the interests of their individual patients first and foremost. They will be constantly confronted with thoughts regarding the financial consequences of their decisions for the care of their other patients. This will inevitably influence the physician-patient relationship negatively.

\subsubsection{Age in the clinical encounter}

In contrast to the previous sections, here a broader set of age-related considerations are presented. A more general subject as expressed by respondents was what the focus should be on dealing with older patients in health care.

\section{Wishes, consequences and capacity}

A first subject concerns the possibility of an alternative for age rationing as it is found in focussing on the wishes of the patient and the consequences of treatment. Age plays a role as a trigger for explicitly reflecting on these consequences, as the following quote illustrates.

Age definitely plays a role in these discussions, which we try to broaden by also looking at life expectancy, healthy life expectancy or functional life expectancy, quality of life and the preferences of the patient himself. So, by determining where autonomous decision-making is possible. These kinds of elements all should be involved in addition to age. Age as a criterion is something we will never settle with (...). Because, I think that we would be doing wrong to the individual in front of you. There is so much heterogeneity between older people, regarding both functional and mental performance, but also in the context of the wishes and expectations, and ageing that you will not be individualizing enough. (KP2, 145-155)

In the next quote a similar point is made. In this case age is not completely denied as relevant, but is used as a marker for focussing more explicitly on the consequences of the treatment for an individual older person. Age is not used as a criterion, but as a starting point for reflection before taking action.

So yes, in that way age does play a role, (...) not while selecting patients, but in the way you deal with these kinds of people. And that's of course a much more sensible way of talking about age. We have to ask ourselves beforehand first, this thing I'm planning to do, is it in the patient's interest? Or am I only doing it because we can do a beautiful examination or use this great machine, so to speak. And secondly, am I prepared to accept the consequences of what I am going to find and can I overview these consequences? And that's what we have to ask ourselves beforehand. And what happens a lot is that certain things happen, that the first step is taken and that sort of fails and then the next step is taken which also fails, and as a consequence another step is taken. (OI1, 273-286).

So, what happens when an 80-year-old person enters the consultation room? Some respondents consider such an age to be a trigger for assessments that are routinely made, but may get extra emphasis in patients with an advanced age. The older patient's capacity 
to deal with a treatment or procedure is one of the first things that spring to mind.

80 years old means an alarm bell goes off, regarding what is this patient able to take and what is his condition now, what should we be doing now to solve this situation in a good way? That is the first thought, and do we think that is too much for the capacity of that body of 80 years and what should we be doing less then, to ensure this capacity will be able to endure this treatment? And what are the risks for the rest of his life? So, it is the balance between the capacity of that person and the misery that you can expect. (KP1, 55-61)

The alarm bell means that in deciding what treatment to provide to an older person, this person's capacity or strength explicitly has to be balanced against the possible side effects to be expected after treatment. Remarkably, this respondent does not mention not treating the patient as an option. Starting point is action, subsequently, if and how the patient will endure the treatment, is decisive.

Age as such is not relevant in any way, because it does not tell that much. It is considered important to set up some kind of measure for vitality to use when dealing with an older patient. In this context, the patient's age only matters in trying to get into view what the patient can bear, comparable to the point made in the previous quote.

Age as such is no argument here, but of course you will naturally be saying, listen up, is age one of the circumstances restricting the possibilities for this patient? And for one patient this can be at the age of 80 , but I also have people of 60 years, and you will be thinking they are so damaged by life, essentially we should consider them as much older. So, you have to try and find some kind of standard for yourself, on how vital is this patient and what will he be able to handle? (OI1, 296-302)

Other respondents explicitly discuss the value of age as an indicator in non-treatment decisions. The life expectancy of the patient and the confrontation with a serious disease at a high age influences the capacity of an older patient to such an extent that in some cases it is considered better not to do anything. In the next quote, it is not age per se that influences the physician's decision. Decisive is the way the patient's body pulls up to the disease, in combination with the fact that she is not that strong.

With this 80-year-old patient you will not be doing this, for two reasons. That is this is a very big procedure which she will probably not be able to bear and might die, or in the post-operative phase because she will not be able to recover. And, secondly, you will realize that the time she has taken to present these metastases, which have already been there 30 years ago when she had the surgery. If she has taken so long, chances are that they will not trouble her that much in the years she has left, 5 or 10 years, because of their presentation history. And so, I decide, it is best to do nothing. (KP1, 170-179)

Although prognosis is what counts, age related life expectancy is clearly a point in consideration. We have earlier seen, though, that being an octogenarian may count as a positive indicator for vitality and thus for life expectancy. 


\section{More central role for older people}

We also found some of the respondents focussing on the role of older people themselves in decision-making. They notice that medicine still carries a paternalistic streak. In our first quote, the respondent stresses that doctors should make more of an effort to make sure that older patients really grasp what's at stake in medical decisions. This includes the understanding that abstaining from life-extending treatments may be a serious option in view of the overall prognosis.

I always expect a lot from the wisdom of older people themselves (...) which is very common, if people would only get the chance to make an assessment themselves. But often, they are simply told, well, you have a gastric haemorrhage, you will get a blood transfusion, and, in fact, it is simply forced on them. And I think if people just would be given more room to consider it themselves, a lot of life-extending medicine for very old people would disappear. But I am obviously thinking of people who really feel they are ready for the end. (BN5, 206-228)

It is suggested that by giving older people more time to reflect on whether they really want treatment, a lot of older people will decide not to proceed. As a result, we will be dealing with smaller amounts of life extending treatments.

However, we did find quotes which are much more explicit in giving responsibility to the older patients themselves. One respondent advocates that older people should be given a more central role in the decision-making process, in order to confront them with the options and arguments from the medical perspective.

And what I am actually hoping for is that we will be working more on a demand-driven basis. And in that way, providing the older patient a more central role in the choices he can make, so as it were, place the problems by the older people themselves. (EJ3, 505-507)

The respondents quoted above believe that involving older patients and shifting more responsibility to them, will lead to a decrease in treatments. Others, however, are not so sure about this.

For me it is actually the same idea, because older people just want a good medical treatment. So, they will not say, please give my treatment to somebody younger than me. And they also will not say, I do not want that treatment because I have already turned 80. (KP2, 393-395)

An older person's age will not guide this respondent in the direction suggested earlier: to forgo treatment because of the patient's age. Involving older patients in decision-making may be appropriate and desirable, but older patients will turn out to be just as assertive in claiming their rights as younger persons.

\subsection{Discussion}

In this paper we investigated how age criteria may play a role in decision-making con- 
cerning older people in health care delivery. The analysis of our data provides interesting perspectives on how the practice of medical decision-making is influenced by age criteria, other than a strictly medical technical criterion. We identified three major ways in which the issue of the influence of age as a fact or value in the medical decision-making process is considered by the interviewed respondents.

In the first major way, the issues of age as a strictly technical criterion, age as a criterion and age criteria and life expectancy are put forward. In this respect, some respondents make a plea for using age as a purely mechanical criterion. However, some strong appeals against age-based-rationing are also made. The seemingly self-evident dividing line between age as part of a medical-technical assessment and age as a broader societal criterion leads to a discussion on how the patient's age influences treatment decisions in medical practice. Finally, the value of explicitly reflecting on the actual life expectancy of the individual older patient, as a way to avoid the need for making age-based decisions, is acknowledged.

In the second way, respondents reject age-based-rationing on the policy level, but state that age-based-rationing is influencing, implicitly or indirectly, the decisions made by physicians. In the quotes assembled in this section, the implication of these normative arguments is acknowledged. Subsequently, respondents vary in their views at what level, and how these rationing decisions take place and should take place.

In the third way, respondents put forward broader age related considerations in clinical practice. Focusing on capacity of strength, vitality and endurance, the wishes and preferences of the older patients and the possible consequences of treatment and care are suggested to be prominent aspects of medical decision-making. In addition, an appeal is made for a more central role for older people themselves and a corresponding responsibility for the problems in the decision-making process. Importantly though, it is suggested that older people will not give up their rights and entitlements to health care delivery. Comparing the three major clusters of views as presented by the respondents, provides a broad spectrum of, sometimes conflicting, images of how age works out as a criterion in the practice of medical decision-making. An important claim is that not every physician considers old age as a problem since it can lead to a more intensive treatment, while it is also suggested that overtreatment of older people is a growing problem in health care today. Furthermore, it is suggested that the technical use of an age criterion is an illusive, while in other cases age is clearly valued as a starting point for initiating or reflecting on medical decisions.

But, also on a conceptual level conflicting views can be identified. As one of the respondents stated that age can play a role as part of a strictly medical technical assessment, other respondents seriously doubted this. In this context, the question is asked what'age as a medical criterion' actually means. What is the dividing line between age rationing and the technical and medical use of an age criterion? The answer is complex, since we can identify several layers of conceptual reasoning in our group of respondents. We identified normative arguments, dealing with the consequences of age rationing for the way older people are valued in society. Nevertheless, we also traced arguments in which the fair innings principle is appreciated. On a more empirical level it is discussed how age influences the physician's decisions by way of practice examples, and on what level of decision-making, in the consultation room or at the policy level, this should be taking place. Finally, the specific roles and responsibilities of a physician when dealing with an older patient are discussed. A prominent issue discussed in this context is the assessment of the real life 
expectancy of the older patient involved. What matters here is that physicians should be careful in assuming that an older patient will generally only have a few years left.

We conclude that in the practice of medical decision-making concerning older people age plays a much more intrinsic and complex role in contrast with the clear-cut view of age as a purely medical criterion. Age appears to be inherent to medical practice as a kind of ambiguous and sometimes ageist tool. This is in conformance with the recurrence of empirical studies in various medical domains in which it is shown that age criteria are influencing the decision-making process by physicians (e.g. Apostolou, 2007; Gnavni et al., 2007; Halvorsen et al., 2008; Osterwalder, Osswald, Buser, \& Pfisterer, 2001; Stahl, Tramontano, Swan, \& Cohen, 2008). The practice of medical decision-making concerning older people is much more complex, and not as self-evident as it is implicated by the views as outcome of the ageism debate.

The professionals dealing with the decisions concerning the care for older people clearly find it difficult not to use age criteria in this context. Despite the rejection of age-based-rationing as a tool for medical decision-making, it still takes place in medical practice, on the level of the physician-patient relationship, both implicitly and explicitly. In other words, by making the medical professionals responsible for the use of age as part of a strictly technical assessment, we are asking too much of the professionals involved. Patients and society expect them to be able to easily separate fact and value that is to distinguish between using age as a purely technological criteria and using age as an instrument for broader quality of life and societal considerations. As can be seen from our results, medical practice simply does not work that way. Medical practice in general is characterized by normative laden judgments, which does not necessarily mean decisions are going off the rails. Medical decision-making is a complex, and delicate process, in which both patient and physician constantly are going back and forth between technical medical assessments and value laden considerations.

Thus, the fact remains that age-based-rationing decisions are influencing the decisionmaking process concerning older people. Underneath the surface of a debate which has been settled in a clear-cut outcome, the care for older people might result in inequalities and injustices in the delivery of health care on the basis of normative and often implicit age related considerations. What matters is that we need to get a better and clearer view on the various views and arguments that are influencing the practice of medical decisionmaking for older people on various levels (Dey \& Fraser, 2000). As seen in our analysis, the experts interviewed talk at cross-purposes. The images of how the practice of medical decision-making concerning older people really takes place are divergent and ambivalent. In addition, the diverse views on age as a medical criterion on the conceptual level show the intricacies and complexities of medical decision- making. In fact, decision-making consists of many layers, as we found observations on a more empirical level, proposals with a normative undertone, and assumptions dealing with physician's behavior. These layers represent different views on the role of the physician, the level of decision-making and the role of age and age-based rationing. We believe the respondent's views are not isolated opinions, but provide the basis for reconstructing the discussions involving these issues, as they are taking place on different levels in health care.

This study might provide an important step in the mapping of the role of age in medical decision-making. In this way, hopefully, a better understanding is achieved of why we still find many examples of age-based-rationing as also shown, in a disparate but consistent way, by the studies referred to above. But, more importantly, it also raises ques- 
tions concerning the trust we have in physicians concerning the care for older patients. According to our respondents, age and age-based-rationing still influence the actions of professionals working with older people. In addition, most of these normative arguments remain implicit. Does this mean patients and society should reconsider the trust we have in physicians in this context? To answer this question, a closer look at medical practice is needed. The experts used in this paper, provide us valuable insights in the opinions and views influencing the debate on the role of age. A plea is made for further research into the dynamics and complexities of the decision-making process concerning older people.

\section{References}

Apostolou, T. (2007). Quality of life in the elderly patients on dialysis. International Urology and Nephrology, 39(2), 679-683.

Binstock, R. H. (2007). Our aging societies: ethical, moral, and policy challenges. Journal of Alzheimer's Disease, 12, 3-9.

Binstock, R. H., \& Post, S. G. (Eds.). (1991). Too old for health care? Controversies in medicine, law, economics, and ethics. Baltimore and London: The John Hopkins University Press.

Bowling, A. (2007). Honour your father and mother: ageism in medicine. British Journal of General Practice, 57, 347-348.

Callahan, D. (1987). Setting limits: medical goals in an aging society. New York: Simon \& Schuster.

Callahan, D. (1990). What kind of life. The limits of medical progress. New York: Simon and Schuster.

Choo, V. (1994). Gaps in UK research into elderly. The Lancet, 344, 745.

Churchill, L. R. (2005). Age-rationing in health care: flawed policy, personal virtue. Health Care Analysis, 13(2), 137-146.

Clarke, C. M. (2001). Rationing scarce life-sustaining resources on the basis of age. Journal of Advanced Nursing, 35(5), 799-804.

Daniels, N. (1985). Just health care. Cambridge: Cambridge University Press.

Dey, I., \& Fraser, N. (2000). Age-based rationing in the allocation of health care. Journal of Aging and Health, 12(4), 511-537.

Giordano, S. (2005). Respect for Equality and the Treatment of the Elderly: Declarations of Human Rights and Age-Based Rationing. Cambridge Quarterly of Healthcare Ethics, 14, 83-92.

Gnavni, R., Migliardi, A., Demaria, M., Petrelli, A., Caprioglio, A., \& Costa, G. (2007). Statins prescribing for the secondary prevention of ischaemic heart disease in Torino, Italy. A case of ageism and social inequalities. European Journal of Public Health, 17(5), 492-496.

Hackler, C., \& Micah Hester, D. (2005). Age and the Allocation of Organs for Transplantation: A Case Study. Health Care Analysis, 13(2), 129-136.

Halvorsen, K., Slettebo, A., Nortvedt, P., Pedersen, R., Kirkevold, M., Nordhaug, M., et al. (2008). Priority dilemma's in dialysis: the impact of old age. Journal of Medical Ethics, 34, 585-589.

Harris, J. (1985). The value of life. An introduction to medical ethics. London/New York: Routledge \& Kegan Paul.

Harris, J. (2005). The Age-Indifference Principle and Equality. Cambridge Quarterly of Healthcare Ethics, 14, 93-99.

Health Council of the Netherlands. (1998). President. What about age? (No. 1998/06). 
Rijswijk: Health Council of the Netherlands.

Hope, T., Sprigings, D., \& Crisp, R. (2002). 'Not clinically indicated': Patients' interests or resource allocation? In K. W. M. Fulford, D. Dickenson \& T. H. Murray (Eds.), Healthcare Ethics and Human Values. An introductory text with readings and case studies (pp. 177-181). Malden/Oxford: Blackwell Publishers.

Kapp, M. B. (2002). Health care rationing affecting older persons: rejected in principle but implemented in fact. Journal of Aging and Social Policy, 14(2), 27-42.

Kilner, J. F. (1990). Who lives? Who dies? Ethical criteria in patient selection. New Haven/London: Yale University Press.

Loewy, E. H. (2005). Age discrimination at its Best: Should Chronological Age be a Prime Factour in Medical Decision Making? Health Care Analysis, 13(2), 101-117.

Maynard, A. (1996). Rationing health care. British Medical Journal, 313, 1499.

Nilstun, T., \& Ohlsson, R. (1995). Should health care be rationed by age? Scandinavian Journal of Social Medicine, 23(2), 81-84.

Osterwalder, R., Osswald, S., Buser, P., \& Pfisterer, M. (2001). Evidence for age-based rationing in a Swiss University Hospital Swiss Medical Weekly, 131, 630-644.

Polit, D. F., \& Beck, C. T. (2004). Nursing Research: Principles and Methods (7th edition ed.). Philadelphia: Lippincot Williams \& Wilkins.

Rivlin, M. (1999a). Is age-based rationing of health care morally defensible? , University of Leeds, Leeds.

Rivlin, M. (1999b). Should age based rationing of health care be illegal? British Medical Journal, 319, 1379.

Springer Loewy, R. (2005). Ageisms. Health Care Analysis, 13(2), 147-156.

Stahl, J. E., Tramontano, A. C., Swan, J. S., \& Cohen, B. J. (2008). Balancing urgency, age and quality of life in organ allocation decisions-what would you do? A survey? Journal of Medical Ethics, 34(2), 109-115.

Thomasma, D. C. (1991). From Ageism toward Autonomy. In R. H. Binstock \& S. G. Post (Eds.), Too Old for Health Care? Controversies in Medicine, Law, Economics, and Ethics (pp. 138-163). Baltimore and London: The John Hopkins University Press.

Truog, R. D., Brock, D. W., Cook, D. J., Danis, M. D., Luce, J. M., Rubenfeld, G. D., et al. (2006). Rationing in the intensive care unit. Critical Care Medicine, 34, 958-963.

Vrakking, A. M., Heide, A., van der, Delden, J. J. M., van, Looman, C. W. N., Visser, M. H., \& Maas, P. J., van der. (2005). Medical decision-making for seriously ill non-elderly and elderly patients. Health Policy, 75, 40-48.

Werntoft E., \& Edberg, A. K. (2009). The views of physicians and politicians concerning agerelated prioritisation in healthcare. Journal of Health Organization and Management, 23(1), 38-52.

Yap, J., \& Celi, A. (2007). Elderly access to medical care: should age be a factor in deciding management? The New Zealand Medical Journal 120, 1-3.

Young, J. (2006). Ageism in services for transient ischaemic attack and stroke. Could be cut by emulating successful efforts against ageism in heart disease care. British Medical Journal, 333, 508-509. 
$\frac{\overline{\underline{i}}}{\bar{z}}$ 


\title{
Chapter 2
}

\section{Informed Consent, Communication And Value Judgments In Medi- cal Care For Older Patients- A Qualitative Study}

\author{
Josy Ubachs-Moust \\ Rob Houtepen \\ Anja Krumeich \\ Wybo Dondorp \\ Ruud ter Meulen \\ Rein Vos
}




\subsection{Introduction}

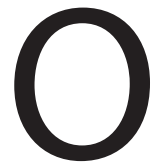

Ider people have been subject of debate for a few decades. Against the background of the growing population of older patients and the increasing scarcity in health care resources, the older patient's rights and needs have often been discussed (e.g. Binstock, 2007; Binstock \& Post, 1991; Bowling, 2007; Callahan, 1987, 1990; Churchill, 2005; Daniels, 1985; Giordano, 2005; Hackler \& Micah Hester, 2005; Harris, 1985, 2005; Kapp, 2002; Loewy, 2005; Nilstun \& Ohlsson, 1995; Rivlin, 2000; Springer Loewy, 2005; Thomasma, 1991; Werntoft \& Edberg, 2009; Yap \& Celi, 2007; Young, 2006). As a result of this debate age-based-rationing is generally rejected as a tool in deciding what care to provide to older people, both at the policy level and in the consultation room of the physician (Giordano, 2005). In addition, the patient's age can only be accepted in medical decision-making if it is to be used as part of a strictly medical-technical assessment in the setting of the physician-patient relationship (Loewy, 2005; Vrakking et al., 2005). A dispersed set of studies in various medical areas, however, showed that age and age-based-rationing still influence the actions of professionals working with older people in an unaccounted way (Apostolou, 2007; Gnavni et al., 2007; Halvorsen et al., 2008; Osterwalder, Osswald, Buser, \& Pfisterer, 2001; Stahl, Tramontano, Swan, \& Cohen, 2008)(and Chapter 4). Age appears to be inherent to medical practice as an ambiguous and sometimes ageist tool. Medical decision-making is a complex and delicate process, in which both patient and physician constantly go back and forth between purely technical medical assessments and more value laden considerations (Quill \& Brody, 1996; Vos \& Willems, 2000). Age as an example of such a value laden criterion - henceforward we will also use the term 'ageist argument' - , is inherent in the decision-making process concerning older people, both implicitly and explicitly (see Chapter 1 ).

Against this background of the value laden role of age in decision-making we want to get a better view of what happens in the consultation room between physician and patient. In dealing with values in clinical practice, the starting point is nowadays largely provided by the rules of informed consent. Informed consent provides a framework against which both physician's and patient's roles are given shape. The idea of informed consent has its origins in ethics, law, and in contemporary medicine's own understanding about the nature of the doctor-patient relationship and the advantages that accrue when patients are knowledgeable about their treatment (Berg, Appelbaum, Lidz, \& Parker, 2001). In this context, the elements of the communication between physician and patient consist of the patient's complaints, his wishes and his fears and the physician's knowledge, expertise and medical assessments. Also, the patient's and the physician's values and personal views are part of this interaction. In the end, the patient is supposed to consent to the proposed treatment or care, after being fully informed by the physician and/or other health care workers. Only when the approval by the patient is voluntary, authentic and reasonably considered, one can speak of true informed consent (Beauchamp \& Childress, 2001; O'Neill, 2002; Schermer, 2001).

Regarding the care for older people the crucial question is if informed consent provides a solution to the issues as discussed above regarding the unaccounted use of age and agebased-rationing in the actions of professionals working with older people. This is, however, also dependent on how the idea of informed consent is operationalized in the inter-

1 There are various interpretations of informed consent. Here we make use of a global idea of informed consent. 
action process between physician and older patient. The ideal of informed consent is not reached all of the time and not regarding every patient. It is believed that cultural values and interests of providers and practitioners are often coloring the way informed consent is practiced (Lin \& Chen, 2007; Patenaude, Rappeport, \& Smith, 1986). In general, informed consent can be conceived as a valuable steppingstone for shaping the physician-patient relationship. However, in the care for older patients there is a suspicion that physicians act in a more or less paternalistic way (Spinewine et al., 2005). Furthermore, in the context of limited or inadequate resources, it is feared that social values will prevail over individual rights of older patients (e.g. Evans, 1997; Harris, 1987; Tsuchiya, 2000; www.helptheaged. org.uk), for example regarding the patient's right to information (Appelbaum, 1993; Graber \& Tansey, 2005; Hall, 1993, 1994, 1997; Petrila, 2003). It is feared that ageism and negative stereotyping produce views that may undermine the basic rights of older people (Breda \& Schoenmaekers, 2006).

Our goal in this paper is to present arguments to reconsider the role of age and ageist arguments in the communication between physician and older patient. We will do so by first identifying the various patterns in the way this communication process is structured. Second, we will perform a comparative analysis of the identified patterns, trying to explicate the most significant ways how the value laden use of age enters the process of decision-making and delivery of care in the setting of the relationship of the physician and the older patient. Third, we will then discuss the presented results in terms of the informative and deliberative models of the physician-patient relationship (Emanuel \& Emanuel, 1992), which present different ways of connecting medical facts and values and shaping distinct roles for the physician and patient in health care. In this way we hope to contribute to the normative debate on the role of age in clinical communication and decision-making. In doing so we are addressing an issue that has not received much attention in ethical theory (Brody, 1993; Pearlman, Miles, \& Arnold, 1993; Schermer, 2001).

\subsection{Methods}

\subsubsection{Data collection}

To gain insight in the interaction between physician and older patient we made use of observations by medical students at the Maastricht University medical school. Observational methods can be used to gather a variety of information, including information on characteristics of individuals and verbal communication (Polit \& Beck, 2004). The data consist of practice descriptions collected by medical students as part of their clinical training period of their studies in the academic hospital and associated hospitals, general practices or mental health care institutions. During their clinical training (from the $3^{\text {rd }}$ till the $6^{\text {th }}$ year) all medical students have to present 12 descriptions out of their field notes, written down during their observation period. These case descriptions are collected, stored and coded by staff members of the ethics department, 'age' being one of the codes. Descriptions giving this code deal with age-related aspects of medical decision-making and concern older patients. At the start of the data collection (January-April 2007), 271 of 5828 practice descriptions in the database of the ethics department were given the 'age' code. ${ }^{2}$

The case descriptions represent a cross sectional view of various fields of medicine and a broad range of academic clinical practice. The cases are summary descriptions provided

2 Cases dealing with neonates or children are not included in this sample. 
by the physician-in-training of the decision-making process in clinical practice and presented and discussed in ethical group meetings guided by staff members of the ethics department. The students did not collect these practice descriptions for the sake of our study. Therefore they provide study-independent information on how physicians in an academic setting deal with older patients. The case descriptions vary in length, between approximately 120 and 350 words. The case descriptions include information about the medical problems of the patient, his or her medical history, the views and arguments of the physician, and the interaction between the physician and the older patient. Physicians-in-training are encouraged by the ethics staff members to select 'everyday' descriptions rather than heroic ones. In presenting these practice descriptions, we did some marginal (grammatical and linguistic) editing, but we did not alter their content.

\subsubsection{Data analysis and construction of role patterns}

Our research has an exploratory character, to discover patterns in the interaction between physician and older patient pertaining to informed consent and the use of age as criterion. Our analysis was performed according to grounded theory (Glaser \& Straus, 1967). In this approach coding is used to conceptualize data into patterns or concepts (Polit \& Beck, 2004). The case descriptions were analyzed separately and simultaneously by two researchers (JU-M, RH). Both analysis were compared and contrasted. In this way investigator triangulation is obtained, which refers to the use of two or more researchers to analyze and interpret a data set. Through collaboration, investigators can reduce the possibility of a biased interpretation of the data. Both investigators brought different skills and expertise to the analysis, benefiting the analysis and interpretation form divergent perspectives (Polit \& Beck, 2004).

To prepare for the first stage of the analysis, we considered whether the case descriptions had an informative nature, presenting relevant information on the medical condition and history of the patient and whether they were written in a clear manner offering us insights in how and at what point in time various aspects of the decision-making process have taken place. Additionally we paid attention to whether diagnostic or treatment related decisions were being made to ensure both were represented in the selection. Finally, we selected practice descriptions on the basis of the medical discipline involved, to ensure a variety in conditions, decisions and clinical settings. Consequently, 48 out of 271 case descriptions were selected, presenting a cross section of all descriptions. We found this selection sufficient to provide the information needed in the light of the explorative nature of our study.

In the first stage of the analysis, we allowed the practice descriptions to 'speak for themselves'. The case descriptions were subjected to a thorough reading, to capture what is going on in the data (Polit \& Beck, 2004). In this phase of open coding, fragments of texts were underlined and descriptive notes were written in the margins. The codes used were the actual words used in the descriptions (Level I codes). At the bottom of each case we assembled these notes and provided each case description with a first impression of the thoughts and ideas that came to mind when reviewing these notes. The combination of the notes with these first impressions gave us an opportunity to compare the results on a 'case-level' as well as on a more conceptual level (Level II codes). The results of these open codes (Level I and II) were then assembled and labelled. In the following step, these labelled issues were compared within and between the case descriptions. Similar issues were then grouped in a table under overarching labels (groups). Several steps were taken 
to verify the results and increase trustworthiness, a concept in qualitative research analogous to reliability and validity in quantitative research (Strauss \& Corbin, 1994, 1998). These include (1) use of separate checking of developed codings by the second analyst on all data and (2) regular meetings of the research team comparing themes and checking field notes.

The table contained the following groups: communication, family, business as usual (standard procedure), justice, age and professional standard. Each group existed of several labels (see Table 1). The table enabled the researcher to discern patterns, themes and correlations between the various groups and labels.

The next phase of analysis is known as selective coding. In this phase we searched for specific patterns and behaviours in the interaction between the older patient and the physician (core category). We were guided by questions, such as what happens in the case description, what is the older patient's role, how is the older patient approached, what kind of information is provided and in what manner, does the family play a role in the decision-making process and how does the communication with the family take place, how is the treatment decision reached, and what image of the older person is construed (i.e. what image of the older patient underlies the physician's actions and attitude, derived from the way the physician treats the older patient).

After finishing the final stage of our analysis we reread the initial collection of 271 case descriptions to make sure no additional role patterns were overlooked. This was not the case. We consider the practice descriptions in this paper representative and instructive for the vast majority of cases. We selected these case descriptions on the basis of their comprehensible description of the 'case-facts' and on the 'natural' character and situation of the cases.

$\begin{array}{lc}\text { Risk communication } \quad \text { Labels } & \text { Groups } \\ \text { Explicit mentioning of age } & \text { Communication } \\ \text { Information on care aspects } & \\ \text { Informed consent as a solution } & \text { Family } \\ \text { Communication } & \\ \text { Treatment decisions } & \text { Business as usual/ } \\ \text { Safety net } & \text { Standard procedure } \\ \text { Occasional extra effort } & \text { Justice } \\ \text { Image construction } & \\ \text { Son-discrimination/equal treatment } & \\ \text { Scarcity } & \\ \text { Image construction } & \\ \text { Good care } & \\ \text { Risk factorlindex } & \\ \text { Statistical argument } & \text { Age } \\ \text { Biological or chronological use } & \\ \text { Age as a determining factor } & \\ \text { (in dubious cases) } & \\ \text { Limited diagnostic treatment because of age } & \\ \text { Medically futile treatment because of age } & \text { Professional standard } \\ \text { Allowing to die } & \end{array}$

Table 1. Labels and Groups

\subsubsection{Comparative analysis of the role patterns}

Finally, we performed a comparative analysis of the identified role patterns, by using four dimensions, each dimension scoring on a 3-point scale $(-, 0,+)$ by one author (JU-M), and checked by two other authors ( $\mathrm{RH}, \mathrm{RV})$. The four dimensions are:

a. The physician wants to refrain from therapy or intervention towards the physician pro- 
actively wants to support therapy or intervention;

b. The physician refrains from giving consent towards stimulates informed consent;

c. The physician keeps the decision-making implicit towards makes the decision-making explicit;

d. The physician uses medical benefits-costs inference schemes towards puts forward ageist arguments in the reasoning process.

Then we added a fifth dimension, scoring:

e. Whether the family (spouse, children) played no (No) role to played a key role (Yes) in the decision-making process.

\subsection{Results}

On the basis of our analysis we were able to identify six role patterns. These patterns represent a gradient varying from physicians respecting the patient's right of autonomy to examples in which this right is bypassed by physicians and/or the older patient's family. In this gradient we find cases in which the older patient is treated as an independent and self-directing individual who is informed about the possible influences of his age on his prognosis and treatment as part of the information that needs to be provided in order to be able to make an informed decision. Via role patterns in which the older patient's age is more than a relevant medical fact and plays a more specific role in the argumentation and decision-making process of the physician, the far end of the gradient represents situations in which a paternalistic attitude of the physician is dominating the physicianpatient relationship.

In the first subsection, we will describe these six role patterns. In the second subsection, we will present the results of the comparative analysis of the identified role patterns.

\subsubsection{Role patterns in the communication between physician and older patient}

Below we will describe the six role patterns (see for a systematic overview of these role patterns Table 2), represented by exemplary case descriptions. Each role pattern will first be illustrated shortly and then further interpreted in the light of the selected exemplary case descriptions.

\section{Age as a medical criterion}

In the first role pattern the physician accepts the patient as a full partner in the decisionmaking process. The age of the older patient plays a role as a carrier of a specific medical risk with no special normative connotation. Age related medical risks are discussed with the patient just as any other relevant medical fact.

An 80-year-old man is joined by his son at the outpatients' clinic for internal medicine after reference by the vascular surgeon, who suspects leukaemia. The man has a blank medical history and is in a very good condition in view of his age. After the consultation the man is told that he probably has leukaemia. He will get a blood transfusion because of a low haemoglobin and trombocyte value and is permitted to go home as soon as possible after the procedure. The patient's son asks if no treatment is possible. The physician explains that is not a good idea, since the patient is already 80 years old. Chemotherapy presents a high burden and a large risk, certainly at this age. The patient goes to the ward and everything is 
arranged for the blood transfusion. (Cl:30)

The physician explains that the patient's advanced age involves medical risks providing a reason for not treating him. Additional questions are answered and the patient and his son are able to reflect on what treatment options he prefers.

Role patterns in the communication between physician and older patient

Age as a medical criterion

Age and life-expectancy

Age-related aspects

Disagreement between older patient and spouse

The physician and family: not or only partly including the older patient

The physician knows best

Table 2. Role patterns in the communication between physician and older patient

\section{Age and life-expectancy}

In the following case the patient is considered independent and competent too, but now the age of the patient plays a more specific role. The life expectancy of the older patient is put forward in deciding what will be the best treatment option.

At the outpatients' clinic we see a woman of 83 years old. Her complaints consist of a changed defecation pattern and rectal blood loss. The colon scope shows that she has an adenoma which can develop into a malign tumour. In the consultation two weeks later the patient is informed that the tumour is completely removed. Now it has to be decided how frequently the patient will be screened. Because of the patient's life expectancy the doctor feels that no screening is indicated. The patient doesn't agree and asks for a second opinion. (Cl:21)

The patient's age is relevant for the physician in deciding not to offer further screening. The fact that the physician has explicitly brought this argument up for discussion enables the patient to respond and ask for a second opinion.

\section{Age-related aspects}

In the current role pattern, as in the previous ones, the patient's competency is not infringed upon. But certain aspects of the patient's situation that are apparently considered age-related are highlighted.

An 82-year-old man is seen by the cardiologist because of complaints of angina pectoris. By placing a stent the complaints of the patient may be reduced. This is however a rather expensive intervention and it is not $100 \%$ certain that the 
complaints will disappear. Moreover the intervention is not without risk and it is not certain that the patient will live longer because of the treatment. The cardiologist proposes to place the stent, but only if the patient really wants it. (CC:6)

The physician in this case has expressed his doubts to the patient, although he has not explicitly mentioned the patient's age and life expectancy as reasons for this doubt. Remarkable is that the physician highlights something that ought to be self-evident by normal standards. Why does this patient need encouragement to opt for treatment only after having made up his mind? Is that something to be expected less naturally in the case of older patients?

In the role patterns following below a variety of situations are discussed in which the norms of open communication with the patient and informed consent in the standard sense are not respected.

\section{Disagreement between older patient and spouse}

This role pattern concerns the role of the family in the decision-making process and the communication with the older patient. This family role can take many forms and the physician has to find ways to deal with this factor while respecting the patient and the family, even when there is disagreement within the family.

A 74-year-old man is complaining of shortness of breath and sporadically angina pectoris. While examining the patient aorta valve stenosis is determined. The cardiologist explains the disorder to the patient and his wife and informs them that the valve can surgically be replaced by an artificial valve. Because the patient's physical condition is still well, the success percentage of the treatment is high. An alternative is medicinal therapy, but the prognosis in this case is much worse. His wife thinks that he should choose surgery; she had a similar operation on the age of 55 and is very satisfied with the result. The patient however is not convinced. He already has five grandchildren and is content with the life he has lived. He has recently been diagnosed with early symptoms of Alzheimer dementia and although this still causes only small problems, he doesn't find it necessary to undergo any life extensional medical intervention. They are not able to make a decision and ask the cardiologist to make a choice. (CC:9)

The cardiologist and the spouse of the patient agree on opting for surgery, expecting medical benefit. However, the patient uses value laden age arguments to refrain from further intervention. Alternatively, the patient and his wife put the physician in a difficult position by asking him to make the decision for them. Strictly speaking from the viewpoint of informed consent, the physician has to deal with the patient only when it comes to decision-making, but the complicating factor is that the patient accepts that his wife plays an inherent role in the decision-making process.

\section{The physician and family: not or only partly including the older patient}

The case descriptions in this role pattern also involve the family. But whereas the patient was still fully involved in communication and decision-making in the previous category, this category contains cases where older patients are not informed or not asked for con- 
sent regarding important elements of the decision.

An 81-year-old man is joined by his son at the outpatient's clinic for urology because of an increased PSA value. The general practitioner wants to exclude prostate cancer. The patient has no further complaints. In spite of his age the man is still very vital and he is very scared that he may have something serious. When his father is gone to get an ultrasound the son of the patient tells the physician that if his father indeed has cancer, he doesn't want his father to know because it would make him very unhappy. The urologist agrees. If someone were 81 years old, he rather wouldn't want to know exactly what is going on. The urologist decides not to follow normal procedures and not to take a biopt and refrain from a rectal examination. Because of this they will never know if he really is suffering from prostate cancer. But even if he is suffering from prostate cancer, the physician doesn't expect him to experience any complaints because of his age. $(\mathrm{Cl}: 15)$

Remarkable in this case is that both the son and the physician do not communicate their decision with the patient. They fear that the patient will not be able to deal with the information. This is all the more remarkable since both the patient and the family physician were worried enough to pursue diagnostic procedures. Information from other cases learns that we may not presume that such an older patient would not be interested to hear all about the prognosis. In support of this presumption we have come across several cases, where information was withheld by the physician, upon request of the family, although the patient repeatedly asked for such information. Reasons for not informing an older patient were found, for example, in the physician's belief that older people do not need to know about all alternatives or all possible outcomes.

\section{The physician knows best}

The last category contains situations in which the physician essentially makes the decision. The first case is an example of an everyday situation in the consultation room of a general practitioner in the setting of an academic network of general practice centres.

A 72-year-old man comes to see his general practitioner with complaints of an increasing cough and shortness of breath. The general practitioner (GP) performs an anamnesis, and measures his blood pressure $(165 / 100 \mathrm{~mm} \mathrm{Hg})$. The patient asks the GP if his blood pressure is ok and the GP answers: 'Yes, very well'. Comments by the physicians-in-training: We were rather astonished. After the consult we asked the GP why he told the patient his blood pressure was fine, whereas it clearly was too high. The GP felt that the man already had reached an advanced age and high blood pressure is very common at that age. He felt it therefore unnecessary to do something about it. (CC:25)

The astonishment of the physicians in training indicates that the physician's judgment on the weight of the patient's blood pressure may be disputable. The point, however, is, even when the reserved attitude of the GP may be considered as reasonable, that age serves as a vehicle to a normative judgment without explicitly informing the patient about these considerations.

The next case illustrates that doctors may also display a proclivity to bypass patient and 
family in more dramatic circumstances.

Mrs B, 92 years and with a history of cardiac disease, was admitted to the hospital for fever, discomfort, fatigue and dehydration. After a week of successful recovery she could go home. However, her condition derotiated rapidly on that same day. The following weekend the doctor on duty had gone to see her and decided to stop all medication. He had found Mrs B in such a bad condition that he decided it was no longer sensible to treat her. Furthermore he remarked 'if he would be 92 , he also wouldn't want to be treated any more'. He had discussed this only briefly with the patient at that moment and he didn't consult the family. Mrs B appeared to have consented to stop all medication. After the weekend the ward physician and I went to visit Mrs B and her family and asked them if they agreed with the policy to stop all medication. Mrs B's clinical condition had improved a bit and she told us that she didn't want to die yet. Her children also wanted to continue the treatment. The treatment was started again, after she hadn't been treated for two days. During the week Mrs B's condition slowly deteriorated and she died five days later. $(\mathrm{Cl}: 13)$

The way that informed consent is dealt with in this case and the liberty that the physician takes to use his own judgment on age and quality of life raises suspicions of paternalism. The case also illustrates that family involvement need not infringe upon communicating with and deciding by the patient. The family in this case played an active part in redressing the physician's proclivity to bypass the patient.

\subsubsection{Comparative analysis of role patterns}

In this section the results of the comparative analysis of the six role patterns are presented (see table 3).

First, it is shown that, when physicians are clearly convinced about the usefulness of a therapy or intervention (role patterns 1 and 4), they present the options to the patient providing the possibility of informed consent, make their reasoning explicit, and do not use ageist arguments. In contrast, when there is uncertainty about the usefulness of medical intervention, even to the extent of wishing to refrain from an intervention (role patterns 5 and 6), informed consent is not provided, and the reasoning is implicit, hiding ageist arguments. Second, besides these clear-cut situations, there are also 'intermediate' cases. The $2^{\text {nd }}$ and $3^{\text {rd }}$ role patterns are in this respect instructive. In the second case the physician is moving to an ageist position, albeit slightly, but using (the short) life expectancy as an argument for refraining from medical intervention. Since the physician makes the argument explicit, this enables the patient to reject this reasoning and opt for a second opinion. In the third case, the physician also shows a somewhat nihilistic attitude regarding further treatment, but now he is leaving much of his ageist reasoning implicit. Surprisingly the physician is bringing up the option that treatment will be done, 'only if the patient really wants it', thus grasping back to an explicit informed consent. 


\begin{tabular}{l|l|l|l|l|l} 
Role pattern & $\begin{array}{l}\text { Proactive } \\
\text { therapy }\end{array}$ & $\begin{array}{l}\text { Informed } \\
\text { consent }\end{array}$ & $\begin{array}{l}\text { Explicit } \\
\text { reasoning }\end{array}$ & $\begin{array}{l}\text { Ageist } \\
\text { arguments }\end{array}$ & Role of family \\
\hline No 1 & + & + & + & - & Yes \\
\hline No 2 & 0 & + & + & 0 & No \\
\hline No 3 & 0 & + & - & + & No \\
\hline No 4 & + & + & + & - & Yes \\
\hline No 5 & - & - & - & + & Yes \\
\hline Nable 3. Comparative analysis of role patterns & - & - & &
\end{tabular}

Third, the role of the family is intriguing. In the first case, the patient and the son walk on together in reflecting upon the options as presented by the physician. In the fourth case, the physician holds a very positive stance towards further treatment, which is shared by the spouse of the patient, whereas the patient defends a nihilistic stance. In the fifth case, the son of the older patient asks the physician to hide a possible diagnosis of cancer for his father (and the physician agrees to do so). In the last case, the family actively engages in reversing the physician's ageist-based decision of refraining from treatment. Thus, the role of the family seems to be quite variable and complex.

\subsection{Discussion}

On the basis of the analysis of 48 out of 271 case descriptions related to the age factor we distinguished six role patterns concerning the communication between physician and older patient. Although this study has an exploratory nature, we believe these role patterns to be relevant for medical practice regarding the older patient. We are aware that the limited number and the context-sensitivity of the cases we presented in this paper imply limitations with regard to their coverage of medical decision situations concerning older patients. However, we did judge them to be examples of the majority of clinical cases we analysed. In addition, the cases as described in the case descriptions do not allow more in-depth and enriched analysis, whence further research (observations, interviews etc.) is necessary.

The communication between physician and older patient shows a great deal of variation encompassing the whole spectrum of interactions in the physician-patient relationship, 
from paternalism to respecting the patient's autonomy and everything in between. The influence of the physician's value judgments on these different approaches of dealing with the older patient in the context of informed consent is considerable.

Our analysis contains a description of the various patterns in which age-related, value laden arguments enter the medical decision-making process in the delivery of care to the elderly. This is not to say, that the identified patterns have to be judged in a normative way, either positive or negative. Obviously, informed consent is a widely acknowledged norm in health care. However, we do not necessarily consider the variation we found in dealing with this norm to be a problem. The basic value underlying the notion of informed consent is respect for the (older) patient as a person. In the ethical literature it is extensively argued that this value need not imply a mechanical adherence to a specific interpretation of informed consent (Balint \& Shelton, 1996; Emanuel \& Emanuel, 1992; Schermer, 2001). For example, when a patient and his wife, as occurred in one of the cases (role pattern 4), did not agree on treatment options, they requested the physician to decide, that is explicitly urging the physician to take a paternalistic attitude deciding for them what is best to do. This is not a priori 'wrong' from an ethical point of view. ${ }^{3}$ However way the physician would decide, following up or declining the request of the couple, we would argue that the physician in this case should strike a balance between respecting the patient's choice and respecting the importance of the role of the spouse. The latter refers to specific ways in which it may be relevant that the patient is old: issues such as a shared marital history and dependency on (the care of) close relatives take on a specific meaning in the context of the life of older people. The notion that older patients should be treated in all respects just like any other patient is too general and abstract in this regard. The normative framework should allow for attention to specific priorities and vulnerabilities of older patients, medically and socially, without stereotyping them. When there is no clear indication of vulnerability or decision incompetence, however, there is no justification for withholding essential information to the patient, be it on request of the family or not. Informed consent needs to be individualised without interfering or degrading the value of the older patient as a person.

The results show complicated ways of how medical facts become connected to value issues, i.e. the use of ageist arguments in medical care delivery. One important way is represented by those cases - the role patterns 1 and 4 - in which physicians are convinced about the usefulness of treatment, following the standard (medical) benefits-costs reasoning. With respect to these role patterns, we draw specific attention to the informative model by Emanuel and Emanuel (Emanuel \& Emanuel, 1992), because in this model a strict distinction is made between facts and values in the communication between physician and patient. In this model the physician provides the patient with all relevant information, subsequently the patient selects the medical interventions he or she wants, and the physician executes these. In presenting the information to the patient, there is no role for the physician's values. The patient makes a decision on the basis of the presented medical facts and his or her own personal values. This informative model is in conformity with medical decision-making studies showing that values play an important role in health care practices, but only from the perspective of the patient (Kassirer, 1994; McNutt, 2004).

\footnotetext{
3 From a procedural point of view, however, this case may lead to a discussion as the physician could have suggested to both patient and his wife to go home and quietly think things over. In addition, from the point of view of the physician, this case also may raise concern, as the physician is not in a position to be able to take these kinds of decisions for patients.
} 
Thus, the informative model does not deny the role of values in decision-making. On the contrary, there is a general awareness that medical decision-making is an inherent value laden and driven process. However, the underlying assumption is that medical facts and values can be separated. In fact, it is presupposed that first physicians accrue evidence about the condition of the patient, the possible options for treatment and care, and that thereafter values enter the process, i.e. in taking account of the preferences, needs and social conditions of the patient in the setting of family, work and social life, leading up to the choice for the best medical proposal to which the patient may consent (Vos, Houtepen, \& Horstman, 2002; Vos, Willems, \& Houtepen, 2004).

The role patterns 1 and 4 seem to be in clear agreement with the informative model. However, these concern cases in which the medical benefits so clearly seem to outweigh the possible side effects and other kind of costs - at least as perceived by the respective physicians -, that merely the medical 'facts' have to be shown to come to the 'correct' decision, choosing, for example, blood transfusion instead of chemotherapy (c.f. case 1).

It is intriguing to see that the physicians attempt to follow this informative model also in those situations, in which they adopt a nihilistic attitude towards treatment, even to the extent of wanting to refrain from medical intervention, as represented in the role patterns 5 and 6 . However in these cases value related issues, that is ageist arguments, underlie or are intertwined with the medical reasoning process, albeit in a hidden way. The reasoning process itself is constructed according to the lines implicated by the informative model. Thus, there seem to be two opposite reasoning 'pathways' connecting therapeutic options with ageist and non-ageist arguments, but both are modelled on the informative model. However, we want to point out that it is not necessarily the case that a nihilistic stance towards medical intervention is coupled with an ageist argumentation - or reversely a positive therapeutic stance with a non-ageist, explicit benefit-cost argumentation. Next to these clear-cut situations, there are also 'intermediate' cases: the $2^{\text {nd }}$ and $3^{\text {rd }}$ role patterns are in this respect instructive. These cases show that the crucial issue is whether the physician makes the value laden arguments explicit ( $2^{\text {nd }}$ case) or leaves these implicit ( $3^{\text {rd }}$ case). In addition, the role of the family does not seem to be coupled with one - or more - of the first four dimensions or with the reasoning pathways as described above. The role of the family seems to be quite variable, that is in some cases complicatory and in others supportive for the older patient.

Thus, the results show that the informative model does not adequately represent the intricacies and dynamics of medical decision-making in the care for elderly patients. This is in agreement with those studies which have put forward fundamental criticism on models of medical decision-making, such as the informative model, which presume the neat separation of medical facts and values (Molewijk, Stiggelbout, Otten, Dupuis, \& Kievit, 2003; Wulff, 1995). Value judgments by physicians regarding the patient's age, his or her quality of life or right to information clearly influence the communication process between physician and older patient. This is of specific importance since in the debate on the role of age in medical decision-making it is generally agreed that age may only play a role as part of technical assessment, in line with the informative model. This starting point is too simplistic in this context.

Matters are much more complex and nuanced than the view that age may only play a role as part of a technical assessment assumes. This has some consequences for the role of age in the communication process between physician and older patient. Whether the age of a patient is considered relevant in this context or not, and if so, in which specific way and 
setting, as a medical criterion or not, depends on the type of role pattern, in which the image of the older patient, the expectations of physician, patient and family, communication styles and legal and moral issues are interwoven. Only in the context of such complex interaction patterns we can determine whether age is dealt with as part of a strictly technical assessment or broader quality of life perceptions. Such perceptions may be subtle and hidden. Furthermore, the idea that every patient ought to be treated as an individual, and which lies at the basis of the ideal of informed consent, is not always evident in practice, in view of the considerable involvement of family members in decision-making that we encountered. And when next of kin is included as a partner in decision-making, we cannot say beforehand whether that harms the older patient's wishes or interests. Therefore, one should be careful of claiming too general opinions concerning the role of age in the communication between physicians and older patients.

Physicians should find ways to deal with the tension between values, e.g. respecting patient rights and fulfilling professional responsibility and facts, e.g. specific medical characteristics of older patients and technical routines. What matters here is whether an older patient can trust the physician to handle this tension correctly.

We consider the deliberative model as identified by Emanuel and Emanuel to be helpful here. This model aims to help the patient determine and choose the best health-related values, with help of the physician. At the extreme, the physician and patient engage in deliberation about what kind of health-related values the patient could and ultimately should pursue (Emanuel \& Emanuel, 1992). We are aware of the points of criticism concerning this model, for instance regarding the assessment of the worthiness of the patient's health-related values which is implied in this model (Schermer, 2001). Relevant for our discussion, however, is that the physician only discusses health-related values and that he or she recognizes that many elements of morality are unrelated to the patient's disease or treatment and beyond the scope of their professional relationship (Emanuel \& Emanuel, 1992). This model asks a lot of the physician dealing with an older patient. Not only does the physician need to be transparent and make knowledgeable to the patient what health-related values are important in his view, but also he must help the patient to recognize and to explicate real health-related values. In this respect the deliberative model puts too much emphasis on the health-related values, particularly those of the patient. Our study shows that physicians use age-related values as well. In this sense, the deliberation model should be conceived of as a dialogical, or participation model (Widdershoven 2000). In a dialogical model both sides - the physician and the patient - enter value driven discussion exchanging but also changing perspectives and views. ${ }^{4}$

The major difference between the informative and deliberative model is that the latter emphasizes the process of making values explicit. In this respect we think it is useful to distinguish between informed consent as a process and as a product. In both models a truly given informed consent by the patient is the aim. However, both models presume different views on the process of informing and consenting and how in this process facts

\footnotetext{
4 We consider the interpretative model not capable of reaching this result as the emphasis lies on explicating and interpreting the patient's values. What we have attempted to demonstrate, however, is that it is the physician's values that need more consideration. It is the communication process by the physician and the various normative laden arguments influencing this process that need to be addressed and made transparent. Concerning the paternalistic model, it is widely recognized that it is justified only during emergencies when the time taken to obtain informed consent might irreversibly harm the patient (Emanuel \& Emanuel, 1992). Therefore, we do not discuss this model in this context further.
} 
and values are related. Our view is that by being transparent about the norms and values influencing the communication and decision-making process, both held by the physicianand the patient, the position of the older patient can be better protected against implicit normative age related arguments.

In conclusion we can say that one should be careful of claiming too general opinions concerning the role of age in the communication between physicians and older patients. As our paper shows, it is too simple and naïve to resign ourselves to the basic assumption that age may only be used as part of a strictly technical assessment in the decision-making and communication process. The practice of the communication between physician and older patient clearly indicates the various ways in which age plays a role. Physicians should find ways to deal with the tension between values and facts. What matters now is that if it is considered desirable to trust physicians in taking care of older people, there is an urgent need for transparency in the criteria and arguments influencing the communication and decision-making process regarding older patients. In this way, trust in the medical profession regarding the care of older people will be enhanced.

\section{References}

Apostolou, T. (2007). Quality of life in the elderly patients on dialysis. International Urology and Nephrology, 39(2), 679-683.

Appelbaum, P. S. (1993). Must we forgo informed consent to control health care costs? A response to Mark A. Hall. The Milbank Quarterly, 71(4), 669-676.

Balint, J., \& Shelton, W. (1996). Regaining the Initiative. Forging a New Model of the Patient-Physician Relationship. Journal of the American Medical Association, 275, 867-891.

Beauchamp, T. L., \& Childress, J. F. (2001). Principles of Biomedical Ethics (5th ed.). Oxford: Oxford University Press.

Berg, J. W., Appelbaum, P. S., Lidz, C. W., \& Parker, L. S. (2001). Informed consent. Legal theory and clinical practice (2nd ed.). Oxford: Oxford University Press.

Binstock, R. H. (2007). Our aging societies: ethical, moral, and policy challenges. Journal of Alzheimer's Disease, 12, 3-9.

Binstock, R. H., \& Post, S. G. (Eds.). (1991). Too old for health care? Controversies in medicine, law, economics, and ethics. Baltimore and London: The John Hopkins University Press.

Bowling, A. (2007). Honour your father and mother: ageism in medicine. British Journal of General Practice, 57, 347-348.

Breda, J., \& Schoenmaekers, D. (2006). Age: a dubious criterion in legislation. Ageing and Society, 26, 529-547.

Brody, B. A. (1993). Assessing empirical research in bioethics. Theoretical Medicine, 14, 211 219.

Callahan, D. (1987). Setting limits: medical goals in an aging society. New York: Simon \& Schuster.

Callahan, D. (1990). What kind of life. The limits of medical progress. New York: Simon and Schuster.

Churchill, L. R. (2005). Age-rationing in health care: flawed policy, personal virtue. Health Care Analysis, 13(2), 137-146.

Daniels, N. (1985). Just health care. Cambridge: Cambridge University Press.

Emanuel, E. J., \& Emanuel, L. L. (1992). Four Models of the Physician-Patient Relationship. Journal of the American Medical Association, 267(16), 2221-2226. 
Evans, J. G. (1997). The rationing debate: rationing health care by age: the case against. British Medical Journal, 314, 822-825.

Giordano, S. (2005). Respect for Equality and the Treatment of the Elderly: Declarations of Human Rights and Age-Based Rationing. Cambridge Quarterly of Healthcare Ethics, 14, 83-92.

Glaser, B. G., \& Straus, A. L. (1967). The discovery of grounded theory: Strategies for qualitative research. Chicago: Aldine.

Gnavni, R., Migliardi, A., Demaria, M., Petrelli, A., Caprioglio, A., \& Costa, G. (2007). Statins prescribing for the secondary prevention of ischaemic heart disease in Torino, Italy. A case of ageism and social inequalities. European Journal of Public Health, 17(5), 492-496.

Graber, M. A., \& Tansey, J. F. (2005). Autonomy, consent, and limiting healthcare costs. Journal of Medical Ethics, 31, 424-426.

Hackler, C., \& Micah Hester, D. (2005). Age and the Allocation of Organs for Transplantation: A Case Study. Health Care Analysis, 13(2), 129-136.

Hall, M. A. (1993). Informed consent to rationing decisions. The Milbank Quarterly, 71(4), 645-668.

Hall, M. A. (1994). Disclosing rationing decisions: a reply to Paul S. Appelbaum. The Milbank Quarterly, 72(2), 211-215.

Hall, M. A. (1997). A theory of economic informed consent. Georgia Law Review, 31(2), 511 586.

Halvorsen, K., Slettebo, A., Nortvedt, P., Pedersen, R., Kirkevold, M., Nordhaug, M., et al. (2008). Priority dilemma's in dialysis: the impact of old age. Journal of Medical Ethics, 34, 585-589.

Harris, J. (1985). The value of life. An introduction to medical ethics. London/New York: Routledge \& Kegan Paul.

Harris, J. (1987). QUALYfying the value of life. Journal of Medical Ethics, 13, 117-123.

Harris, J. (2005). The Age-Indifference Principle and Equality. Cambridge Quarterly of Healthcare Ethics, 14, 93-99.

Kapp, M. B. (2002). Health care rationing affecting older persons: rejected in principle but implemented in fact. Journal of Aging and Social Policy, 14(2), 27-42.

Kassirer, J. P. (1994). Incorporating patients' preferences into medical decisions. The New England Journal of Medicine, 330(26), 1895-1896.

Lin, J.-N., \& Chen, K.-M. (2007). Cultural issues and challenges of informed consent in older adults. Tzu Chi Nursing Journal, 6(5), 65-72.

Loewy, E. H. (2005). Age discrimination at its Best: Should Chronological Age be a Prime Factour in Medical Decision Making? Health Care Analysis, 13(2), 101-117.

McNutt, R. A. (2004). Shared medical decision making. Journal of the American Medical Association, 292(20), 2516-1518.

Molewijk, A. C., Stiggelbout, A. M., Otten, W., Dupuis, H. M., \& Kievit, J. (2003). Implicit normativity in evidence-based medicine: a plea for integrated empirical ethics research. Health Care Analysis, 11(1), 69-92.

Nilstun, T., \& Ohlsson, R. (1995). Should health care be rationed by age? Scandinavian Journal of Social Medicine, 23(2), 81-84.

O'Neill, O. (2002). Autonomy and trust in bioethics. Cambridge: Cambridge University Press. Osterwalder, R., Osswald, S., Buser, P., \& Pfisterer, M. (2001). Evidence for age-based rationing in a Swiss University Hospital Swiss Medical Weekly, 131, 630-644.

Patenaude, A. F., Rappeport, J. M., \& Smith, B. R. (1986). The physician's influence on in- 
formed consent for bone marrow transplantation. Theoretical Medicine, 7, 165-179.

Pearlman, R. A., Miles, S. H., \& Arnold, R. M. (1993). Contributions of empirical research to medical ethics. Theoretical Medicine, 14, 197-210.

Petrila, J. D. (2003). The emerging debate over the shape of informed consent: can the doctrine bear the weight? Behavioral Sciences and the Law, 21, 121-133.

Polit, D. F., \& Beck, C. T. (2004). Nursing Research: Principles and Methods (7th edition ed.). Philadelphia: Lippincot Williams \& Wilkins.

Quill, T. E., \& Brody, H. (1996). Physician recommendations and patient autonomy: finding a balance between physician power and patient choice. Annals of Internal Medicine, 125, 763-769.

Rivlin, M. (2000). Why the fair innings argument is not persuasive. BMC Medical Ethics, 1(1). Schermer, M. H. N. (2001). The different faces of autonomy. A study on patient autonomy in ethical theory and hospital practice. Amsterdam: University of Amsterdam.

Spinewine, A., Swine, C., Dhillon, S., Franklin, B. D., Tulkens, P. M., Wilmotte, L., et al. (2005). Appropriateness of use of medicines in elderly inpatients: qualitative study. British Medical Journal, 331(935).

Springer Loewy, R. (2005). Ageisms. Health Care Analysis, 13(2), 147-156.

Stahl, J. E., Tramontano, A. C., Swan, J. S., \& Cohen, B. J. (2008). Balancing urgency, age and quality of life in organ allocation decisions-what would you do? A survey? Journal of Medical Ethics, 34(2), 109-115.

Strauss, A. L., \& Corbin, J. (1994). Grounded Theory Methodology: An Overview. In N. K. Denzin \& Y. S. Lincoln (Eds.), Handbook of Qualitative Research (pp. 273-285). Thousand Oaks, Calif: Sage Publications Inc.

Strauss, A. L., \& Corbin, J. (1998). Basics of Qualitative Research. Techniques and Procedures for Developing Grounded Theory (2nd ed.). Thousand Oaks: Sage Publications Inc.

Thomasma, D. C. (1991). From Ageism toward Autonomy. In R. H. Binstock \& S. G. Post (Eds.), Too Old for Health Care? Controversies in Medicine, Law, Economics, and Ethics (pp. 138-163). Baltimore and London: The John Hopkins University Press.

Tsuchiya, A. (2000). Qualy's and Ageism: Philosophical Theories and Age Weighting. Health Economics, 9, 57-68.

Vos, R., Houtepen, R. H., \& Horstman, K. (2002). Evidence-based medicine and power shifts in health care systems. Health Care Analysis, 10, 319-328.

Vos, R., \& Willems, D. (2000). Technology in medicine: ontology, epistemology, ethics and social philosophy at the crossroads. Theoretical Medicine and Bioethics, 21, 1-7.

Vos, R., Willems, D., \& Houtepen, R. H. (2004). Coordinating the norms and values of medical research, medical practice and patient worlds - the ethics of evidence based medicine in orphaned fields of medicine. Journal of Medical Ethics, 30, 166-170.

Vrakking, A. M., Heide, A., van der, Delden, J. J. M., van, Looman, C. W. N., Visser, M. H., \& Maas, P. J., van der. (2005). Medical decision-making for seriously ill non-elderly and elderly patients. Health Policy, 75, 40-48.

Werntoft, E., \& Edberg, A. K. (2009). The views of physicians and politicians concerning age-related prioritisation in healthcare. Journal of Health Organization and Management, 23(1), 38-52.

Wulff, H. R. (1995). The inherent paternalism in clinical practice. The Journal of Medicine and Philosophy, 20, 299-311.

www.helptheaged.org.uk. Half of doctors say NHS is ageist.

Retrieved 27 January 2009, fromhttp://www.helptheaged.org.uk/en-gb/Campaigns/ 
News/Archive/news_NHS+is+ageist_270109.htm

Yap, J., \& Celi, A. (2007). Elderly access to medical care: should age be a factor in deciding management? The New Zealand Medical Journal 120, 1-3.

Young, J. (2006). Ageism in services for transient ischaemic attack and stroke. Could be cut by emulating successful efforts against ageism in heart disease care. British Medical Journal, 333, 508-509. 


\title{
Chapter 3
}

\section{Value Judgments In The Decision-Making Process For The Elderly Patient}

\author{
Josy Ubachs-Moust \\ Rob Houtepen \\ Ruud ter Meulen \\ Rein Vos
}

Published in Journal of Medical Ethics

J. Med. Ethics 2008;34;863-868 doi:10.1136/jme.2008.025247 


\subsection{Introduction}

T

he position of the elderly patient in healthcare is a delicate subject. The role of age in the decision-making process takes a specific place in the ethical and medical debates on ageism. Commonly, the focus is on problems that arise in the light of the difference between chronological and biological age (Bhanot, Naik, Gopalakrishanan, \& Naqashabandi, 2005; Goffaux et al., 2005; Loewy, 2005), in deciding on an age limit or not (Dey \& Fraser, 2000; Meulen \& Ubachs-Moust, 2005), and in consideration of the legal and ethical right to equal treatment and non-discrimination (Giordano, 2005; Harris, 2005). It is implicitly held that age somehow may play a role in the medical decision-making process. However, explicitly or implicitly, the normative question always comes down to the problem of whether the elderly patient's right to equal treatment is (or should be) respected. The discussion we have found in the literature so far remains abstract and very distant from what happens in medical practice. What is missing in the discussion on the role of age as a factor in medical decision-making is exactly how age plays a role in this process for the elderly patient.

Our research question in this paper focuses on how age influences the decision-making process as a normative argument. In our research we have made use of the analysis theory of Toulmin (Toulmin, 1958), a structural model that was developed to explicate the architecture of arguments used in practical reasoning (Upshur \& Colak, 2003). We adjusted this model by including an additional component, namely the distinction between arguments that are empirical versus value-driven, to explore and clarify age-related arguments phrased in a normative way. We applied this model to practice descriptions made by medical students after they attended consultations and meetings in medical practice during their clinical training. By viewing the notes in this way, new insights can be generated on the role of age in the medical decision-making process. In this paper, we present three exemplary practices in order to show in detail what happens in the argumentation process and how normative or value judgments concerning age play a role in this process. The descriptions may appear to be clear-cut examples of inadequate clinical practice, but the argumentation involved is more subtle than expected at first sight. During their training students are sensitized to ethical issues and are capable of judging the ethical character of the descriptions. However, in our analysis we provide a deeper understanding of how the role of age influences the decision-making process and may make the outcome indeed reprehensible.

\subsection{Methods}

\subsubsection{Data collection}

We used the database of practice descriptions discussed in clinical ethics meetings at the medical school of Maastricht University. In the clinical training period of their studies in academic hospitals, in associated hospitals, in general practice or in mental healthcare settings, all medical students have to present 12 practice descriptions from their field notes. Staff members of the ethics department, 'age' being one of the codes, coded the practice descriptions. At the time of the analysis, 271 out of 5828 practice descriptions had received the 'age' code. These descriptions represent a cross-sectional view of various fields of medicine and a broad range of clinical practices. The practice descriptions are descriptions of the decision-making process from the viewpoint of a physician, as de- 
scribed by a physician-in-training. We have good reasons to assume that physicians who are used to having students around do not experience them as external observers of their behavior. We think this ensures that the physician's behavior and argumentation patterns as described in the practice notes display more or less natural situations. The practice descriptions typically include information about the medical problems of the patient, the patient's medical history, and the views and opinions of the physician. They give information on the view of the physician and the physician-in-training. In presenting the practice descriptions, we have done some editing, but we have not altered their content.

\subsubsection{Data analysis}

We selected three exemplary practices to present our analysis; in our view, these are representative of the argumentation pattern of the majority of descriptions we studied. Furthermore, they were chosen for analytical reasons. In our analysis of the practice descriptions we made use of Toulmin's argumentation theory, in which he outlined an analytical approach to the analysis of everyday arguments in practical reasoning (Toulmin, 1958) (fig 1). Briefly, the model states that in practical reasoning one concludes to some action (the claim or conclusion), which is backed up by different kinds of arguments, namely data, warrants and backings, but which can be disputed (rebuttals). ${ }^{5}$ His structural model involves identifying and separating the various components of practical reasoning into a specific order and structure in such a way that different types of arguments can be perspicuously appraised (Upshur \& Colak, 2003).

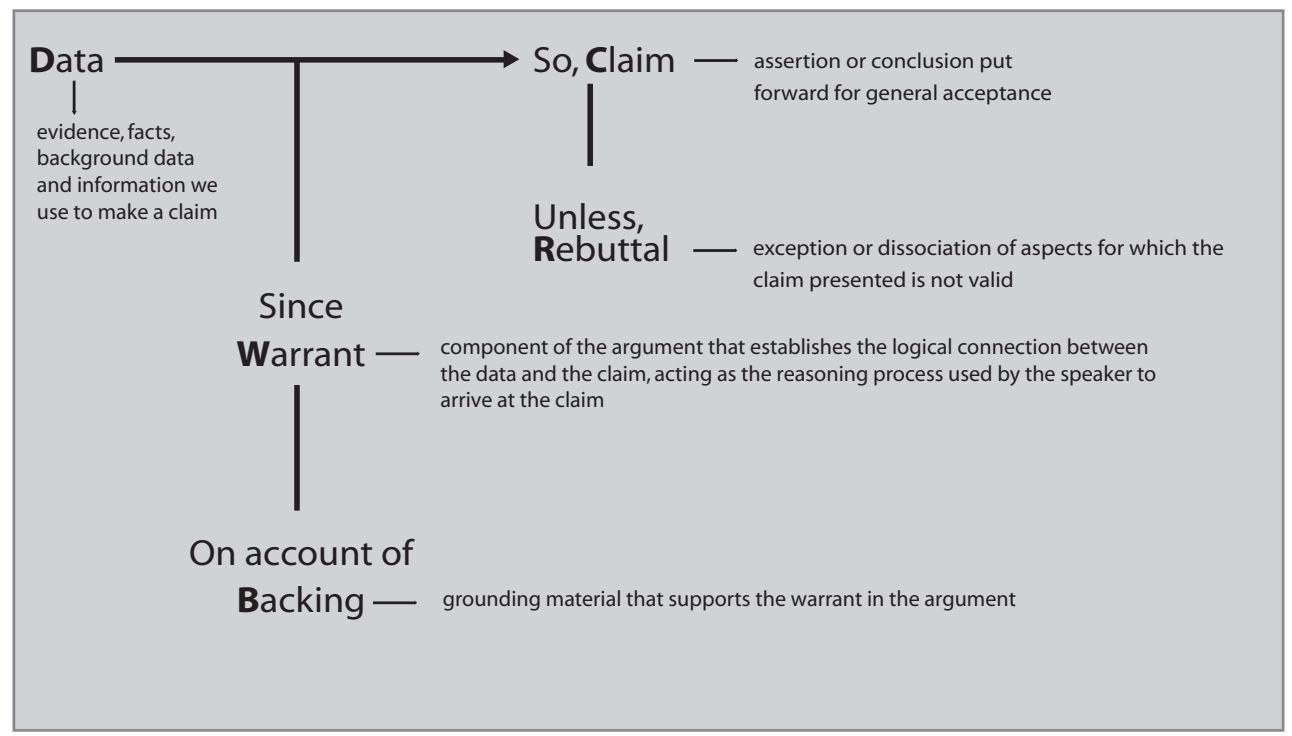

Figure 1. Components of the Toulmin model as described by Mackay et al (Mackay, Schulz, Rubinelli, \& Pithers, 2007).

It is a general model of practical reasoning, which can be aptly applied to medical decision-making as a very prominent form of practical argumentation. For our purpose, we

5 In his model, Toulmin also made use of qualifiers to indicate the strength of an argument made. For the purpose of our research, this was not needed. In addition, a more detailed analysis is required to be able to qualify a claim made. The material as we use it in this paper does not provide these details. 
adjusted Toulmin's model. ${ }^{6}$ By evaluating the components that we distinguished with the help of the Toulmin model, we explored the use of normative factors in the decisionmaking process regarding an elderly patient. To this end, we distinguish between normative arguments (value judgments) and descriptive arguments (observations, data or evidence). ${ }^{7}$ By expanding the Toulmin model in this way we are able to investigate how age normatively plays its role in medical decision-making.

\subsection{Results}

The first practice description is an example of the complexity of the argumentation structure in the medical decision-making process.

\subsubsection{Practice description 1}

A lively 85-year-old man, with no cardiac history, came to the emergency cardiovascular room with progressive dyspnoeic complaints and severe oedema of the lower extremities. Diagnostic tests showed that he was suffering from serious heart failure because of extreme aorta stenosis (fig 2). During the morning's discussion, a conservative policy was proposed, because of his advanced age. This led to a fierce discussion. Some consultants believed that this older man might still have had a right to a replacement of the aorta valve. The attending doctor, however, believed that dying at an advanced age is a natural phenomenon and should not be fought. Doctors should not take over the function of God in these matters. It is perfectly possible to fight the symptoms conservatively and in that way increase the quality of life. Extension of life should not be the major objective here.

Using the Toulmin model, we first identified the data used in the argumentation, which consist of the patient's sex, age, medical condition and history, and the medical complaints requiring his attendance at the emergency room. The claim is to proceed to a conservative policy. The warrant for this decision includes three factors. The first factor is based on the diagnostic results, which show that the patient is suffering from severe heart failure (W1). The second factor is the patient's advanced age (W2). The fact that conservative treatment will fight the symptoms and increase the quality of life is the last warrant (W3). The backing of the warrant consists of three elements: the comment of the attending physician that dying at an advanced age is natural (B1); that this should not be fought (B2); and that physicians should not act as God in these matters (B3). The rebuttal to the claim is provided by different actors from the attending physician, namely other physicians present at the morning consultation who state that this patient may still have a right to be treated. The distinction between normative and descriptive argumentation is helpful in further analyzing the description. The first warrant (W1) is an observation: a description of the 'facts' of the case. Here these facts consist of the results of the diagnostic tests.

6 We are aware of other structural arrangements of the Toulmin model allowing a more interactive approach (www-rohan.sdsu.sdu/digger/305/tpulmin_model). However, in this paper we choose to highlight the differences rather than the interactions of day-to-day practice, as the latter requires different research methods. 7 This distinction is also used by Brown in his model on ethical process (Brown, 1999). 
The second warrant (W2) is also an observation, but the relevant fact now is the patient's age, which can be empirically determined by the date of his birth. The third (W3) is clearly a value judgment. It is the attending physicians' opinion that conservative treatment will be the best option for this patient, although disputed by the other physicians. The first backing (B1) is a hidden value judgment, since not everybody believes we should accept dying at old age. The second (B2) is a straightforward and explicit value judgment: dying at old age should not be fought. The third element (B3) is a value judgment concerning the role of physicians. The rebuttal at last is provided by somebody else other than the attending physicians and is framed in a language of ethics ('right') and not in a language of risks and benefits. The warrant, the backing and the rebuttal all contain value judgments, mostly age-related, which influence the decision. Age-related value judgments are pervasive and go right through the categories and classes of arguments. This case is complicated even more by the fact that the physicians do not agree and bring different value judgments to the fore. Furthermore, if the attending physician really believes that dying in advanced age is a natural phenomenon, he should not be offering conservative treatment either. On the other hand, though, conservative treatment prior to consideration of surgery has some merit in this case. If we take a closer look at the argumentation structure, we notice that some of the value judgments are presented as backing of the claim and therefore to some extent remain hidden. Normative argumentation regarding the age factor takes place both at the surface level and the undertow of the decision that is being made. Age-related value judgments, therefore, are not always immediately visible.

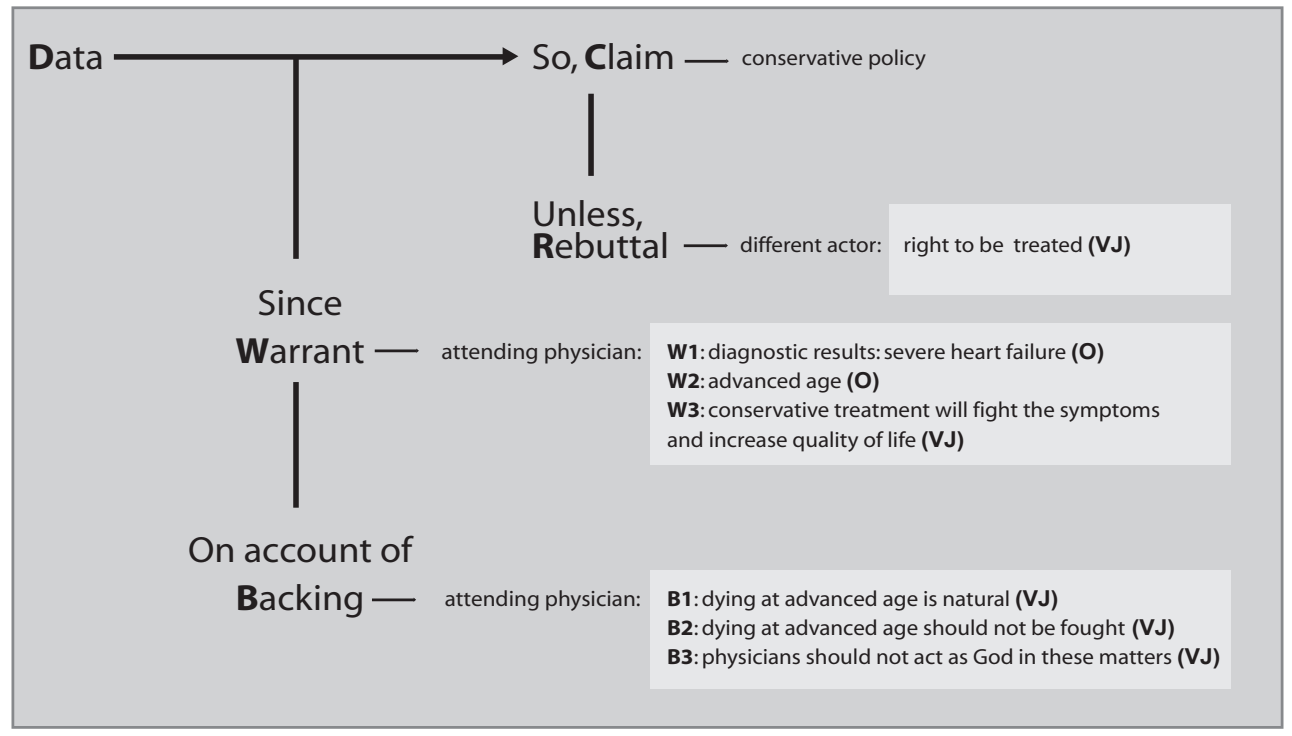

Figure 2. Normative argumentation and practical reasoning: practice description 1. O, observation; VJ, value judgment.

\subsubsection{Practice description 2}

An 82-year-old very jaundiced man was admitted at the internal/oncology ward. He appeared lively and 65 years old at the most. His medical history was blank and he used no medication (fig 3). A CT scan showed a large tumor in the pancreas, without evidence of metastasis. The same day, the patient's situation 
was discussed in the internal/surgical consultation, where it was established that Whipple surgery with removal of the pancreas would be possible. It would, however, be difficult because the tumor had grown very close to important blood vessels and because the Whipple procedure is difficult in itself. The two surgeons present immediately decided that an 82-year-old man would not be able to cope with this surgery and therefore they only wanted to place a palliative stent, although they had not seen the patient yet. The attending internist did not agree with this course of events and insisted that both surgeons would meet the patient before making this kind of decision.

The data are the patient's sex, age, medical condition and history, and present complaints. The claim consists of the decision not to perform the Whipple procedure but to place a palliative stent instead. The fact that the tumor had grown very close to important blood vessels, which increases the difficulty of the surgery, is the warrant (W1). The backing is provided by the difficulty of performing the Whipple procedure (B1) and by the consideration of the surgeons that an 82-year-old patient would not be able to cope with such surgery (B2). The attending physician provides the rebuttal by insisting that the surgeons should meet the patient before making a decision. If we take this analysis one step further we see that the warrant for the claim is an observation. Evidence can be produced (CT scan) to show that the tumor indeed has grown very close to important blood vessels. The backing consists of two elements. The first one (B1) is an observation. It is believed by oncology surgeons that the Whipple procedure is difficult and risky. This can be proven for example on the basis of evidence in medical journals. The second element of the backing (B2) is a value judgment presented as a fact. It is the surgeons' opinion, putatively of a medical nature, that an 82-year old could not deal with this kind of surgery. The phrase 'an 82-year-old' patient instead of saying 'this 82-year-old-patient' indicates that it is a normative attitude on how cases like this should be dealt with. The rebuttal consists of two elements: first, the value judgment that you cannot judge a patient and make a decision regarding his health before actually seeing him; second, the value judgment that the surgeons will be surprised if they in fact meet the patient. After all, the patient is described by the medical student as very vital and as if he is almost 20 years younger than he really is (chronologically). Remarkably, the value judgment provided by the attending physician is age related and positive, in contrast to the surgeons' negative age related value judgment. The value judgment provided by this physician is based on the view that biological age as expressed through the vitality of the patient is a better foundation for medical decisionmaking than chronological age (Bhanot, Naik, Gopalakrishanan, \& Naqashabandi, 2005; Goffaux et al., 2005). If the surgeons visit him, they will probably agree. Both the attending physician and the surgeons, however, may be basing their case on incomplete evidence. First, the surgeons not taking the patient's biological age into account, and second, the attending physician not understanding the realities of Whipple's surgery. In addition, none of them seems aware of what the patient thinks. However, the case description does not provide us enough details to comment on that last aspect. The model, furthermore, reveals that the central normative argumentation is to be found at the rebuttal to the claim. Compared with the previous practice description (practice description 1) the conflicting value judgments are more central and more explicit. Additionally, and interestingly, the physician uses a positive perception on old age to make an exception to the claim. 


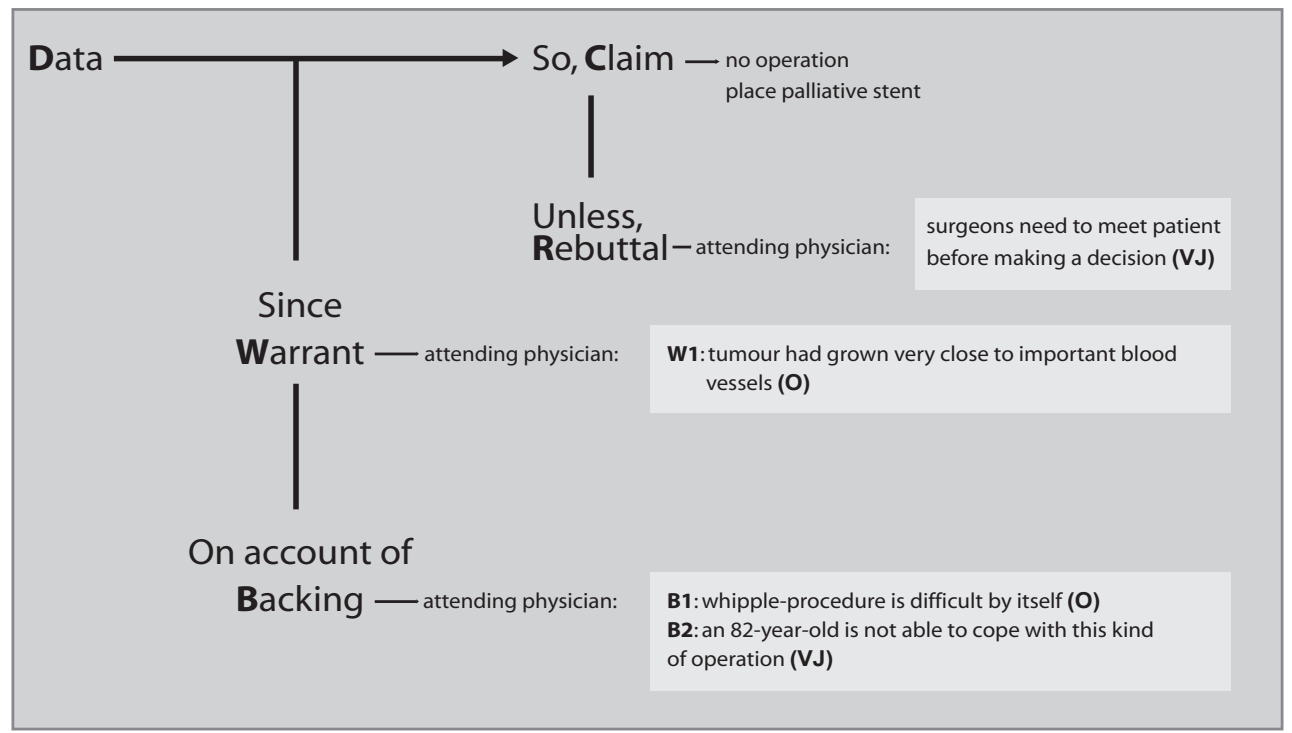

Figure 3. Normative argumentation and practical reasoning: practice description 2. O, observation; VJ, value judgment

\subsubsection{Practice description 3}

A 78-year-old healthy and lively looking man was seen in the gastroenterology outpatient clinic. His medical history indicated some sigmoid diverticula, hypertension and diabetes mellitus, with hypertension and diabetes being well regulated (fig 4). The patient came to discuss the result of an echogram of his liver. This had been requested because the laboratory results incidentally showed disturbed liver function. The patient had no further complaints correlated to these deviations, and actually had no complaints at all. During the echogram the patient had already received some information on what they were seeing, so he already was somewhat prepared for what the physician was telling him. The deviations found with the echogram were strongly suspected to be metastases of a still unknown cancer. Subsequently the doctor told him that he did not want to perform further research into the origin of metastases, or into other metastases. He did not want to start treatment either, and since the patient had no complaints, he did not talk about pain control. The arguments which the doctor used were akin to: 'You have lived a beautiful life ...' and 'to perform all those diagnostic tests at your age .... The patient resigned himself to it, and remained calm.

The patient's age, sex, medical condition and history, and the reason for seeing a physician, are the data of this practice description. The claim is the decision not to perform any more diagnostic tests and not to start treatment. The two warrants are remarkable. The arguments the physician uses for his decision are examples of age-related value judgments: having lived a beautiful life (W1) and testing that makes no sense at a certain age (W2). They are expressions of the physician's view on the value of the life of an older person and the use and burdens of performing diagnostic tests on older people. Notable is the fact that the physician straightforwardly presents his arguments to the patient. The argumentation pattern and the decision-making process are thus made transparent. Apart from 
the frankness of the physician in presenting age related value judgments to the older patient, it is also remarkable that value judgments can already play a part at the phase of generating data. The data element in the argumentation pattern has so far not been given much attention. Medical data -and evidence in general- seem to be clear, evident and undisputed. However, as this case shows, decisions based on age-related value judgments can influence the type of data that physicians have at their disposal. In this case it might be suggested that the clinician jumped to a diagnosis (Peschl, Werle, \& Mathis, 2004). Even to the extent that he made a flawed assumption based on the data presented and then justified his decision using value judgments, however, the case does not provide enough information to be certain in that regard. In the Toulmin model that we have used so far, therefore, arrows have to be drawn from the various components, including the claim backwards to the data. Data are part of the practical reasoning that is not represented, but generated, inferred and interpreted: not only guided by evidence-based arguments, but also by normative-based arguments.

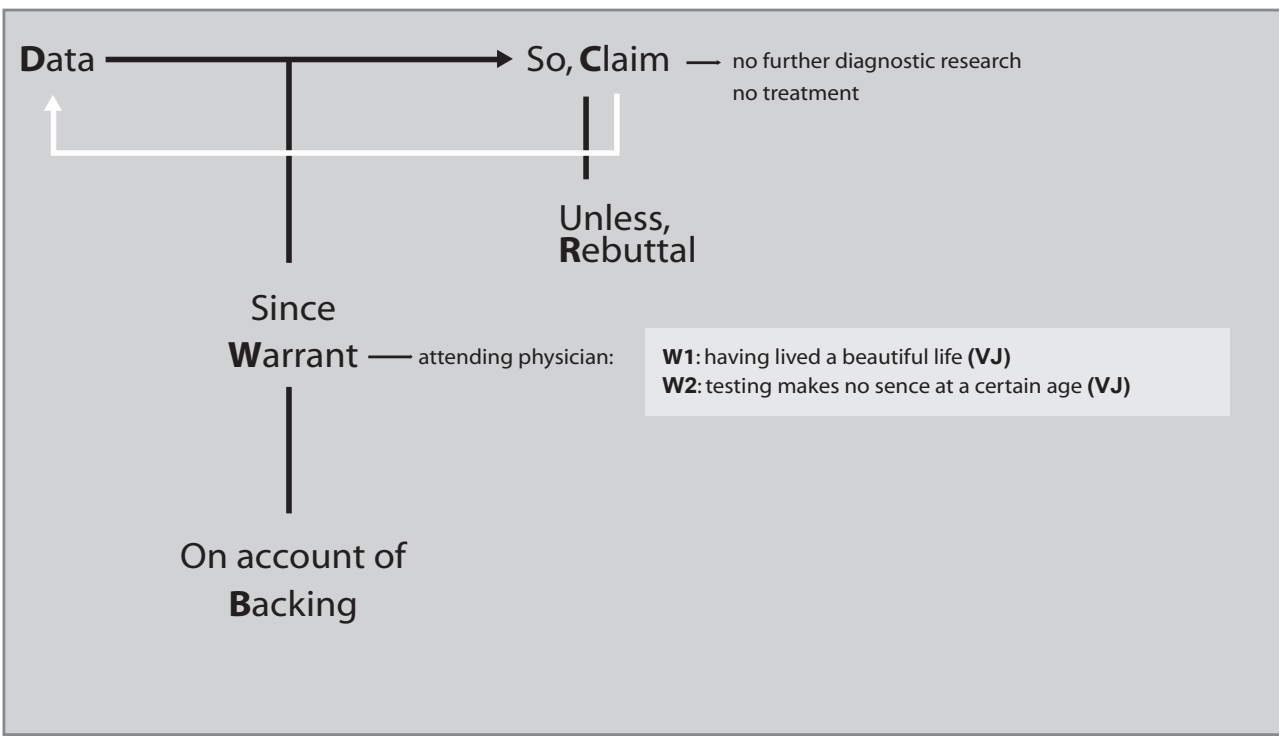

Figure 4. Normative argumentation and practical reasoning: practice description 3. VJ, value judgment.

\subsection{Discussion}

By comparing the three practice descriptions as modeled through the Toulmin structure of practical reasoning, the following conclusions can be drawn. We see that age-related values are ubiquitous, present in every phase of the reasoning pattern and in every component of the argumentation pattern. Age-related value judgments are found in the warrant, the backing of the warrant and the rebuttal to the decision. With the help of the model, a closer look also revealed an undertow of normative age-related argumentation. Value judgments on age may remain hidden below the surface, as some of these judgments are playing their role in the background of the decision-making process. But we also uncovered an explicit use of age-related normative argumentation at the rebuttal or the warrant to the claim. Indeed, we even concluded that value judgments can influence the kind and amount of data that physicians use in their decision-making. Such explicit 
value judgments were not exclusively used for arguments against further diagnosis or treatment of older patients. We found no systematic 'ageist' pattern in the clinical decisions by physicians.

Another intriguing aspect is found in practice descriptions 1 and 2: some of the value judgments would not have been addressed if there had not been a disagreeing physician present. Medical decision-making is very often depicted as a situation of an individual physician facing an individual patient. However, in practice, as here in the case of an academic hospital, we see the 'communal' structure of medical decision-making. As is common in medical practice, many people are involved: cooperating, communicating and deliberating facts and values in dealing with complex issues for particular patients. Whenever physicians work and decide by themselves, however, awareness of the normative component of the decision-making process may be lacking. We conclude that it takes a systematic effort to uncover, specify and address the role of age-related value judgments in clinical practice. However, such an effort is worth taking, not only by ethicists, but more importantly by physicians. In medical practice, there is not always a disagreeing physician on hand, but it is obvious from the practice descriptions analyzed that value judgments constantly and intrinsically influence the medical decision-making process, either implicitly or explicitly. We are aware that the low number and the context-sensitivity of the descriptions we have presented severely limit their coverage of medical decision situations concerning older patients. However, we did judge them to be exemplary practices of the vast majority of clinical practice descriptions we analyzed. In addition, the practice descriptions as described in the notes do not allow deeper or richer argumentation analysis; further research (observations, interviews, etc.) is necessary.

The Toulmin model and the expansion to the model provide a clear view of the normative argumentation and practical reasoning pattern of the role of age in the decision-making process for the elderly patient. Although the physician may not strictly be using an age criterion in the decision-making process, the results show that by way of value judgments age-related arguments influence this process. These value judgments often do not have a formal role in the process. In other words, by way of these value judgments, the age factor plays an important role in the decision-making regarding an elderly patient, but this is not recognized as such. Age-related value judgments are pervasive. This does not imply that these judgments lead to ageist decisions. After all, we also came across examples in which physicians valued and treated an elderly patient as an individual patient, considering his or her condition and weighing benefits and costs as in any patient devoid of bias against age. It is preferable that the decision-making process should be more transparent in this respect. The visibility of these judgments can enhance an open and trusting physician-patient relationship. The literature on medical decision-making does not offer enough opportunities to reveal these arguments. According to Siegler, the goal of decision analysis is to reach the best medical decision for a patient in the light of the facts, the patient's personal preferences and values, and uncertainty that exists in any clinical situation (Siegler, 1987). Decision models and decision trees are developed to support physicians in reaching this goal (Parmigiani, 2002; Rao, 2007; Wulff \& Gøtzsche, 2000). In these models distinctions are made between medical and non-medical determinants (Vrakking et al., 2005), between diagnostic and other cues (Sorum et al., 2002), and between medical indications, informed patient preferences, external factors and quality of life judgments (Siegler, 1987). What is missing, however, is how value judgments play their role in the various components and stages of the practice of medical decision-making. In 
this paper, we have tried to fill in this gap. Although our analysis shows how age-related arguments normatively play a role in the decision-making process, this should not come as a surprise. After all, medical decision-making is a deeply human affair: decisions made about people by people. Value judgments naturally have their part in this process. As Upshur and Colak state, clinicians often find themselves in situations where there is little, if any, research data available, or there is substantive disagreement about the interpretation of the research data (Upshur \& Colak, 2003). This makes explicit the fact that in such situations a physician's experience and intuition may potentially serve as the backing of a warrant (Upshur \& Colak, 2003). What we would like to add to this analysis is twofold. Decision-making is not only about medical facts, such as the patient's clinical situation and prognoses. Both medical facts and value judgments influence the decision. Moreover, these facts are colored by such judgments on 'good old age'. Recognizing the influence of value judgments, however, is not enough. Transparency requires a deliberative approach to decision-making, putting all relevant arguments openly on the table, from start to finish. Analyzing the decision-making process according to the Toulmin structure is helpful in sensitizing professionals in this way. The differences in the argumentation patterns and the consequences for the patients involved show the need for insight in these patterns. In addition, mapping exactly where and how age-related value judgments influence the decision-making process takes the discussion on the role of age in this process to a higher level. In this discussion, however, the clinical wisdom in the professional's course of actions should not be neglected. Further research in this regard is therefore warranted. Furthermore, dealing with the age factor in such a deliberative manner will improve the physician-patient relationship and create confidence and trust, which are at the heart of medical practice.

\section{Acknowledgments}

We owe many thanks to Dr. Bart Penders for his help in designing, and in teaching how to design, the figures as presented in this chapter. We would like to thank Dr. David Townend for helping us in getting our message across in clear and correct English.

\section{References}

Bhanot, S. M., Naik, P., Gopalakrishanan, R., \& Naqashabandi, K. (2005). Biological Age vs. Chronological Age. European Urology, 48, 168.

Brown, M. T. (1999). The Ethical Process. An approach to controversial issues (Second ed.). Upper Saddle River: Prentice Hall.

Dey, I., \& Fraser, N. (2000). Age-based rationing in the allocation of health care. Journal of Aging and Health, 12(4), 511-537.

Giordano, S. (2005). Respect for Equality and the Treatment of the Elderly: Declarations of Human Rights and Age-Based Rationing. Cambridge Quarterly of Healthcare Ethics, 14, 83-92.

Goffaux, J., Friesinger, G. C., Lambert, W., Shroyer, L. W., Moritz, T. E., McCarthy, M., Jr., et al. (2005). Biological Age-A Concept Whose Time has Come: A Preliminary Study. Southern Medical Journal, 98(10), 985-993.

Harris, J. (2005). The Age-Indifference Principle and Equality. Cambridge Quarterly of 
Healthcare Ethics, 14, 93-99.

Loewy, E. H. (2005). Age discrimination at its Best: Should Chronological Age be a Prime Factour in Medical Decision Making? Health Care Analysis, 13(2), 101-117.

Mackay, J., Schulz, P., Rubinelli, S., \& Pithers, A. (2007). Online Patient Education and Risk Assessment: project OPERA from Cancerbackup. Putting inherited breast cancer risk information into context using argumentation theory. Patient Education and Counseling, 67, 261-266.

Meulen, R. H. K., ter, \& Ubachs-Moust, J. (2005). Health care rationing: is age a proper criterion? In M. L. Johnson \& V. L. Bengston (Eds.), The Cambridge Handbook of Age and Ageing. Cambridge: Cambridge University Press.

Parmigiani, G. (2002). Modeling in Medical Decision Making. A Bayesian Approach. West Sussex: John Wiley \& Sons, LTD.

Peschl, R., Werle, A., \& Mathis, G. (2004). Differential Diagnosis of Focal Liver Lesions in Signal-Enhanced Ultrasound Using BR1, a Second-Generation Ultrasound Signal Enhancer. Digestive Diseases, 22, 73-80.

Rao, G. (2007). Rational Medical Decision Making. A case-based approach. New York: McGraw Hill Medical.

Siegler, M. (1987). Decision Analysis and Clinical Medical Ethics: Beginning the Dialogue. Medical Decision Making, 7, 124-126.

Sorum, P. C., Stewart, T. R., Mullet, E., González-Vallejo, C., Shim, J., Chasseigne, G., et al. (2002). Does Choosing a Treatment Depend on Making a Diagnosis? US and French Physicians' Decision Making about Acute Otitis Media. Medical Decision Making, 22, 394-402.

Toulmin, S. E. (1958). The Uses of Argument. Cambridge: University Press.

Upshur, R. E. G., \& Colak, E. (2003). Argumentation and Evidence. Theoretical Medicine, 24, 283-299.

Vrakking, A. M., Heide, A., van der, Delden, J. J. M., van, Looman, C. W. N., Visser, M. H., \& Maas, P. J., van der. (2005). Medical decision-making for seriously ill non-elderly and elderly patients. Health Policy, 75, 40-48.

Wulff, H. R., \& Gøtzsche, P. C. (2000). Rational Diagnosis and Treatment. Evidence-Based Clinical Decision-Making (Third ed.). Oxford: Blackwell Science Ltd.

www-rohan.sdsu.sdu/digger/305/tpulmin_model. Retrieved 23 May 2008 
誊 


\title{
Chapter 4
}

\section{Trust In Medical Decision-Making Concerning Older People: The Views Of Key Professionals In The Dutch Health Care Practice}

\author{
Josy Ubachs-Moust \\ Rob Houtepen \\ Trudy van der Weijden \\ Ruud ter Meulen \\ Rein Vos
}

Published in Health:

Health 2010;14;564-584 


\subsection{Introduction}

T

rust in doctors is an important matter at the level of the physician-patient relationship (Kao, Green, Zaslavsky, Koplan, \& Cleary, 1998; Mechanic \& Schlesinger, 1996; Pearson \& Raeke, 2000) but it is also an important issue at the level of society (Hall, 2006; Pfadenhauer, 2006; Van der Schee, Groenewegen, \& Friele, 2006). Trust is the expectation that individuals and institutions will meet their responsibilities to us, patients and the public. It affects almost every aspect of doctor-patient interaction, from personal disclosure to co-operation in treatment (Mechanic, 1998). In addition, as a society we want to trust the medical profession that they treat patients according to medical standards and do not use unfair criteria like age, race or disability. We also do not want them to act from financial motives, or market-induced economic criteria, which for example may lead to a lower quality of care, the dumping of 'uneconomic' patients or discharging patients too early. Mechanic considers five dimensions of trust: (1) expectations about physicians' competence; (2) the extent to which doctors are concerned with their patients' welfare; (3) physicians' control over decision-making; (4) physicians' management of confidential information; and (5) physicians' openness in providing and receiving information (Mechanic, 1998). This multidimensional concept of trust is appropriate for both interpersonal trust between physician and patient, and society's trust in the medical profession. There is a suspicion that because of growing scarcity treatment decisions concerning older people are influenced by age-based arguments (Evans, 1997; Harris, 1987; Tsuchiya, 2000; www.helptheaged.org.uk). The medical profession is obviously confronted with possibly conflicting duties regarding all patients, but we believe that this tension is more marked in the case of older people. In addition, individualizing older people's care is found to be difficult (Victor, 2005). Proportionality and effectiveness of treatment are more difficult to address in the care for older people. The tension surrounding trust regarding physicians' duties at the individual and social level is therefore analyzed in the context of medical decision-making concerning older people.

Historically, society attempted to assure its citizens that they would receive safe and effective medical care through the licensing of the profession. Professionalism can be described as the basis of medicine's contract with society. It demands placing the interests of patients above those of the physician, setting and maintaining standards of competence and integrity and providing expert advice to society on matters of health. The principles and responsibilities of medical professionalism must be clearly understood by both the profession and society. Essential to this contract is public trust in physicians, which depends on the integrity of both individual physicians and the whole profession (ABIM Foundation ACP-ASIM Foundation European Federation of Internal Medicine, 2002). Medical professionalism consists of those behaviors by which physicians demonstrate that they are worthy of the trust bestowed upon them by their patients and the public because they are working for the patients' and the public's good (Swick, 2000). To do their job right, physicians need some professional freedom - that is some discretionary power to make decisions, as they believe to be right. Physicians need this freedom because we may expect that they act with their patients' interests in mind and because of their specific expert knowledge, which serves both the individual patient's interests as well as society's interest. Physicians themselves define what good care is and need some professional freedom to be able to do that. This freedom, however, is not absolute and is accompanied by accountability (Centre for ethics and health, 2004), both to the patient and the larger public. 
Society has relied on the ethical values of the profession and its social contract with society to provide an adequate supply of physicians through medical education and training (Richmond \& Eisenberg, 2000). Of late, however, medical professionalism has been buffeted by the tumultuous changes affecting the industrialized world. These include the explosion of information technology (Van der Weyden, 2002), the increasing emphasis on scarce resources and cost effectiveness and the introduction of market forces and private financial initiatives; but also growing individualism, decline of solidarity and an increased awareness of the limitations of expert knowledge. These changes have their repercussions on the debate on the content and scale of medical professionalism and on the debate on trust in doctors. It has been argued that there is a declining confidence in the robustness of the public service ethic and that self-interest is creeping into the way public services are delivered (LeGrand, 2003). Trust in medical care arrangements and in one's physician are to some degree interdependent. Trust in one's physician typically comes from direct experience but trust in medical institutions and arrangements is shaped to a considerable degree by the media and by informal public opinion. When patients become suspicious of the motives and practices of organizations, this can affect the way they interact with their doctors, particularly if they become doubtful that their doctors are acting solely in their interest (Mechanic, 1998).

Our research question is whether, according to various key professionals we interviewed, society can trust physicians to respect the older person's interests in a time of increasing pressure from society and government to take issues of increasing costs into account. This article aims to contribute to a better understanding of what trust in medical practice entails and what are the necessary conditions for a society to put trust in the medical profession. The article is based on interviews with various key professionals in clinical and societal decision-making. The focus is on care for older people under the condition of scarcity in health care resources. As mentioned earlier, there is a suspicion that, in the context of limited or inadequate resources, utilitarian and other economic motives may increasingly influence medical decisions, leading to unfair and age-based decision-making (Evans, 1997; Harris, 1987; Tsuchiya, 2000; www.helptheaged.org.uk). Before presenting and analyzing our results, we will start with describing the methods we used in gathering our empirical material. Furthermore, because of the explorative character of our study we were not theoretically guided by one concept or vision of trust.

\subsection{Methods}

The aim of this study is to learn about respondents' views and experiences as to whether older people and society can trust doctors regarding medical decision-making concerning older people in a time of increasing scarcity in health care resources. We are specifically interested in the views and opinions of various key professionals in clinical and societal decision-making. Such key professionals can be found 'inside' medical practice, as well as 'outside' medical practice, like policy-makers and researchers who help to organize the health care system and who may influence public views and the public trust in the health care system. What arguments and conditions regarding trust in doctors are expressed in these interviews and what, if any, action is required based on these results?

\subsubsection{Design}

The present study employed a qualitative design consisting of semi-structured in-depth 
interviews with 24 key professionals focusing on decision makers and those in the line of professionally organizing or influencing the decision-making process on a national level in 2004. The interviews were analyzed qualitatively using grounded theory analysis.

\subsubsection{Sample and recruitment}

The first author conducted the semi-structured in-depth interviews on the role of age in medical decision-making on both the macro and micro level of health care. The respondents are key professionals in their fields of experience in the Dutch health care practice. They were selected to guarantee heterogeneity. Criteria used were their field of work (for example as a geriatrician or lawyer in the area of health care), their experience in decisionmaking regarding older people on a macro level (for example as a policy-maker in a hospital or at a Ministry) or micro level (physicians) and, if applicable, their position in the discussion on the role of age limits in health care decision-making. Because of the more general policy-orientated and professional-orientated focus patients were not included in this study. We focused on the views and opinions of physicians, decision-makers and those trying to influence the decision-making process, regarding older people in general. Interviews were conducted with four physicians in the field of geriatric care (two oncologists and two geriatricians), seven policy-makers on a national level at the Ministry of Health, Welfare and Sport, at a local level in hospital management, and at the National Institute for Public Health and the Environment, three scientific researchers in the field of health care, two bioethicists, two lawyers in the field of health care, two medical guideline developers, two health economists and two relevant interest group representatives (one representative of an anti-age-discrimination organization, and one employee of a large union for older people). The questions were not disclosed to the respondents before the interview, except regarding two respondents who asked to receive a copy of the questions beforehand. The interviews ranged in length from 45 to 60 minutes. All the interviews were conducted in Dutch. Each interview was recorded on tape and transcribed ad verbatim. After 24 interviews no new information or arguments were raised by interviewees (saturation point), subsequently no more interviews were conducted.

For this article, we made a selection of illustrative quotations from all respondents. We found this selection sufficient to provide the information needed in the light of the explorative nature of our study. In presenting the interview quotations we did some marginal editing (grammatical and linguistic errors), but we did not alter the content.

\subsubsection{Analysis}

Each interview transcript was first submitted to open coding by the first author (JU-M) and independently by one other researcher, varying per interview. During this process and subsequently the results were discussed in the research team (investigator triangulation). In this phase the interviews were read thoroughly and notes were written in the margin, to capture what was going on in the data (Polit \& Beck, 2004). Consensus on coding was reached by discussion between the researchers. In the next step these codes were condensed in broader categories. In this phase, the quotations were divided into three categories: informed consent; views on justice and equality; and views on old age in medical decision-making or health care policy. The following phase of the analysis, known as selective coding, consisted of coding those data that are related to the central category, trust in doctors (Polit \& Beck, 2004). We were interested in the arguments and views regarding trust in doctors in the treatment of older patients and the conditions, which are 
thought to be crucial for making trust a real process and practice as suggested by our respondents. In this article, we will primarily focus on the arguments put forward in the three trust categories. In this way, we attempt to produce a description of the professionals' conception of public trust and its essential conditions in the medical profession.

\subsection{Results}

In this section, we present the results of the analysis of the interviews with various respondents, which provide us with insights into the limits of the physician's discretionary powers. The arguments, views and opinions of the various respondents may build up to boundaries and marking points of justifications for physicians' professional discretion. Based on these arguments we can clarify the contours of trustworthy practices. Three categories of coding emerged from the data. These categories are gradients on a line from complete trust via qualified trust to no trust at all.

\subsubsection{Distrust}

The first category in this section contains quotations, which provide us insights into reasons for not trusting physicians, from the point of view of some of the respondents. We distinguished three groups of respondents. The first group focuses on an age-bias and prejudices regarding the utility of treatment regarding older people, present in medical practice. This suspicion of bias can take many forms; an example is found in the interview with a representative of an older people's interest group.

Indirect discrimination can also be found in the way someone is treated, this may be unintentionally, for example physicians not operating on an older patient because of his age (Interest group representative 1, p. 1).

Physicians describe discrimination as a non-medical bias. As a result, older people may not receive certain treatments. Physicians' decision-making is influenced by non-medical prejudices regarding older people.

A policy-maker, with a medical professional background, also mentions prejudices regarding treatment of older people. This respondent reported a kind of therapeutic nihilism in the care for the older patient.

I have recently stated that strangely enough many treatments which are possible for older people are not employed, quite simply. So, available and tried treatments are not employed. In other words, there still is an actual kind of emotional threshold which is mainly found at the side of the care-giver, to be rather reserved regarding treatment. I think this has to do with a kind of therapeutic nihilism. People are not convinced of the usefulness of a treatment of that sort. (Policy-maker 2, p. 10)

The reasons for not treating older people are not evidence based. This quotation is also an example of a non-medical bias, which prevents older people receiving some treatments. There is an emotional threshold to treat patients of a certain age.

The second group is formed by respondents who focus on the lack of scientific rationality in medical decision-making as another reason for a sense of distrust towards the medical 
profession. According to one of the health economists' responses physicians make arbitrary choices continuously.

In medical practice choices are made all the time. Intensive care doctors do make choices also all the time. But these are all arbitrary choices. (Health economist 1, p. 10)

The subjective character of physicians' decision-making is enough reason for distrusting physicians, according to this respondent. Later in the interview, the respondent argues that this fact should be acknowledged and that the medical profession and society should take action to remedy this situation.

A third reason for distrust is the claim that the medical profession is acting on a one-sided rationality with a blind spot for other social priorities.

And one of the restrictions of people working in health care, one of their professional deformities, is of course that they sort of make their own health care absolute. Health care is everything and everything has to give way to health care. But in everyday life there are obviously multiple things we value. It is not just health care, but also education, safety and we also want to live a nice life. These are all things we value. (Health economist 2, pp. 5-6)

According to this health economist, physicians have a narrow perspective on the importance of health care and medicine. They are unwilling and unable to take issues of scarcity and distribution into account.

Looking back to the quotations presented in this section we may conclude that various reasons are reported for not trusting physicians. First, medical practice as a whole is confronted with an age-bias and prejudices regarding the utility of the treatment of older people. In addition, respondents comment on the arbitrary and perhaps illogical nature of medical decision-making. Furthermore, it is observed that physicians are not capable of putting their own profession into perspective. Reasons for not trusting physicians in this section are provided by health economists, a policy-maker and an employee of an expertise centre on age and life-course.

\subsubsection{Qualified trust}

In the second category, we find respondents who are willing to trust physicians in taking care of older people but only under certain qualifications. They point out the boundaries and marking points of the physician's professional discretion. Here we can also identify three groups of respondents. We will start this section with the discussion on the practice of medical decision-making. The first quotations concern physicians' discretion regarding the medical decision-making process.

Well, the problem here is that in fact diseases at the age of 20 are not always the same as diseases at the age of 70 . So, age does play a part here. You see, an acute leukemia over 60 years is a different acute leukemia from under 60 years. That is a fact. Biological change. So insofar I think it's correct to use age as a criterion. (Physician (oncologist) 2, p. 7) 
Age is not ruled out as a consideration, but is only legitimate as a strictly medical criterion. Diseases differ according to age and consequently treatment should also differ. One cannot treat a 70-year-old in the same way as a 20-year-old. Because of their different ages, their bodies and their reactions to treatment are different. Age, therefore, can be of importance in the medical decision-making process, albeit having only a minor role.

My firm opinion is that in principle age should only play a subordinate role in decision-making. But does play, can definitely play a role. (Geriatrician 1, p. 2)

There are also some qualifications made by some of the respondents regarding the individual physician's competence. For example, a surgeon claims that physicians have to keep their knowledge up to date regarding both prognosis and treatment of older people and reach a good individualized decision.

Because we do not teach it, we do not realize what the problem is, we do not define and tackle it.... And so I started reading and one of the most important things I realized is that, besides the statistical fact that someone who is 80 years old statistically has a longer survival than someone who is younger, but besides that, the body is growing older and the flexibility of lung tissue is changing which means that the lung function has decreased intrinsically. ... So, the whole physical stress adaptation has changed and that is something you have to take into account, next to the statistical chance of longer survival. (Physician (oncologist) 3, p. 3)

In other words, a good decision is reached by the combination of evidence and competence. But can we trust physicians to keep the age consideration within strict medical boundaries?

The physician's consultation room, that's all behind closed doors. And in the end you can't tell whether that's all justified. (Ethicist/lawyer 1, p. 3)

The fact that we do not know what happens exactly in the consultation room and are therefore not able to determine whether their decisions are justified, is a reason to qualify the trust in physicians. Their current practice is insufficiently transparent according to this respondent, who therefore suggests that doctors ought to subject themselves to social control and public justification regarding the role of age in medical decision-making.

This argument leads us to the second group of respondents that focus on the physician's relationship with policy and society. One of the respondents brings forward the issue of physicians making allocation decisions. These kinds of decisions should be made on the level of the Government or on the level of national guideline developers. But the respondent does not necessarily lay the blame on physicians being too eager to decide for themselves, since the system may put them in an undesirable position. In this quotation, it is argued that physicians should not be put in situations where they cannot focus on the interests of the older patient because of the (financial) interests of their other patients.

And especially not, if the physician's consultation room is that lower level. Because, we will be confronting the physician with things he does not know how to deal with. You will be putting him in a position in which he is treating a patient, 
while at the same time thinking of 10 other patients in the back of his head. So, I feel that these kinds of decisions should be made on a higher level as much as possible. (Ethicist/lawyer 1, p. 3)

In the relationship between physician and patient, physicians need to be able to concentrate on the individual patient and focus on the individual patient's interests. The interests of society as a whole should not interfere with this relationship, and need to stay outside the consultation room.

One way of avoiding social pressure on physicians to make these kinds of decisions is to ensure that the health care budget is large enough. According to one policy-maker, physicians do not like to make financial decisions, so if we can take away this responsibility, we may have more trust in their decisions.

Another thing we should not be doing as a government is not giving enough money to health care and then blame physicians for using improper criteria. Because that is not something they do just for fun. They really don't like doing that, they'd rather help everyone without fear of favor. (Policy-maker 5, p. 7)

In other words, if physicians are allowed to focus on the kind of treatment that is medically necessary for the individual patient, we are able to trust them.

But of course the physician is not alone in deciding. Physicians have to take the older person's preferences into account when making a treatment decision. The third group of respondents focuses on this aspect. Communication plays a central role here.

Well, I believe, that in a number of cases patient preferences are still not clear enough and in addition are not always respected. And those care preferences of vulnerable older people do not always point in the direction of more care and more intensive treatments. (Geriatrician 4, pp. 2-3)

This requires a sufficient level of communication between physician and patient on physicians' considerations and patients' preferences. A failure to take older people seriously and a lack of respect for patient preferences are often referred to when discussing the poor standard of medical treatment of older people. One of the physicians in our sample warned against the risk of over treatment of this group of patients. This physician draws a picture in which older people too often are subjected to treatments too soon. Insufficient time is spent on reflecting on the consequences of these treatments for the quality of life of the older patient. The usual discussion is on the utility of the treatment, while the real issue ought to be the desirability of treatment from the perspective of the patient.

So yes, in that way age does play a role ... not while selecting patients, but in the way you deal with these kinds of people. And that's of course a much more sensible way of talking about age. We have to ask ourselves beforehand first, this thing I'm planning to do, is it in the patient's interest? Or am I only doing it because we can do a beautiful examination or use this great machine, so to speak. And secondly, am I prepared to accept the consequences of what I am going to find and can I overview these consequences? And that's what we have to ask ourselves beforehand. And what happens a lot is that certain things happen, that the first step is taken and that sort of fails and then the next step is taken which 
also fails, and as a consequence another step is taken. (Geriatrician 1, p. 7)

Questions like what the consequences are of initiating a specific treatment or diagnostic procedure and what the next step will be, and just as importantly whether we are willing to take that next step should be reflected on and discussed with the older person before the intervention is started. Here the issue is shifted from age as a medical risk factor to quality of life as an issue to be taken into account in cases of invasive diagnostics or major treatment. The latter approach puts the emphasis on proper communication between, in this case, the physician and the patient including the patient's relatives.

So, in handling this patient, age does also play a role. The fact that you take the effort to go over your treatment policy with a close relative to see whether you can get a kind of consent by proxy. (Geriatrician 1, pp. 6-7)

A final qualification of trust in doctors is dependent on the medical specialty involved. According to this respondent, certain specialists may fail to communicate with older people.

And obviously, there are specialists who are inclined to say that their interventions are not available for all ages. So, cardiologists, I think are a great example. An 85 -year-old female patient needs to be catheterized. No, never mind, because we'll not treat her. (Geriatrician 1, p. 4)

The patient's advanced age is a reason for not providing him or her with a certain treatment, and that is how it ends. Crucial here is that the older patient is not involved in the decision-making process.

The qualifications and criteria as discussed in this section indicate the limits of physicians' professional discretion. Three groups of qualifications can be distinguished. The first category deals with the decision-making process. The fact that age can only be used as a medical criterion and the fact that physicians have to keep their knowledge up to date, are both necessary to reach a good treatment decision. As a second category, we found qualifications in the respondents' contributions regarding the physicians' relationship with policy and society. Public justification and transparency are the key terms here. In the final category, respondents discuss the professional's relationship with the patient and his family. Communication is the central issue here. The physician has to pay attention to the individual patient's preferences, but also has to reflect on possible overtreatment and the consequences for the quality of life of an older patient before starting treatment. In addition, the role on the medical specialty on the decision-making and communication process is mentioned.

\subsubsection{Trust}

In the final section, we find respondents who display a great sense of trust in doctors regarding the treatment of older people, for which they provide no explicit qualifications. First, we'll discuss a respondent's trust in doctors which is based on his observation that physicians do not focus on using age as a criterion. When dealing with an older person they are acting strictly medically.

And for that reason, a compromise regarding treatment on the basis of age 
is absolutely wrong. The only way age can be of importance is that, well an organism is 80 years old and in that way has been exposed to the wear and tear of 80 years. And the ability to adapt is restricted and that's something you have to take into account when making your decisions. And maybe additional measures have to be taken therefore. But, whether to treat or not, is not an issue. (Physician (oncologist) 3, p. 1)

Trust in doctors implies their capability to focus on the medical circumstances of the patient involved. It is not about deciding whether to treat but, given the patient's age, how to treat.

On the other hand, as the next selection of quotations shows, sometimes age plays a different role. In this second group, respondents discuss the thorough way of medical decision-making.

Because it also concerns, whether we want to prevent medicalization. So, getting old, already being old, do you have to get even older? And do we really have to add two or three months to someone's life expectancy by giving a simple little pill? Because that is what it is really about, of that order, or maybe a little more. (Guideline developer 1, pp. 3-4)

Trust here is based on the respondent's observation that physicians can be considered to be intelligent and conscientious professionals. In medical practice, this leads to age being part of a complex, but rational assessment of what will be the best treatment for a specific patient, as the next respondent describes.

Age definitely plays a role in the discussions, which we try to broaden by also looking at life expectancy, healthy life expectancy and functional life expectancy, quality of life and a person's own preferences. There is so much heterogeneity between older people, both regarding functional performance and mental performance as well as wishes, desires and ageing, that you won't be able to individualize enough. If you would just say, we will take the age criterion that would be really easy and probably also efficient if you can reduce care in that way. But, I don't think it's advanced enough for the way we want to perform health care. (Geriatrician 4, p. 4)

A patient's healthy life expectancy and personal preferences are more informative than age itself in deciding how to treat an older patient. Making these complex decisions requires tailor-made work by physicians, not general guidelines on age.

Third, we can identify respondents who discuss the presence of other, non-medical aspects, which can influence the decision-making process. For example, when a physician weighs up the patient's social situation, this does not change the next respondents' trust in the medical profession.

Imagine, an attending physician has two patients he wants to operate on, but only one bed is available at the intensive care unit. He will be weighing up all sorts of things. For example, even if it concerns two women of the same age and one has little children and the other has not, I wouldn't be surprised if he chooses the one with the children. He will then think of something medical to explain the 
urgency for this one patient. And I don't think that's such a bad thing, as long as it's not really indecent.... But if a physician to the best of his belief says I am also influenced by a patient's social situation, I don't find it that hard to take. (Policymaker 5, pp. 3-4)

As long as we agree on the basic principles of medical decision-making, we should be all right, according to this respondent.

This does not mean, however, that physicians should be considering predetermined social considerations in every situation. The next, non-physician, respondent illustrates this by way of the example of cost-benefit analysis.

And one of the reasons for not using cost effectiveness analyses is because physicians make these decisions. And physicians hate this utilitarian perspective, they refuse it. They state, that's not how medicine works and right they are. (Policy-maker 7, p. 17)

We have to respect how physicians want to work. Physicians should not act as executives of preset utilitarian standards when practicing medicine. The social aspect of medical decision-making cannot only be decided on at the macro level. However, not all is left to the physician's own discretion.

See, a physician has his input too, rules imposed on him by hospital management, but then you are dealing with a kind of relationship of which you can assume interaction taking place. That is, a physician is aware of what he is supposed to be doing. (Interest group representative 2, p. 4)

Physicians' embededness in their institutional context and the control by their peers limits the physicians' freedom to some extent. The interaction taking place in this context is a valuable source for medical decision-making.

On the basis of the quotations presented in this section the contours of an image of the conscientious, trustworthy physician arises. Physicians are aware that their decision-making process cannot solely be based on clinically relevant factors. Age-related decisions contain a social aspect as well. The conscientious and trustworthy physician is known by the way he or she handles his or her professional freedom regarding this aspect. The physician's virtuous character is characterized by his or her ability to choose the right intervention taking into account the individual situation of the patient on the one hand and expectations of society on the other hand. The uncertainty of medical decision-making and the fact that doctors are not perfect are acknowledged. We trust doctors because of the fact that we all agree on the basic principles of medical decision-making and the ability of physicians to justify their decisions.

\subsection{Discussion}

In this article, we focus on whether we can trust physicians when making decisions about the treatment of older people in a context of scarcity, according to the views and opinions of various key professionals. Can we rely on the physician to respect the older person's 
interests in a time of increasing pressure from society and government to take issues of increasing costs into account? This question focuses on the discretionary freedom physicians need in order to make decisions, as they believe to be right. They need this freedom to act in accordance with the complexity and individualistic character of providing care. We trust physicians to use this freedom with the patients' interests in mind and on the basis of their expert knowledge. In addition, taking care of older people asks for knowledge that is even more specialized. First, the care for older people is on average more complex than for other patients. Often older people are dealing with more diseases and complaints at one time (co-morbidity) and the interaction between these different ailments and medications have to be taken into account (Health Council of the Netherlands, 1998). In relation to this, the prognosis of how the body of the older patient will react after treatment is more uncertain. Consequently, there is a risk of too heroic treatment, without considering the condition of the patient after treatment. Also, when taking care of older people cure and care elements of treatment are often mixed, for example in hip surgery or eye operations for very old people to help them maintain or improve their quality of life. This may blur the focus of treatment, if not for the doctor than for patient and family. Furthermore, older people may be more inclined to leave matters in the hands of the physician or the family, potentially introducing unwarranted forms of paternalism. Another complicating factor is the ambivalence in older people concerning their wishes and prospects. They are more frequently in doubt themselves regarding what care they still want and what level of quality of life they can live with. Also, they may feel pressure from society to deal with the increasing costs and may be aware of the discussions taking place regarding lifeextending treatments.

Thus, physicians need their professional freedom to deal with the complex character of the care for older people. Both individual patients and society must be able to trust physicians to use their freedom correctly.

In this context, respondents discussed, for example, the subjective and arbitrary way of medical decision-making. But also the conscientious and trustworthy character of physicians is emphasized and the way they use their discretionary room to individualize the patient care. In addition, physicians' competencies regarding decision-making and communication are discussed as well as their accountability towards society. These issues of competency and accountability and the connection between them are also the subject of discussion in the debate on medical professionalism, to which we will turn now. While reading up on this debate we found that medical professionals themselves discussed these issues at great length. In the guidelines and statements of professional medical associations, we found many references to the issues of trust, competency and accountability.

Medical professionalism is defined as a set of values, behaviors and relationships that underpin the trust the public has in doctors (Royal College of Physicians, 2005). Therefore, on an individual level, physicians should be guided by a duty to put the patient first before all other interests. Both the Royal College of Physicians and the Royal Dutch Medical Association state that the trust that the public puts in doctors rests on this practical realization of medical professionalism (Royal College of Physicians, 2005; Royal Dutch Medical Association (KNMG), 2007). Further exploring this public level, professionalism is valued because it is an important lever for improving the quality of services to all patients (Royal College of Physicians, 2005), regarding for example patient safety and prevention of illness. Furthermore the issue of accountability is dealt with as we found many references to physi- 
cians' obligations to recognize, disclose to the general public and deal with conflicts of interest that arise in the course of their professional duties and activities (ABIM Foundation ACP-ASIM Foundation European Federation of Internal Medicine, 2002; Royal College of Physicians, 2005; Royal Dutch Medical Association (KNMG), 2007). Doctors must be clearer about what they do, and how and why they do it (Royal College of Physicians, 2005). In addition, as part of their medical professional responsibilities towards both patient and society, physicians are required to avoid scrupulously superfluous tests and procedures. The provision of unnecessary services not only exposes one's patients to avoidable harm and expenses but also diminishes the resources available to others (ABIM Foundation ACP-ASIM Foundation European Federation of Internal Medicine, 2002). In this context, it is appreciated that physicians must recognize the importance of just allocation of health care resources, balancing effectiveness, efficiency and access with optimal patient care (Frank, 2005) and should have knowledge on what care is covered by health insurance plans (Royal Dutch Medical Association (KNMG), 2007). Therefore, physicians' accountability to society against the background of scarce resources entails a responsibility to make effective and wise health care decisions. It does not mean physicians should decide how these resources should be divided between patients. Thus, the possible conflicting responsibilities of physicians regarding the patient and the public are recognized and dealt with.

Furthermore, we found that in the debate on medical professionalism a comparable division between a focus on the micro or macro level is made. In general, a distinction can be made between a restricted and a broader conception of medical professionalism. In the more restricted and traditional view there is an emphasis on physicians' codes of professional behavior. Physicians are accountable for their actions, but this accountability is mainly directed internally, towards their fellow physicians. Physicians themselves have generated these traditional codes without subjecting them to the scrutiny of patients and the public. For example, these codes have rarely appealed to more general ethical standards or to a source of moral authority beyond the traditions and judgments of physicians (Beauchamp \& Childress, 2001). In addition, it is argued that professional ethics, based on virtue and duty, has confined itself to the special interests and obligations of physicians (Coulehan, 2005). However, within this internal conception of medical professionalism physicians have taken steps to ensure that the patient and the physician-patient relationship play a central role in these codes. For example, the ethical principles of medical decision-making, respect for autonomy, non-maleficence, beneficence and justice were used as a framework for professional behaviour. Furthermore, the concept of shared decisionmaking has been gaining ground and emphasizes both physicians' and patients' responsibilities for a successful relationship (Charles, Gafni, \& Whelan, 1997; Gwyn \& Elwyn, 1999). The focus in the restricted view, however, remains intact. Physicians are in this view still nearly exclusively accountable towards their peers and the ethical framework resulted in focusing mainly on the patient's right to autonomy versus paternalism, while the ethical principle of justice has not been receiving the same attention (Walker, 2009).

A different view holds that the patient-centered peer accountability of the restricted view is only one part of the concept of medical professionalism. In this view medical professionalism does not only revolve around the interaction between physician and patient. The individual physician is also expected to be aware that when putting the interests of his patient first, his actions are scrutinized by society. Professionalism operates on both an individual and a collective level (Swick, 2000). In this view, physicians have some form 
of social accountability on three levels. First, for safeguarding the interests of individual patients on the basis of the ethical framework as mentioned earlier. Second, for the quality of medical decision-making and, third, for being aware how treatment decisions at the individual level may influence society's interests as a whole. So, in addition to the need to create and nurture a healing relationship between physician and patient these other elements of medical professionalism reflect broader responsibilities that the physician has to society and the profession, regarding for example access and cost effective medical care (Swick, 2000). This accountability, however, does not mean that in this view no professional freedom exists for the professional to act according to his own virtues and those of his peers. The broader view on medical professionalism strives to combine physicians' accountability towards themselves, their patients and society. Thus, medical professionalism in this view involves safeguarding both patient trust and public trust.

The way the professional associations deal with the issues of trust and accountability provide a good framework. In combination with the arguments used in the debate on medical professionalism, we could be able to form a relatively clear picture of what it means to deal with the issues of trust and accountability at both the level of the physician-patient relationship and at the level of society. However, this picture remains rather abstract. We believe the answers provided by the respondents in our study can provide more specific directions, in comparison to the literature so far.

We found roughly three categories of answers: distrust, trust, and qualified trust. In each category, we found different reasons to give or withhold trust and views on how far the discretionary power of doctors should go and whether physicians can be trusted regarding their professional freedom.

The three categories offer us insights in how the contours of trustworthy practices of medical decision-making can be drawn. In the distrust category, respondents discuss the way physicians' decision-making process is influenced by non-medical factors, as for example prejudices regarding old age and the utility of treatment of older people. In general, it is stated, medical decision-making is subjective and arbitrary. Every issue put forward by one of the respondents in the distrust section is enough reason for them to limit the physician's freedom in dealing with older people.

The quotations as discussed in the distrust category actually specify the reasons why trust in doctors is not self-evident. They convey the importance of being more precise and explicit about what trust in doctors entails. In fact, they indicate the omissions regarding these conditions in the literature on medical professionalism as discussed earlier. In addition, we believe that these specifications are not only missed in the care for older people, which is the subject of our research. We need more specific directions on multiple areas in health care, as for example in the care for very young children where parents are confronted with major trust issues all the time.

In the trust category, decision-making is considered to be conscientious, not arbitrary. Medical decision-making is in actual fact grounded on the basic principles that we as a society agree upon. Furthermore, cost-benefit analyses are rejected as useful for medical decision-making. A lot of emphasis is put on the conscientious and trustworthy character of physicians, who act independently but are subjected to some level of control by colleagues and hospital management. Physicians use their discretionary room to fine tune and individualize their patient care. According to these respondents, we can trust physicians regarding the professional freedom they have in taking care of older people. The respondents' sense of trust as found in this category fits well with Jones' account of trust 
(Jones, 1996). According to Jones trust is an attitude of optimism expecting that the goodwill and competence of another person will cover the domain of our mutual interaction and that the trusted person will be moved favorably towards us. At the centre of trust is an attitude of optimism about the other person's goodwill and competence (Jones, 1996). Thus, the respondents in this category support a laissez-faire policy regarding physicians' discretionary actions.

The arguments of the respondents in the trust category can be considered as a reversion to the doctor-centered view as discussed earlier (Coulehan, 2005). A view which has been rejected by medical professionals themselves as being too restricted and by the participants of the debate on medical professionalism (ABIM Foundation ACP-ASIM Foundation European Federation of Internal Medicine, 2002; Royal College of Physicians, 2005; Royal Dutch Medical Association (KNMG), 2007; Swick, 2000).

If we compare these two categories, a few issues attract attention. For example, the respondents in the distrust category prefer to limit the physicians' discretionary freedom because too much is left to an individual physician's discretion, resulting in arbitrary and normative decisions. The respondents in the trust category obviously have a different view on what professional discretion contains. In their opinion, it concerns the necessary freedom of every physician to be able to individualize the way he or she treats his or her patients. That is what medicine is about. If this freedom would be restricted, physicians will not be able to perform their duties properly (Coulehan, 2005). Both categories represent two different worlds that fundamentally disagree. The respondents of both categories can be charged with mutual blindness. The trust respondents appear to be prejudiced regarding the virtues and competencies of physicians. An explanation for this can be found in the fact that the respondents in this category mainly consist of physicians and policy-makers with a medical professional background. They emphasize the relationship between physician and patient to such an extent that they overlook the public side (Walker, 2009). The objections brought forward by the health economist respondents in the distrust category seem to display a similar one-sidedness as the physicians they criticize. They take the point of view of their own profession, while not acknowledging other perspectives and interests that influence medical decision-making. But medical practice cannot exist without individualized medical decision-making. By condemning this out of hand, these health economists in fact reach a biased conclusion and are too focused on decision-making processes while forgetting about the importance of one-on-one relationships.

So the trust and the distrust group both represent a one-dimensional perspective: full trust in the virtuous character and competencies of the medical profession seems to be too far-fetched while dismissing the moral values of their exceptional responsibility as untrustworthy seems to be unfair.

The respondents in the qualified trust category discuss the criteria physicians and the physicians' contexts have to meet in taking care of older people. These criteria provide the boundaries and marking points of the medical professional's freedom. For example, age can only be used in decision-making as a medical criterion. Decision-making has to be made transparent, and allocation decisions have to be left out of the relationship between physician and patient. In addition, physicians have to keep their knowledge up to date and pay attention to the individual patient's preferences. Age can play a role in medical decision-making and can be important in the communication between physician and patient. Physicians should act within the boundaries and marking points set by these 
respondents and that is how their discretionary room and the trust in their decisions are shaped. It is noteworthy that one of the respondents in this category claims on the basis of his clinical experience that overtreatment of older people is an important issue that is often overlooked. This observation sheds a new light on the assumption that the focus in this discussion should be on under treatment of older people. Future research regarding this issue is needed and offers new possibilities for gaining more insight in the role of age in medical decision-making.

If we compare the views and arguments of the qualified trust category with the one-dimensional perspective of the other two categories, the qualified trust category can best be described as taking place in-between the two extremes. The criteria in this category can be divided in two subcategories. They focus on the competencies of physicians on the interpersonal (micro) level between physician and patient as well as on the boundaries of the practice in which they have to work, the social (macro) level. For example, physicians have to keep their knowledge up to date and have to take patient preferences into account. However, according to these respondents they still need to justify publicly their decisions. While the respondents in the distrust category focus exclusively on public trust and the trust category mainly deals with trust on the interpersonal level, the qualified trust category deals with both levels and the interaction between them. Actually, the results on the basis of the qualified trust category confirm the views as brought forward by medical professional organizations (ABIM Foundation ACP-ASIM Foundation European Federation of Internal Medicine, 2002; Royal College of Physicians, 2005; Royal Dutch Medical Association (KNMG), 2007). In addition, they correspond to the broader view on medical professionalism as discussed earlier (Swick, 2000). Furthermore, on the basis of the preconditions as formulated in the qualified trust category we are able to identify what the medical professionals' responsibilities towards society are on three levels: regarding the individual patient's rights and the quality of medical decision-making, as well as regarding some awareness of the budgetary consequences of medical decisions. But, most importantly, these preconditions on three levels give us leads on how to fill in the discretionary room with which doctors operate and what their social responsibility entails. They also show how these levels are linked to each other and interact.

The medical profession and society together have to invest in ensuring that physicians' competencies enclose ways to deal with the new issues in modern, globalizing, high-tech societies by educating (future) physicians and holding them more accountable for their decisions and their openness to and competences of sharing decisions with those patients who wish to be involved. However, while focusing on the medical professionals' responsibilities towards society we need to be careful not to neglect traditional medicine all together. Certain aspects of traditional professionalism are still valuable to today's medicine. In many ways, today's culture of medicine tends to be hostile towards altruism, compassion, integrity, fidelity, self-effacement and other traditional qualities (Coulehan, 2005). These qualities are still important and valuable to every patient searching for a physician to trust and therefore need to be esteemed also. However, focusing only on the trustful relationship between physician and patient and emphasizing the virtuous character of physicians is, as we have attempted to show, no longer enough.

We cannot simply draw general conclusions regarding our results. Our study consisted of just a small sample of key persons in Dutch health care. However, the professionals that were interviewed are key professionals and experts in their field. Further investigation 
is needed, though, to establish whether these results can be translated to other patient groups.

\subsection{Conclusion}

To conclude, physicians need their professional discretion to individualize their care for older people, to apply their special knowledge and skill to the specific complaint and needs of an older patient (Health Council of the Netherlands, 2006). However, physicians are not completely free to act as they please, for instance regarding the role of age in medical decision-making. The preconditions as identified in the qualified trust section provide the boundaries and marking points between which physicians have to move regarding the care for older people. We have to qualify these leads and use them in defining and interpreting what constitutes public trust in the medical profession. The qualifications provide us with insight into where and how to invest in trust under these and under different circumstances in taking care of older people. Physicians can be held accountable by society on the three levels as identified in the qualified trust category regarding the individual patient's rights and the quality of medical decision-making, as well as regarding some awareness of the budgetary consequences of medical decisions. This means that physicians have to reflect on the financial effect of their decisions and thus explicitly consider the fact whether they are providing the treatment because it is necessary or simply because it is possible. A special focus regarding this last aspect is needed for the possibly negative consequences for older people because of the increasing scarcity in resources. Older people must be able to trust their physicians in putting their interests first and not allow cost utility based allocation decisions to take over the decision-making process in the consultation room. Requiring physicians to be aware of the budgetary consequences of their decisions and explicitly reflect on the reasons for providing the treatment is not the same as advising them to follow blindly cost utility based decisions without regard for the individual older patient. It does not mean physicians should decide how resources should be divided between patients, but it requires physicians to make effective and wise health care decisions. The professional's autonomy is a counterbalance against all sorts of external factors, like bureaucracy, and the economical and legal discourse, which could distract physicians from living up to the responsibility society has entrusted them with (Freidson, 2001), such as advocating the individual patient's interests.

An important conclusion is that trust is never finished: trust needs to be gained and negotiated in a continuous process of action and interaction. As Khodyakov writes:

Trust is a process of constant imaginative anticipation of the reliability of the other party's action based on (1) the reputation of the partner and the actor, (2) the evaluation of current circumstances of action, (3) assumptions about the partner's actions, and (4) the belief in the honesty and morality of the other side (Khodyakov, 2007, p. 126).

The preconditions of the respondents in the qualified trust section can be helpful here. More research into how these conditions can be translated in ways to shape trust on the social level is necessary. This research needs to focus on trust at the interpersonal level as well. As the quotations in the qualified trust section show, both levels of trust influence each other. The importance of the interaction of both levels is also recognized in the Char- 
ter on Medical professionalism, which states:

Physicians must reaffirm their active dedication to the principles of professionalism, which entails not only their personal commitment to the welfare of their patients but also collective efforts to improve the health care system for the welfare of society (Sox, 2002, p. 246).

Trust will never reach an unshakeable final shape: it will only be gained by a continuous effort, a process of action and interaction that can easily be lost as well. The process of shaping and strengthening trust needs to be given more attention. Physicians need to realize that the demand of public responsibility does not clash with the special nature of their professional actions (Health Council of the Netherlands, 2006). Physicians are accountable to society regarding the care for older people. This does not mean that they lose their professional autonomy in doing so: in fact by being aware of social expectations and implementing them in their practice, trust in their profession will be gained and their professional autonomy may be strengthened.

\section{Acknowledgements}

We would like to thank Dr. David Townend for helping us in getting our message across in clear and correct English and Dr. Wybo Dondorp for his valuable and detailed comments on the various versions of this chapter.

\section{References}

ABIM Foundation ACP-ASIM Foundation European Federation of Internal Medicine. (2002). Charter on Medical Professionalism: Annals of Internal Medicine.

Beauchamp, T. L., \& Childress, J. F. (2001). Principles of Biomedical Ethics (5th ed.). Oxford: Oxford University Press.

Centre for ethics and health. (2004). Ethics and Health Monitoring Report. Zoetermeer: RVZ. Charles, C., Gafni, A., \& Whelan, T. (1997). Shared decision-making in the medical encounter: what does it mean? (or it takes a least two to tango). Social Science and Medicine, 44(5), 681-692.

Coulehan, J. (2005). Today's Professionalism: Engaging the Mind but Not the Heart. Academic Medicine, 80(10), 892-898.

Evans, J. G. (1997). The rationing debate: rationing health care by age: the case against. British Medical Journal, 314, 822-825.

Frank, J. R. (Ed.). (2005). The CanMEDS 2005 physician competency framework. Better standards. Better physicians. Better care. Ottowa: The Royal College of Physicians and Surgeons of Canada.

Freidson, E. (2001). Professionalism. The third Logic. Cambridge: Polity Press.

Gwyn, R., \& Elwyn, G. (1999). When is a shared decision not (quite) a shared decision? Negotiating preferences in a general practice encounter. Social Science and Medicine, 49, 437447.

Hall, M. A. (2006). Researching medical trust in the United States Journal of Health Organization and Management, 20(5), 456-467.

Harris, J. (1987). QUALYfying the value of life. Journal of Medical Ethics, 13, 117-123. 
Health Council of the Netherlands. (1998). President. What about age? (No. 1998/06). Rijswijk: Health Council of the Netherlands.

Health Council of the Netherlands. (2006). Performance indicators and public reporting in health care. A review of the scientific literature and an ethical analysis. The Hague: Health Council of the Netherlands.

Jones, K. (1996). Trust as an Affective Attitude. Ethics, 107, 4-25.

Kao, A. C., Green, D. C., Zaslavsky, A. M., Koplan, J. P., \& Cleary, P. D. (1998). The relationship between method of physician payment and patient trust. Journal of the American Medical Association, 280, 1708-1714.

Khodyakov, D. (2007). Trust as a process: A three-dimensional approach. Sociology 41, 115132.

LeGrand, J. (2003). Motivation, Agency, and Public Policy. Of Knights and Knaves, Pawns and Queens. Oxford: Oxford University Press.

Mechanic, D. (1998). The Functions and Limitations of Trust in the Provision of Medical Care. Journal of Health Politics, Policy and Law, 23(4).

Mechanic, D., \& Schlesinger, M. (1996). The impact of managed care on patients' trust in medical care and their physicians. Journal of the American Medical Association, 275, $1693-$ 1697.

Pearson, S. D., \& Raeke, L. H. (2000). Patients'Trust in Physicians: Many Theories, Few Measures, and Little Data. Journal Of General Internal Medicine, 15, 509-513.

Pfadenhauer, M. (2006). Crisis or Decline? Problems of Legitimation and Loss of Trust in Modern Professionalism. Current Sociology, 54(4), 565-578.

Polit, D. F., \& Beck, C. T. (2004). Nursing Research: Principles and Methods (7th edition ed.). Philadelphia: Lippincot Williams \& Wilkins.

Richmond, J. B., \& Eisenberg, L. (2000). Medical Professionalism in Society. New England Journal of Medicine 342(17), 1288.

Royal College of Physicians. (2005). Doctors in society. Medical professionalism in a changing world. Report of a Working Party of the Royal College of Physicians of London. London: RCP.

Royal Dutch Medical Association (KNMG). (2007). KNMG Manifesto on Medical Professionalism. Utrecht: The Royal Dutch Medical Association (KNMG).

Sox, H. C. (2002). Medical Professionalism in the New Millenium: A Physician Charter. Annals of Internal Medicine, 136(3), 243-246.

Swick, H. M. (2000). Toward a Normative Definition of Medical Professionalism. Academic Medicine, 75(6), 612-616.

Tsuchiya, A. (2000). Qualy's and Ageism: Philosophical Theories and Age Weighting. Health Economics, 9, 57-68.

Van der Schee, E., Groenewegen, P. P., \& Friele, R. D. (2006). Public trust in health care: a performance indicator? Journal of Health Organization and Management, 20, 468-476.

Van der Weyden, M. B. (2002). Medical professionalism in the new millenium: a physisician's charter. Medical Journal of Australia, 177, 263-265.

Victor, C. (2005). The epidemiology of ageing. In M. L. Johnson (Ed.), The Cambridge handbook of age and ageing (pp. 95-105). Cambridge: Cambridge University Press.

Walker, M. (2009). Groningen Naturalism in Bioethics. In H. Lindemann, M. Verkerk \& M. Walker (Eds.), Naturalized Bioethics. Toward Responsible Knowing and Practice (pp. 1-20). Cambridge: Cambridge University Press.

www.helptheaged.org.uk. Half of doctors say NHS is ageist. 
Retrieved 27 January 2009,

from http://www.helptheaged.org.uk/en-gb/Campaigns/News/Archive/news NHS+is+ageist 270109.htm 


\section{Chapter 5}

\section{New Views On Medical Professionalism: Building Medical Practices In Health Care Delivery For Older People}

Josy Ubachs-Moust Rob Houtepen Rein Vos 


\subsection{Introduction}

$\mathrm{n}$ the previous chapters, we have discussed the role of age and age-based-rationing in the decision-making and communication process concerning older people. The role and impact of value judgments and the consequences for trust in the medical professional form a Leitmotiv in these discussions. In Chapter 6 we will further explore the concepts of trust and accountability. In this chapter, we will attempt some more groundwork for this discussion.

An important question returning in each chapter is what the consequences are for the patient's and public trust in medical professionals. What matters here is the distinction we made between physicians performing medical acts, in a comprehensive sense of the word medical, and physicians performing medical technical acts. The latter consists of those actions physicians themselves usually consider medical acts: collecting data about symptoms, signs and condition of the patient (anamnesis and physical examination), the construing of the (differential) diagnosis and the provision of therapy or prevention (Chapter 1): a rather objective process of gathering evidence and providing treatment. However, medical practice is not only about these technical assessments of the patient's condition. Various normative, value laden judgments play, and should play a role in medical decision-making. Medical technical acts are therefore one version of medical acts. In this chapter, we will take a closer look on the role and impact of the value laden judgments in the decision-making process concerning older people. In this context, we will use the call for more accountable and trustworthy professionals as a starting point. First, we will take a closer look on what is discussed in the context of trust by medical professional organizations in the United Kingdom, USA, Canada, and the Netherlands. Today, the charters on medical professionalism of the national medical associations attempt to define what patients and the public can expect from doctors. In addition, they define their focus in the context of both patient and public trust and accountability. Subsequently, we will provide a more detailed description of what we believe trust and accountability entail in the context of the care for older patients. We conceptualize this as building new practices, for we will present a set of important building blocks in the form of what medical professional should (Do's) and what they should not do (Don'ts). To illustrate this practice building endeavor we will use the model of the Royal Dutch Medical Association (KNMG) concerning the physician's roles and responsibilities.

\subsection{The medical profession in a changing society}

The medical profession is one of the most established and probably one of the strongest professions today and has acquired a powerful position in society for a long time. Doctors and other health care professionals have a distinctive basis of legitimacy that lends strength to their authority (Starr, 1982). The medical profession itself provided the legitimacy for medical actions by developing codes and charters, exposing professional goals and conduct. In this way the profession was able to demonstrate to the public its trustworthy character and at the same time to provide a framework for assessing the soundness of medical practices. As a next step, disciplinary tribunals were set up through which physicians were held accountable for their actions based on their own charters, by their peers. In other words, it was of great importance for the medical profession to gain and 
to keep the power on what happens in medical practice and who makes the decisions in this context. This illustrates the value of the codes and charters for the medical profession, namely the protection of professional autonomy. The public was considered to trust the profession based on their actions and their codes.

However, by the early 1970's, professional medical ethics had acquired a bad reputation in the Western world as being more a set of rules to protect the interests of physicians than a code of moral conduct to protect patients (Coulehan, 2005; Stevens, 2002). The professional's autonomy was threatened by some developments that called into question the trust in doctors. While medical treatment became more efficacious than ever before, the fact that it also can be potentially harmful to patients was gaining attention. As technology advanced, patients developed higher expectations of treatment, but at the same time they became progressively less satisfied with the personal aspects of medical care (Coulehan, 2005). In addition, the pressure from the government to provide cost-effective care as well as high quality care increased. The public made a call for more transparency in the decision-making process and insurance companies tried to influence what treatments are being offered to patients.

That trust in doctors is no longer self evident is clear from the changes in medical soaps through the decades. Where Dr. Killmore addressed the dilemmas of a very authorative and trustworthy doctor, series like St. Elsewhere and House tell us that there may be lots of reasons to distrust doctors' sound judgment in medical decision-making. Whether it's greed, arrogance or addiction, doctors may have lots of other things on their mind in and around patient care.

Subsequently, the medical profession herself feels her professional autonomy is being threatened. The fear of doctors is that non-medical professionals will to an increasing degree determine the actual care provided (Royal Dutch Medical Association (KNMG), 2007). The Royal Dutch Medical Association explicitly discusses this issue by stating that physicians fear that more and more people from outside the profession will be prescribing the content of care (Royal Dutch Medical Association (KNMG), 2007). Referring to external forces as patient consumerism, government regulations, financial imperatives, medical information on the internet, litigation, technology and the explosion in medical knowledge, the Canadian Medical Society raises concerns about the new healthcare environment and the tumultuous changes in medical practice and on the issue how to prepare physicians to meet the needs of society (Frank, 2005). New stakeholders, parties and people claiming commitment to clinical practice, such as the industry, government, patient organizations, and insurance companies all bring different interests and values into the open, influencing everyday medical practice.

In this context, we want to focus on two issues. Firstly, are the possibly conflicting values of the various stakeholders adequately accounted for in medical practice? For example, the tension between the government, emphasizing the principle of equal access for all patients, and insurance companies attempting to influence the provision of treatments. Secondly, does the medical profession provide an adequate answer for handling its responsibilities towards these different stakeholders, such as respecting the rights of patients and treating patients equally, and acting according to the medical professional standard, clinical guidelines and the organizational requirements of the health care institution: is the profession sentient towards the tension that can exist between these responsibilities? 


\subsubsection{Reshaped medical professionalism}

The disputed trustworthiness of the medical profession lead to a call for more accountability regarding the physician's actions. This call for a broader accountability, encompassing more than a perfect performance of an operation or implementing new technologies, confronts the medical profession with a need to reflect on their roles and responsibilities towards individual patients and towards public institutions. New charters and codes are being developed since the late 1990's, as a response to these developments and with a renewed focus on the role of values in clinical practice. These charters share a similar background, that is a confrontation with a decline in individual patient and public trust as well as a confrontation with threats to the physician's professional autonomy by both societal developments and external parties forcing themselves a role in clinical practice.

In these new charters the medical professional organizations reflect on the threats they are confronted with. Trust and accountability play an important role in these statues. For example, according to the Royal Dutch Medical Association medical professionalism assumes mutual respect, individual responsibility and accountability (Royal Dutch Medical Association (KNMG), 2007). The value of individual and public trust is recognized by the medical profession and forms the basis of their covenant with society. In the British report Tomorrow's doctors, it is stated that patients must be able to trust doctors with their lives and well-being. To justify that trust, it is stated that the medical profession has a duty to maintain a good standard of practice and care and to show respect for human life (General Medical Council, 2003). According to Swick, a definition of medical professionalism must account for the nature of the medical profession and must be grounded in what physicians actually do and how they act, individually and collectively. Therefore, medical professionalism consists of those behaviors by which physicians demonstrate that they are worthy of the trust bestowed upon them by patients and the public, because they are working for the patients' and the public's good (Swick, 2000).

So, what defines a good doctor, a doctor whom we can trust? Medical associations have responded to this question by generating three types of charters: the competence type, the conduct type, and the mixed competence-conduct type.

\subsubsection{The competence type of charter on medical professionalism}

In 1996 the Royal College of Physicians and Surgeons of Canada published the influential CanMEDS Physician Competency Framework. Since then it has been extensively reviewed and updated; the most recent version dates from 2005 (Frank, 2005). The Framework tries to provide an answer to the difficulties the profession is confronted with, as identified above, by broadening the competencies required from physicians, as a way to increase trust in doctors. The CanMEDS Roles Framework identifies six roles, which together shape a medical expert. These roles are: the professional, the communicator, the collaborator, the manager, the health advocate and the scholar (Frank, 2005). Furthermore, in the Framework of 2005 we find a reference to the dual responsibilities of physicians in today's medical practice that is responsibilities towards individual patients and towards society. We also find references to some other stakeholders but since these are not really elaborated upon these references remain rather general and limited.

\subsubsection{The conduct type of charter on new medical professionalism}

The conduct type of answer is provided in the Charter on Medical Professionalism, by the American Board of Internal Medicine (ABIM-Foundation), the American College of 
Physicians-American Society of Internal Medicine (ACP-ASIM Foundation), and the European Federation of Internal Medicine who focus more on the role of values in clinical practice (ABIM Foundation ACP-ASIM Foundation European Federation of Internal Medicine, 2002). In comparison to the charters above, such as the CanMEDS Framework, we do not find a broad list of competencies, but a focus on normative principles and responsibilities. The charter is based on three Fundamental Principles, concerning the primacy of patient welfare, of patient autonomy and of social justice. Furthermore, a set of Professional Responsibilities is framed in terms of commitments, such as commitment to professional competence, honesty with patients, to improving quality of care, to a just distribution of finite resources, to scientific knowledge, to maintaining trust by managing conflicts of interest and to professional responsibilities. The way these responsibilities are described demonstrates receptiveness for the role of non-medical technical and normative arguments in the decision-making process. For example, regarding the conflicts of interest with for-profit industries, including medical equipment manufacturers, insurance companies, and pharmaceutical firms, physicians have an obligation to recognize these conflicts of interests, to disclose these to the general public, and to deal with these conflicts of interest that arise in the course of their professional duties and activities (ABIM Foundation ACP-ASIM Foundation European Federation of Internal Medicine, 2002). But also, by explicitly stating that medicine's contract with society demands placing the interests of the patients above those of the physician, and setting and maintaining standards of competence and integrity (ABIM Foundation ACP-ASIM Foundation European Federation of Internal Medicine, 2002), the charter provides a broad description of 'good' medical conduct, not only focusing on medical-technical acts, skills and competencies.

\subsubsection{Comparison of the Charter on Medical Professionalism and the CanMEDS Framework}

Both the Charter on Medical Professionalism and the CanMEDS Framework are too onesided. The CanMEDS Framework focuses too much on the competencies of physician's and as a consequence overlooks the role of values in clinical practice (Frank, 2005). The Charter on Medical professionalism, however, remains too abstract as it fails to address the competencies needed for dealing with these values (ABIM Foundation ACP-ASIM Foundation European Federation of Internal Medicine, 2002). Consequently, both endeavors do not provide leads for dealing with the different values of the various stakeholders influencing the provision of care in general and care for older people in particular.

In comparison with the CanMEDS Framework, the Charter on Medical Professionalism pays more attention to the dual structure of responsibilities of physicians. Here also, however, this duality is generally limited to the responsibilities of patient and society, including the role of for-profit industries and opinion leaders. Because the relevance of multiple stakeholders is not really accounted for, the Charter does not include other parties like the government, the patient's family, employers, professional organizations, patient groups representatives and institutional management which, as we have seen have their own interests and values and influence medical practice. As a result, the Charter provides a too naïve view on the role of stakeholders in decision-making.

When examining the descriptions of the medical professional's roles in the CanMEDS charter, we notice that the role of health-related values, such as justice, responsible use of authority and influence, and advocacy for individual patients, populations and communities, in decision-making is addressed only marginally, although we do find some leads indicating a certain susceptibility to the impact of values on the professional's behavior 
as well as to the distinction between medical acts and medical technical acts. As we have seen in the previous chapters health-related values play an important role in the communication and decision-making process in the care for older people (see Chapter 2 and 3). Consequently transparency and accountability concerning these values are part of medical professionalism also and, in addition, play a role in the context of judging the trustworthiness of an individual physician and the professional organization as a whole. Ethical values, however, just play a minor role in this Framework as they are mentioned as one of many aspects of some of the enabling competencies.

In addition, we think the dual structure of doctors' responsibilities should be further specified. First, a relevant focus concerns the relational aspects of dealing with the patient and patient's representatives. The second focus is on the private and public institutions involved in organizing and regulating health care. Among these institutions are government agencies, health care organizations, insurance companies, patient organizations and other stakeholders. So, on further analysis of the CanMEDS charter, the dual structure of physician's responsibilities refers to a multiple stakeholder model, a prime dual focus within this model.

Regarding the conduct type of charter by the ABIM and ACP-ASIM Foundations, we want to put forward two points of criticism regarding this approach. First, the emphasis on principles and commitments goes at the expense of a focus on what to do with these principles and the values underneath in practice. By using the word 'responsibilities' the charter places a lot of emphasis on the virtuous character of physicians. Physicians must 'reaffirm their active dedication to the principles of professionalism' and the charter is 'intended to encourage such dedication'.

Secondly, a focus is missed on what competencies are needed to incorporate these values, and more specifically, how to deal with conflicting values, in everyday medical practice. The Charter thus recognizes the role of values in medical practice, but fails to address how to act upon this knowledge. As a result, the Charter is not able to shake off a rather abstract level of principles and commitments.

\subsubsection{The mixed competence and conduct type charter on medical professionalism: the Dutch charter as an example}

The structure of the model by the Royal Dutch Medical Association is inspired by the CanMEDS Framework (Royal Dutch Medical Association (KNMG), 2007). The Royal Dutch Medical Association distinguishes five roles concerning knowledge and science, communication, collaboration, organization, and acting socially. The roles are made more concrete as they are specifically related to the call and need for accountability. The public demands good doctors to be open about and accountable for their decisions, not only to their peers but also to the public. This demand from society is approached in a positive way, as it is stated that by being accountable physicians demonstrate their medical professionalism. Accountability legitimizes their actions (Royal Dutch Medical Association (KNMG), 2007). In addition, through his accountability the professional demonstrates that he is worthy of trust. Furthermore, the Dutch Royal Medical Association states that medical professionalism is based on providing optimal care for individual patients. The problem is, however, that this starting point can be at odds with insurers, supervisors, and government, who all have their own views and opinions on what good and quality care is, and who are trying to influence clinical practice (Royal Dutch Medical Association (KNMG), 2007).

In recognizing these external forces and developments, the Royal Dutch Medical Association attempts to link these values from outside with the physicians' competencies by 
arguing that medical professionalism comprises the values, forms of conduct and relationship with society as a whole that support and justify people's trust in doctors, thus placing normative and technical behavior next to each other (Royal Dutch Medical Association (KNMG), 2007).

\subsubsection{Criticism of the Dutch model}

The Royal Dutch Medical Association's approach attempts to deal with the threats to the professional's autonomy, such as the changing market forces, changes in the health care delivery systems, the increasing role of external parties as insurers and patient organizations. The Dutch charter aims to connect physicians' responsibilities and the various aspects of their accountability. It combines values and competences. However, next to the criticism of the competence and conduct type charter exposed above, we want to argue that two crucial things are missing in this approach.

The first thing missing is that the Royal Dutch Medical Association fails to recognize the physicians' accountability to the other stakeholders, influencing medical practice, in addition to the patient and society at large or government agencies. The structure of the Dutch health care system with a large role for the civil society, unlike for example the British National Health Service, comprises various parties with a formally and socially acknowledged role in the health care system. These different stakeholders, such as patient organizations, insurers, employers, and professional organizations all have different points of view and different interests. It is therefore necessary to be even more precise regarding the physicians' accountability, that is, to specify accountability to whom and for what aspect. In addition, these stakeholders all bring their views and values into clinical practice. Holding physicians accountable for recognizing these values and the way they are employed in the decision-making process is a crucial step, a step which is not yet taken by medical professional organizations.

The second thing missing is related to what we have discussed in Chapter 1 and 2, in which we have demonstrated that value judgments are an essential part of medical practice. Accountability for the use of values in charters, codes of conduct and guidelines is important, but if there it stops, is too broad and abstract. Value judgments play their often implicit, role in the discretionary freedom physicians need to adjust their decisions to the specific characteristics of the situation, e.g. decision-making for individual patients and their families, and communication with particular insurance companies or patient organizations. Value judgments therefore should be taken into account in the discussion on medical professionalism. But, value judgements are considered to be tricky. Professionals usually view them as personal, subjective, and intuitive. They often lead to controversy and discussions, which gives values the reputation of being difficult and troublesome issues. Nevertheless, values are inherently part of medical decision-making, and therefore have to be made explicit, in the same way as physicians are open about the scientific evidence they use or which medication they prefer.

\subsection{Building a new medical practice}

We conceive the various charters on new professionalism as attempts to build new medical practices which are adaptive to changes in society and are productive in shaping new medical professionals which are accountable to and are trustworthy for society. In our analysis of the charters above we identified a number of critical points, which have to be 
incorporated in building a practice of new medical professionalism, namely a focus on both values and competences, a specification of value judgments and competent actions, and attention for the various stakeholders.

Our aim is to fill in these critical points by sketching the contours of a new medical practice. In doing so we will propose a set of building blocks for such a practice by presenting the kind of actions which medical professionals should do (Do's) and the kind of actions which they should not do (Don'ts).

On our conception of practice we do not only mean the kind of actions physicians and other health care workers perform in their consultation rooms and their interaction with (individual) patients. On the contrary, with practice we conceive of all kind of social arrangements that is the infrastructure within which all kind of medical actions are performed. Furthermore, a practice consists of multiple sites where medical actions are performed. Thus, next to consultation rooms, laboratories and surgery rooms, other sites can be identified such as meeting rooms, committees for developing policies, protocols and guidelines, and professional education rooms for developing and upgrading of skills and competencies.

We propose to distinguish two kinds of arrangements to shape a practice, i.e. relational and institutional. The former implies the framing of value systems and competencies which are necessary for the direct interaction with all the relevant stakeholders in a practice. This concerns not only colleagues ('peers') and other health care workers ('internal accountability'), but also, for example, patients and patient organisations, representative organisations for the elderly, insurers, and policy makers. The latter concerns institutional arrangements for facilitating, guiding, preserving and protecting the relational processes in practice. Examples are supervising authority bodies, national or regional commissioners bodies (e.g. ombudsman), report and benchmarking policies, mediating and second opinion arrangements, and incentives measures.

Above we said to sketch the contours of the new practice by proposing building blocks. By this we mean to say that we can only indicate the directions for building up such a practice. A comprehensive and fully specified account of such a practice is not only possible, but also undesirable, because a practice has to be built by the involved stakeholders. Our hope is that we are able to provide some interesting directions.

To illustrate our practice building endeavour we use the model by the Royal Dutch Medical Association concerning the various roles of a physician, because as a mixed type of charter it already aims at combining values and competencies (the first critical point addressed above). We will fill in this model by specifying the kind of actions which medical professionals should do (Do's) and what they should not do (Don'ts), thus attempting to meet the other two critical points addressed above. In this respect the criteria used by the interviewed professionals regarding the qualified trust category have been used (see Chapter 4). These criteria have a dual structure. Some are proposed as stringent criteria producing boundaries which should not be crossed in order to build trust in medical practice. Others are produced as constitutive criteria producing new avenues and horizons to be pursued in order to build trust in medical practice. We did not aim at an extensive analysis of all the criteria put forward by the interviewed professionals. Instead, we extracted the major clusters of criteria, which could be connected with the kind of competences identified by the Dutch professional model. ${ }^{8}$

8 We followed the same method of analysis as used in Chapter 4. The models were all theoretically driven. In our analysis, we extracted a number of 'pickets' that were formulated as Do's or Dont's that is what physicians should or should not do. Subsequently we selected the most valuable ones, which we were also able to frame 


\subsubsection{The roles of medical professionalism: Do's and Don'ts}

The KNMG identifies five roles of medical professionalism: knowledge and science, communication, organizing, collaboration and acting socially (Royal Dutch Medical Association (KNMG), 2007). In this section, we will explore what these roles imply for the care for older people. In addition, we will demonstrate the role of value judgments in various aspects of medical decision-making in this context.

\section{A. Knowledge and science}

\section{- Interaction of diseases}

Physicians should not just be focusing on the 'symptoms' as dealing with one aspect has consequences for the rest (realize that the various diseases and complaints interact and have consequences for other professionals in a chain of care and for their treatments)

\section{- Complexity and individualization}

Because of the complex nature of the care for older patients physicians have to individualize their care (especially regarding older patients: complexity and challenging)

\section{- Evidence and doubt}

Physicians have to realize that the available evidence is not suitable for answering the question of the desirability of the treatment

The first role identified by the KNMG, Knowledge and Science, pertains to the physician as a science based medical expert, who keeps his knowledge up to date. In the context of the care for older people we distinguish several issues that require further attention.

First, the high frequency of multi morbidity and multiple treatments is a prominent feature in the care for the elderly. In many cases, there is a lack of evidential basis for medical actions, which poses problems of insecurity and carefulness and makes good communication with other health care professionals even more urgent than usual. This concerns, what is called in ethics, the 'problem of many hands' (Poel \& Zwart, 2010; Thompson, 1987): next to the question who is responsible for what, the issue is how the 'whole chain' of health care delivery can take responsibility for the elderly patient. Next to supportive tools as interactive electronic patient databases, it might be helpful to develop new arrangements, technologically through discussion and monitoring platforms through the internet and organizationally to set up assessment and monitoring committees with representatives from the 'care chain' to connect the various health care professionals. Furthermore, the issue is how to involve elderly patients and their families.

Second, the care for older patients can be characterized as complex considering the often problematic character of the older patient's health status and the uncertain prognosis of the older patient's condition after treatment (Boyd et al., 2005). This requires competencies for individualizing health care for the elderly, but also implicates new ways of framing protocols and guidelines, possibly to be developed, implemented, monitored and evaluated by multi professional teams.

The physician's technical skills often appear not able to cover over all aspects of the care in the list of competencies as identified by the Royal Dutch Medical Association. 
for older patients. Moreover, age-related value judgments also play their part here, as both physician and patient have to reflect on what care is needed and what care is still desirable, which should therefore be a crucial aspect of the competency list of physicians. This concerns a valuational competency, because the desirability question of every treatment decision for an older patient cannot be merely answered with the available evidence. For example, a cardiologist has successfully treated an older patient. The patient is given time to recover at the hospital and receives an appointment to check up on him a few weeks later. It appears that the patient has a very hard time in coping with the after effects of the treatment. A few months later he is still not feeling well. The cardiologist involved, however, is not handling these problems, as the patient has returned to his general physician or gerontologist. Moreover, he may not even be aware of the problems that have arisen. In other words, is the evidence the cardiologist is using to decide whether to treat or not suitable for the treatment of older people? It is not only a science-based and technical issue, but also a value topic, because questions of vulnerability, endurance, resilience and strength of social networks are at stake, which are important to answer the desirability question of the treatment for an older patient (Agich, 2003; Campbell \& Buchner, 1997; Hamerman, 1999; O'Connor, 2005; Tronto, 1993).

\section{B. Communication}

\section{- Desirability in communication}

The desirability of the treatment needs to be explicitly reflected on at the relational level (this issue should be discussed from a medical, societal en personal perspective)

\section{- Patient network appreciation}

Physicians should appreciate the role of the patient's personal network (shared marital history and voluntary aid: important sources of information)

- Intercollegiate discussions

Physicians need to be aware of the importance of discussing the care of an older patient with their colleagues (value judgments are often explicated in discussions between professionals)

In the context of addressing the desirability-question, the communication skills of physicians play an important role. In addition to the general requirements concerning the communication between physician and patient, we will discuss some other aspects which are especially important in the care for older patients relating to communication with the patient's family and the network of health care professionals and other stakeholders.

An important aspect of the communication between physician and older patient is the explicit discussion of the desirability of the treatment, from a medical perspective, a societal and a personal perspective. This question should become part of every decision-making process. Physician and older patient should engage in a conversation concerning the consequences of the proposed treatments and whether both patient and physician are willing to accept these. But also, we need to be aware of the role of desirability-judgments from the perspective of the physician in addition to the objective medical arguments he makes use of. For example, a physician might find it acceptable for a patient to consider a rehabilitation process of a few months, while the patient may feel that at this stage of his life, he does not want this anymore. What matters here is that both patient and physician 
may not be sharing the same values regarding health, priorities in health care and the role of the patient's age or stage in life. The situation becomes more complex, considering the increasing trend towards organisation in health care - e.g. shared decision-making, multidisciplinary teams, and disease management. Conflicting views and perspectives at various levels might be at stake. But complexity can also arise, because society may send mixed signals. On the one hand older people are encouraged to remain active and involved for as long as possible. At the same time the fear of too heroic treatments implies a passive attitude, asking from the patient - and the physician - 'that it perhaps would be better to let life take its course'. For example, in a leading Dutch newspaper in the context of health care reform the question is asked whether all medical means must be employed to keep every patient alive? And, is it always self-evident to start en expensive chemo-treatment, to extend a life for a short time (NRC Handelsblad, 2010). Furthermore, physicians should be aware of the impact of these value judgments on reaching their decisions, but should also be able to identify tensions and potential conflicts between their value judgements and the value judgements of the other stakeholders in health care delivery for the elderly. Finally, in addition to recognizing the significance of the desirabilityquestion physicians have to reflect on the way the physician communicates these value judgments with his patients.

In the care for older people the family often plays a crucial role (see Chapter 2). The shared history of older partners, but also the intimate relationship with people offering voluntary aid is a valuable source for understanding the patient and his values. In reflecting on the desirability of treatment, the patient's personal network needs to be appreciated also as a valuable source of information.

Identifying value judgments in the context of the desirability of treatment is a complex tasks for both patient and physician. To warrant that these normative arguments do not remain hidden, physicians and patients therefore need to make an effort to identify these arguments and subsequently talk about them with each other. In Chapter 2 we discussed the four models of the physician-patient relationship by Emanuel and Emanuel. In this chapter we criticised the informative model as being too restricted as it conceives the communication between physician and patient too much as a medical technical process in which value judgments do not play a role. Here again it becomes clear that the deliberative model of the physician-patient relationship as identified by Emanuel and Emanuel best fits our goal (Emanuel \& Emanuel, 1992 and Chapter 2). If we want physician and patient to explicitly discuss the desirability of the treatment, we need room to openly reflect on the value judgments which may influence this decision. However, the model has to be extended incorporating family and other supportive persons into the deliberative process.

The last aspect we want to discuss here, concerns the discussions that take place between colleagues in a health care setting. Value judgments often are made explicit in discussions between fellow physicians or in the treatment team (see Chapter 3). In addition to the models of Emanuel and Emanuel who focused on the relationship between physician and patient (Emanuel \& Emanuel, 1992), we now see that in the interaction between colleagues and other health care workers also an important source of information is found for answering the question of the desirability. The complex and challenging character of the care for older people as discussed in the previous section is relevant here also. Physicians are confronted with a lot of doubts and dualities requiring explicit discussion, It is, therefore, not only on the level of the physician-patient relationship that we have to look 
for possible value judgments but also at the level of the health care setting.

\section{Organizing}

\section{- Chain of care/patient focused network care}

The care for older patients should be given shape alongside a chain of care

\section{- Connecting consequences}

The various links should be in close connection with each other concerning the consequences of the decisions that are made

In line with the final comments in the previous section concerning the intercollegiate discussions we need to discuss the way the care for older people is organized. Health care in general is now known more and more by physicians working within a team context and through participation in health care chains. Rarely do doctors still work alone (Royal Dutch Medical Association (KNMG), 2007). As seen from the practice descriptions we analyzed, the organization of the care for older people basically not differs from the way care is provided to other patient groups. Business as usual as older patients are treated as every other patient, taken from one link in the health care chain to the other. In the Dutch literature on organizing the care for older patients it is believed that to prevent neglecting complaints or diseases because of lack of expertise, a focus on the patient is needed in organizing the care along side a patient focused network (Nieuwenhuijzen Kruseman, Bussel, \& Pijpers, 2006). The preference for patient focused network care instead of disease focused chain care involves that all complaints will be dealt with in a coherent manner, preferably by one person or a small multidisciplinary team. So, in addition to individualizing the care for an older patient, professionals are required to have an eye for generalization, as they are required to be capable of dealing with more than one complaint or disease at the same time (Nieuwenhuijzen Kruseman, Bussel, \& Pijpers, 2006). A fragmentation of care which affects the quality of care provided in an negative way, needs to be prevented. Starting point should be that every physician has his own responsibilities in addition to a shared responsibility. Arrangements have to be made concerning the various tasks to be performed and everybody's responsibilities concerning these tasks (Royal Dutch Medical Association (KNMG), 2007). In addition, it is suggested by Wesseling, in the context of the Dutch health care system that, hospitals have to set up multidisciplinary care units for patients with multi morbidity, who can not be cured, but who's health condition can be improved, as for instance older patients (Wesseling, 2003). What makes this proposal worthwhile is the fact that in these care units older people can be admitted directly. In addition, one specialism will fulfill the role of coordinator, which ensures that the responsibility for the patient will not be passed on indefinitely. Furthermore, a valuable initiative in this in context has been taken by one Dutch hospital. In this hospital a Geriatric Diagnostic Outpatient's clinic has been setup, providing older patients to have all their diagnostics done in two days, giving the patient one week rest in between (Schipholt, 2007).

Organizing the care for older people therefore requires special attention. It is urgent to develop a patient focused network care and the centralization of diagnostics and professionals in the care for older people. This also helps to ensure a closer connection of the various links in the health care chain and to provide opportunities for an explicit discussion of the desirability of the various treatments. In this context, issues such as who is responsible 
for what part of care delivery, how are all the various links kept up to date, and how is the patient handling the treatments and are they effecting his other conditions, can be dealt with. We need to keep in mind that not being able to plan appointments on one day is unpleasant and inconvenient for all patients, but this is especially the case for older patients. They are often dependent on public transport, walk with difficulty and are generally not very energetic. On an organizational level, these issues need to be addressed as well. Health care organizations have to reflect on the priority of these practical objections and relate this to the way care is delivered and organized in their setting.

\section{Collaboration}

\section{- Process focus}

Not the partial product but the process should be the starting point in the care for older patients (chain of care)

\section{- Desirability in chain of care}

The desirability of the treatment needs to be explicitly reflected on in every link of the chain of care (from a medical, societal and personal perspective)

\section{- Non mechanical approach}

Physicians should be aware of a too 'mechanical' use of a chain of care (although the various links in the chain are connected, the chain may not be working properly)

On the subject of collaboration, the Royal Dutch Medical Association states that physicians are more and more working in a team and are taking part in chains of care. This has its consequences for the physician's responsibilities, as they are being shared with and divided between other physicians or professionals (Royal Dutch Medical Association (KNMG), 2007). Important in this context is that every professional is aware of his own responsibility, while also acknowledging his responsibilities towards other professionals. In the interest of the patient it is therefore important that it has to be clear who is responsible at what time for which part of the chain. Starting point should be that every professional has its own responsibility and at the same time has a shared responsibility (Royal Dutch Medical Association (KNMG), 2007). A chain of patient focused network care is of specific importance in the care for older patients (Nieuwenhuijzen Kruseman, Bussel, \& Pijpers, 2006). In general, older patients have more than one illness or complaint, which requires specific attention. Every medical professional treating an older patient should realize how his or her actions can influence the wellbeing of the patient in regard to the other complaints. In other words, what matters is the process. Every link in the chain of care should be involved or consulted when making a decision, especially in the context of a medical specialist treatment. The way health care is organized today, however, makes these proposals more difficult to realize as patients are generally seen in the context of one disease or complaint, with one specialist at a time.

We want to take this responsibility one step further by introducing the issue of the desirability in every link of the chain of care. This means for example that a cardiologist should not just be repairing the heart and send the patient home, but be committed to the care process before treatment and in the aftercare. In this process the desirability of the treatment should be explicitly discussed. The value of adding the desirability question here is that it reduces the risk of a too mechanical use of a chain of care: as long as the various 
links are connected that chain is intact and working properly. An explicit reflection on the desirability of the treatment in every link of the chain offers two valuable advantages.

Firstly, as we have seen value judgments play an important role in the treatment decisions of older people, an issue which is missed in the literature on the chains of care. In Chapter 3 we discussed that these value judgments are made explicit in discussions with colleagues and other professionals. The various links in a chain of care and the collaboration and discussions with the professionals in these links can therefore serve as a valuable source for identifying these value judgments. In addition, it is important to realize that every link provides its own discretionary room, which can lead to assumptions not in line with the premises from the previous link. Collaboration between the various professionals in the chain of health care delivery can be helpful in explicating the role of value judgments in the decision-making process throughout the health care chain.

Secondly, explicitly addressing the question of the desirability of the treatment every time a decision is made reduces the risk of being confronted with unexpected and unintended consequences of medical actions. It is not enough to discuss the desirability issue at the beginning of the chain as it is very likely that the patient gradually, moving up the chain, may become feeling differently regarding certain treatments. The route that has been initially mapped needs to be adjusted. Still too often, a once started and agreed upon course is blindly followed, moving the patient from one chain to the next, until things really cannot go on any longer (Charles, Gafni, \& Whelan, 1999). Thus it is important to realize that the discretionary freedom not only concerns the decisions on the level of the physicianpatient relationship, but is crucial on the level of the whole chain of care also. Physicians are thus accountable for addressing the issue of the desirability of the treatment on the level of the physician-patient relationship and on the level of a chain of care.

\section{E. Acting socially}

- Societal desirability

The desirability of the treatment should be discussed from the perspective of society (capacity)

\section{- Patient group desirability}

The desirability of the treatment should be discussed in relation to the consequences of the treatment for older patients as a group (proportionality and medically futile care and over and under treatment)

\section{- Institutional desirability}

The desirability of treatments should also be discussed in relation to the consequences of the treatment for the institution and the other professionals in a chain of care (proportionality)

According to the Royal Dutch Medical Association, accountability towards society entails, for example, the physician's responsibility to make his effort regarding medical education and the development of medical science in relation to public health. In addition, physicians should act in accordance with generally accepted medical ethical standards. In the context of choosing between two interventions with the same effectiveness, physicians should take their responsibility and make a decision based on the patient's preferences or safety or efficiency arguments. In addition, physicians have to strive for providing efficient 
care (Royal Dutch Medical Association (KNMG), 2007).

Physicians' accountability regarding the desirability in this context does not concern the individual costs for individual patients. It is not directed at holding physicians accountable for financial issues apart from other arguments. It does concern accountability towards the broader consequences of the decisions regarding what is most preferable on the level of older patients as a group. It also entails accountability towards the consequences of the physician's actions for the other stakeholders and professionals in the chain of care. As we have seen, in the context of the discussions with fellow physicians the decision-making process and the arguments used become more visible. This is also relevant for the judgments used on this level as physicians should not be making these assessments alone. The issue of proportionality for both the institution and his colleagues and the consequences for the group of older patients can best be identified in collaboration with other professionals and professional organizations. Subsequently, physicians can be held accountable for the choices they make in the context of the desirability of the treatment on this level also. Furthermore, the physician's social role in this context also concerns the physician's involvement in the discussion on the consequences of the ageing of the population. For example, the debate on life-extension and whether we really should accept the fact that we all grow older. Physicians are mostly concerned with addressing the health problems of their patients in the best possible way, thereby not reflecting on these broader societal issues and the values involved.

\subsection{Concluding remarks}

We have seen that medical professional organizations throughout the world are struggling with the task of identifying a new medical professional character. In our perspective, for discovering such a character, we need building blocks. The building blocks in the form of the various Do's and Don'ts as identified above, provide handles for framing the contours of a new practice and for individualizing the medical professional's responsibility on the relational and institutional level as described above. We have attempted to address the critical points as named above, a focus on both values and competences, a specification of value judgments and competent actions, and attention for the various stakeholders. However, these building blocks have to be further specified, on both the relational and institutional level. We believe the stakeholders themselves should perform this task. In the next chapter, we will turn to the second part of the diptych, the development of a framework of accountability and trust in the care for older people. The Do's and Don'ts as identified in this chapter as a basis for building a new medical practice, form the starting point of the endeavor in Chapter 6.

\section{Acknowledgments}

We would like to thank Dr. Wybo Dondorp, Prof. Guido de Wert and Prof. Ruud ter Meulen for their valuable and detailed comments on the various versions of this chapter.

\section{References}


Charter on Medical Professionalism: Annals of Internal Medicine.

Agich, G. J. (2003). Dependence and autonomy in old age. An ethical framework for long-term care (Second and revised edition ed.). Cambridge: Cambridge University Press.

Boyd, C. M., Darer, J., Boult, C., Fried, L. P., Boult, L., \& Wu, A. W. (2005). Clinical practice guidelines and quality of care for older patients with multiple comorbid diseases. Implications for pay for performance. The Journal of the American Medical Association, 294(6), 716-724.

Campbell, A. J., \& Buchner, D. M. (1997). Unstable disability and the fluctuations of frailty. Age and Ageing, 26, 315-318.

Charles, C., Gafni, A., \& Whelan, T. (1999). Decision-making in the physician-patient encounter: revisiting the shared treatment decision-making model. Social Science and Medicine, 49, 651-661.

Coulehan, J. (2005). Today's Professionalism: Engaging the Mind but Not the Heart. Academic Medicine, 80(10), 892-898.

Emanuel, E. J., \& Emanuel, L. L. (1992). Four Models of the Physician-Patient Relationship. Journal of the American Medical Association, 267(16), 2221-2226.

Frank, J. R. (Ed.). (2005). The CanMEDS 2005 physician competency framework. Better standards. Better physicians. Better care. Ottowa: The Royal College of Physicians and Surgeons of Canada.

General Medical Council. (2003). Tomorrow's doctors. London: General Medical Council Hamerman, D. (1999). Toward an understanding of frailty. Annals of Internal Medicine, 130(11), 945-950.

Nieuwenhuijzen Kruseman, A. C., Bussel, B. C. T., van, \& Pijpers, E. (2006). De zorg voor chronisch zieken. Liever patiëntgerichte netwerkzorg dan ziektegerichte ketenzorg. Medisch Contact, 61(45), 1803-1806.

NRC Handelsblad. (2010, 22 april 2010). Hervormen van de zorg is meer dan bezuinigen. NRC Handelsblad.

O'Connor, P. J. (2005). Adding value to evidence-based clinical guidelines. The Journal of the American Medical Association, 294(6), 741-743.

Poel, I., van der, \& Zwart, S. D. (2010). Reflective equilibrium in R \& D networks. Science, Technology \& Human Values, 35(2), 174-199.

Royal Dutch Medical Association (KNMG). (2007). KNMG Manifesto on Medical Professionalism. Utrecht: The Royal Dutch Medical Association (KNMG).

Schipholt, I. L. (2007). Maatwerk voor kwetsbare ouderen. Ons primaire doel is niet genezen, maar beter laten functioneren. Medisch Contact, 62(14), 601-605.

Starr, P. (1982). The Social Transformation of American Medicine. New York: Basic Books, Inc., Publishers.

Stevens, R. A. (2002). Themes in the history of medical professionalism. The Mount Sinai Journal of Medicine, 69(6), 357-362.

Swick, H. M. (2000). Toward a Normative Definition of Medical Professionalism. Academic Medicine, 75(6), 612-616.

Thompson, D. F. (1987). Political ethics and public office. Cambridge: Cambridge Mass: Harvard University Press [paperback 1990].

Tronto, J. C. (1993). Moral boundaries: a political argument for an ethic of care. New York: Routledge.

Wesseling, G. (2003). Van het kastje naar de muur. Medisch Contact, 58(45), 1-3. 


\section{Chapter 6}

\section{Shaping Trust And Accountability In Health Care Delivery For Older People: Giving Voice To The Elderly}

Josy Ubachs-Moust Rob Houtepen Rein Vos 


\subsection{Introduction}

$\mathrm{n}$ the previous chapter, we identified the building blocks, which provide handles for framing the contours of a new practice and for individualizing the medical professional's responsibility on the relational and institutional level. We specifically addressed the role of trust and accountability in these building blocks in the context of the care for older patients. In this chapter, we will further go into what the influence and role of value judgments mean for patients' and public trust in doctors. We will provide a detailed description of a new framework of accountability of physicians as a foundation for trust in physicians. Here also our focus will be on the decision-making for older patients.

Before we can attend to this matter, though, we need to gain some insight in trust as it is discussed in bioethical literature. Furthermore, we will demonstrate that in addition to trust we need accountability.

\subsection{Trust and accountability}

The relationship between physician and patient is based on trust. A patient trusts a physician to respect his privacy, to understand the vulnerable position he is in, to put the patient's interests first and to act according to the medical professional standard. The concept of trust has a venerable heritage in medicine. The axiom of care, to help or at least to do no harm is closely tied in with the pathos of trust: the vulnerable individual appealing for responsiveness within an unavoidable asymmetrical relationship (Zaner, 1991). In addition, as we have seen in Chapter 4, public trust in physicians entails trust regarding the protection of the individual patient's rights and the quality of medical decision-making, as well as regarding awareness of the consequences of medical decisions, including budgetary and societal consequences (see Chapter 4). As shown in Chapter 3, trust in medical professionalism and trust in the individual actions of physicians in medical practice, also necessitates trust in the way physicians handle value judgments. Trust in doctors is equal to trust in skills and expertise of physicians, in their technical ability to perform procedures correctly, but also in their ability to recognize their personal views and value judgments, and to distinguish them from technical assessments based on science and medical knowledge. But trust alone is not enough. In addition to trust we need safeguards and criteria to base trust on. In addition to trust, we need accountability. However, there are different frameworks of interpreting accountability.

\subsubsection{The contract-based framework of accountability}

An important framework in the context of trust and accountability is provided by contractbased theories, which are known for their notions of bargaining and negotiation, and self-interest and rationality. Contract theorists endorse a particular mode of reasoning, namely deliberative rationality. The contractarian method asks individuals to negotiate their values in order to arrive at a mutually shared set of values and norms (Durante, 2009). Contracts have been described as static and instrumental (Pettersen, 2009). The prime framework in many of these theories is provided by the physician-patient relationship. Against the background of the growing awareness that physician and patient interest are not always compatible (Schermer, 2001; Slevin, Plant, Lynch, Drinkwater, \& Gregory, 1988) and to put an end to medical paternalism, the idea of a more or less formalized contract between physician and patient was gradually gaining ground in the second half of the 
$20^{\text {th }}$ century. The four principles of medical ethics patient's autonomy, beneficence, nonmaleficence, and justice, were meant to protect the patient's interest and strengthen the patient's role in medical decision-making. Before, trust was viewed as a kind of unavoidable trust as the patient often has no choice but to trust (Zaner, 1991) patients had little or no say in the decision-making process and where put in a position where their only option was to trust the medical professional. In the context of the contract-based perspective, trust is viewed as valuable, but only as supplementary to the central position of the contract between physician and patient. In as far as the patient is dependent on his physician and has no choice but to trust him, the contract is a means to limit the risks inherent in this trust (Schermer, 2001). Trust is seen in the light of the importance of contracts and agreements between patient and physician, with a large role for formal regulation such as legislation and protocols in defining the terms of such contracts. Bruhn describes trust as becoming more like an economic good, something that can be negotiated, calculated and traded (Bruhn, 2005). The physician's accountability is based on the way the physician handles his responsibilities and obligations in the context of the contract-based relationship between physician and patient and of the relevant regulation (Childress, 1982). Within the contract framework, accountability is also given shape at the institutional level by law and by medical professional organizations and health care institutions developing guidelines and practice guides to formalize and direct the medical professional's actions and his accountability. On the public level, there is a social contract between physicians and society, through which the government grants physicians privileges of income, professionals status, professional autonomy and self-governance. In return, society expects the profession of medicine to respond to social needs (Thompson \& Davis, 2008), in addition to the needs of individual patients.

\subsubsection{Criticisms of the contract-based approach of accountability}

The contract approach has fallen into some disfavour, however, as contracts are generally only appropriate for those who are relatively equal in power and capacity and are capable of voluntary agreements. They are less appropriate in relationships where one party is vulnerable as a result of limited power, sickness and/or age (Baier, 1986; Peter \& Morgan, 2000). In addition, Schermer argues that rules and regulations intended to diminish the risk of trust, as is the case in the contractual form of trust, can start to function in a way that undermines rather than promotes or warrants public trust. A system that is inspired by distrust and is based exclusively on control, safeguards and sanctions may undermine real trust rather than sustain or enhance it (Schermer, 2001). Also, it might be expected that the increasing attention paid to individual rights and to autonomy have increased public trust in the ways that medicine is practiced and regulated. But, according to O'Neill this is not the case. She ascribes loss of trust to the supposed untrustworthiness of health care workers and those who legislate and regulate health care. The perception is that they often pursue their own interests instead of those of patients or the public (O'Neill, 2002). A contract between physician and patient appears not capable of overcoming these drawbacks. Hence, less paternalism has not necessarily resulted in more trust in doctors.

Founding trust and accountability on the rules for legitimate actions by medical professionals is, as it seems, a too narrow approach. Katz, for example, argues that if we value the idea and concept of informed consent, we have to value the concept of trust to be acquired through conversation as well. Disclosure and consent are meant to replace the traditional unilateral trust by mutual trust that extends from physician to patient as well 
as from patient to physician (Katz, 2002). Trust encompasses the physician respecting the patient's rights, and being technically competent, but also his willingness to share the burden of decision-making with patients. Katz emphasizes a reciprocal cooperation between physician and patient, which presumes mutual communication, that is to say both physician and patient sharing information, wishes, doubts and fears back and forth. This conversational framework of trust enables to do justice to the varieties in dealing with informed consent (see Chapter 2) and to make value judgments in medical decision-making more explicit (see Chapter 3).

The value of mutual communication is also recognized by Pellegrino and Thomasma as they believe that the physician is impelled to develop from the very outset a relationship with the patient that includes becoming familiar with the patient and wanting to meet the challenges of illness, disability, and death (Pellegrino \& Thomasma, 1993). Baier shares the fear of physician's abuse of power, which led to the contractual based relationship between physician and patient, but instead emphasizes the open nature of trust, linked to the virtuous character of physicians. Trust is a reliance on somebody else's competence and willingness to look after the things one cares about (Baier, 1986).

Tronto accepts Baier's view on trust as a basis for her discussion of consent-as-a-grantof-authority (Tronto, 2009). Tronto argues that trust in Baier's perspective rests upon experience of some sort and makes a projection into the future about the reliability of the entrusted one. In Tronto's discussion of consent-as-a-grant-of-authority it is argued that the act of consent is an acknowledgment of the doctor's responsibility to take care of the patient which is based not so much on an agreement but rather on a relationship. Consent consists of an acknowledgement of the existence of such a relationship as well as an assignment of responsibilities within it. Because the patient expects that the doctor will act not only according to the agreed upon terms but also in the patient's best interests, it creates trust. A grant of authority is an act of trust; the assumption being made by the grantor is that the person entrusted will act in ways that are consistent with the reasons one consented and granted authority in the first place (Tronto, 2009).

These broader perspectives on trust correct a certain one-sidedness of the contract view, but do not provide sufficiently elaborated alternatives. They address several difficulties within contract-based theories, but fail to present an approach capable of dealing with these issues, yet simultaneously preserving the valuable aspects of the contract framework, especially those in terms of accountability.

Furthermore, it is noteworthy that the debate on trust in medicine is mainly concentrated on the relationship of trust between physician and patient. The broader issue of public trust in addition to personal trust in your physician is only receiving sporadic attention. Schermer, for example, argues that we can trust a physician as a person, because we like him and know him well, but we should also trust him as a physician, because we trust the medical profession in general (Schermer, 2001). Any alternative framework to the contract view should explicitly deal with the physician's and medical professional organization's accountability. Before elaborating our alternative framework, it is necessary to remove one further stumbling-block: trust is not mere confidence.

\subsubsection{Doing accountability: confidence versus trust}

While physicians used to be only accountable to their patients and their peers, a gradual shift towards broader societal accountability has emerged. The increasing influence of 
managed care and its attendant obligations of physicians to meet explicit, high professional standards and to achieve high quality care for patients, require new and transparent forms of accountability (Donaldson, 2001). In various ways physicians are confronted with limits to their professional freedom. They are increasingly asked to account for the way they spend medical resources. It is believed that because we cannot as a matter of course trust doctors to put societal interests first, society must control and check their actions (Checkland, Marshall, \& Harrison, 2004). Various instruments have been developed to challenge physicians to be transparent about their actions, and to prove their trustworthiness. The underlying philosophy of instruments like performance indicators, both process and outcome measures, is that publishing more and better data will be a useful tool to bring about beneficial change (Davies \& Lampel, 1998). It is believed that we cannot simply rely on trust; we need systems of accountability which secure control and reporting (O’Neill, 2004).

Questions are raised, however, about the consequences and usefulness of these instruments. Are published health outcomes contributing to quality improvement, or is perhaps the remedy worse than the malady (Davies \& Lampel, 1998)? An important aspect of this form of accountability is transparency. Information about performance must be made available to various parties, such as governments and hospital boards, but also to the public. In discussing the possible benefits of transparency many authors rely upon the distinction between confidence and trust, originally made by the German sociologist Luhmann. ${ }^{9}$ According to Baier, it is not useful to delineate these as two strictly separable concepts. We should rather think of them as a continuum with on the one hand confidence in social systems and on the other hand trust in specific individuals (Baier, 1994). Thus, in discussing trust in doctors, we have to acknowledge that within the spectrum covered by trust in doctors an important role perhaps is played by confidence in doctors as representatives of the health care system. The crucial question therefore is whether and, if so, how trust in doctors involves more than this confidence aspect.

Harrison and Smith argue that the present emphasis on surveillance, performance measures, and rules shows a preoccupation with confidence instead of trust. Confidence governs everyday interactions where we assume relative certainty and security provided by abstract systems, while trust is necessary where there is vulnerability or when uncertainty tends to arise between individuals (Harrison \& Smith, 2004). Patients and citizens should have confidence in the medical professionals' technical skills and knowledge, but they also need to put trust in their powers of judgments and these do not only concern medical-technical matters, but also the goals and values to be served and respected by medical actions (Schermer, 2001). The emphasis on performance indicators and other measurement tools thus promotes only the confidence aspect of trust. An important consequence of the emphasis on confidence is that it does no justice to the practice of medicine, as it obscures the essential uncertainty associated with much diagnosis and treatment.

Furthermore, Harrison and Smith argue, founding accountability on confidence diminishes the role of morality in everyday medical practice (Harrison \& Smith, 2004). Putting confidence in certainty cannot provide answers to the moral dilemmas of health care, as it neglects aspects of uncertainty, discretion, and morality. Harrison and Smith give the example of people who have to confront loss of independence, loss of relationships, and anticipation of death; these persons have to grapple with uncertainty, despair, and vulner

9 Here we use the discussion by Baier (Baier, 1994) regarding the distinction as made by Luhmann (Luhmann, 1979). 
ability and are engaged with moral and existential issues. This example is particularly relevant for our discussion of the care for older people as this patient group is often confronted with these issues.

Confidence alone cannot provide an adequate response to these dilemma's or to the problematic decisions that they often involve. Harrison and Smith are worried that patients and professionals become morally indifferent to these dilemma's and lose the capacity to respond to them, which will undermine trust in the provision of care (Harrison \& Smith, 2004). It has also been argued that reliance upon these confidence-driven performance indicators both implies distrust and generates more distrust (Power, 1997).

According to O'Neill this accountability culture explicitly seeks to marginalize professionalism and professional standards, by excluding the judgments of knowledgeable practitioners (O'Neill, 2004). However, external incentives and accountability in terms of performance do not have to be a problem, as long as it is realized that they should not disrupt public trust in health care and the essential motivation of professionals. Instead, performance measures should be encouraging and enhancing motivation and public trust. It appears, however, that governments and other parties demanding accountability are mainly focusing on presenting numbers and are overlooking the way systems are aiming at improving the quality of care (Netherlands Health Council/Council for Public Health and Health Care, 2006). In other words, control and accountability are not necessarily a bad thing, it is the way they are used that clashes with building trust in professional practices.

From the discussion above, we derive two important topics for developing an alternative framework of accountability: professional judgment and morality are essential ingredients for a framework of accountability that builds and maintains trust.

\subsubsection{A new accountability framework: the empowered professional and public accountability}

Thus, we need a new view of accountability, which consists of two components. First, this form of accountability should strengthen professionals' judgmental abilities in the decision-making process, concerning the care for older people. We will draw from recent proposals some important lessons offering a new perspective on the role of professionals. None of these proposals suggests returning to complete freedom of the medical profession, in which they are only accountable to themselves, but they provide a different perspective on the role of professionals in performing accountability and building trust. We will discuss three suggestions all explicitly linking accountability to trust.

Second, we will argue, following the work of Erman, that a new conception of public accountability is necessary for accountability processes in complex practices such as the care for the elderly (Erman, 2006). Instead of the question to whom professionals should be accountable, the question becomes for what should professionals be accountable? The 'what' encompasses value-driven issues, particularly desirability and public need topics regarding elderly people and health care delivery.

\subsubsection{The empowered professional}

Three suggestions in recent literature regarding the strengthening of professional judgmental abilities will be discussed.

Firstly, in her 2004' paper O'Neill argues for a view of accountability that would support rather than supersede the intelligent placing and refusal of trust ( $\left.\mathrm{O}^{\prime} \mathrm{Neill}, 2004\right)$. Regaring accountability, the problem is that the focus has been too much on a managerial account- 
ability, which leads to an overly formulistic and mechanistic approach to accountability. In this way, faith in professional's actions is undermined. By focusing, and trusting on, those who devise and revise performance indicators, we push trust in doctors back a stage while in the end we still have to decide whether to place or refuse trust. The true question is whether complex systems of managerial accountability help the public to place and refuse trust. We need forms of accountability that allow people to make intelligent and informed judgments about where to place their trust. O'Neill's proposal has to be viewed against the background of her worries about the negative connotation surrounding trust. She believes that by concentrating on an intelligent form of trust and accountability, these negative associations can be overcome. Accountability can be called intelligent, O'Neill explains, if professional and institutional performance is assessed by those who are sufficiently informed to judge what they assess and sufficiently independent to judge it reasonably (O'Neill, 2004). ${ }^{10}$

Secondly, Checkland et al. propose a new form of accountability which relies not so heavily on measures designed to increase confidence, since these may actually endanger trust in the decisions of individual doctors (Checkland, Marshall, \& Harrison, 2004). The general call for greater openness as a way to improve quality of care is underscored, but Checkland et al suggest reaching that by being transparent about difficult decisions rather than about performance per se. Difficult decisions may arise because of being accountable to multiple audiences. This can be illustrated by the situation in which a physician is held accountable for looking after the patient's interest while at the same time he is bound by the organizational rules of the hospital he is working in. The pragmatic procedures from the lab or the admissions-office are important on the institutional level, but can conflict with the interest of an individual patient. At the same time though, Checkland et al acknowledge the potential risk that the release of information on conflicting pressures, associated with the accountability to multiple audiences, might affect confidence in institutions. Subsequently, Checkland et al state that the challenge is to find a form of professionalism that is prepared to open itself to scrutiny and, through openness, allow trust to develop. They point at the crucial role of medical professionals themselves, because they fear that neglecting trust at the micro level by policy makers in favor of complex measures to improve confidence, runs the risk of disrupting the internal, moral motivation of physicians (Checkland, Marshall, \& Harrison, 2004).

Thirdly, while Checkland et al emphasize the content of accountability, Davies and Lampel focus on the process of accountability (Davies \& Lampel, 1998). They refer to the intrinsic nature of a profession, i.e. the complexity and uncertainty of decision-making in professional practices. The very idea of a profession implies skills, expertise, and tacit knowledge, which cannot be encapsulated by rules and regulations. Therefore systems of accountability are required which empower and reward rather than weaken or punish healthcare professionals in pursuing quality improvement and self-development. In addition, too much emphasis on competition, regulation and supervision undermines trust. Rather than increasing attempts at control a new framework is required which unlocks the potential of medical professionals to improve their performance (Davies \& Lampel, 1998). The three suggestions described above converge in their attempts to strengthen the judgmental basis of professional practices: informed, independent and intelligent decision-making should be coupled with attention for openness about difficult decisions and

10 O'Neill uses the word 'objectively' in her paper. We, however, prefer the term 'reasonably' in this context, as we believe an assessment of accountability can never be completely objective. 
moral dilemmas, with appreciation of informal knowledge and skills, and with remodeling peer review from repression towards reward driven practice, that is a shift from a 'correction culture' to an 'improvement culture'. They point at the intrinsic features of professionalism, which show that judgment is the key to create new forms of accountability. The question then rises whether these proposals are in danger of backsliding into professional internalism. The answer is that both internal and external accountability are needed. Accountability is not a single entity but a practice that is the collective activity of professionals. From the above it is clear that internal accountability is both the process and outcome of judgmental actions performed by virtuous, skillful and moral professionals. But how should external accountability be conceived? This will be elaborated below.

\subsubsection{External accountability and its virtual voice}

In developing a new conception of external accountability in professional practices we will make use of the discourse perspective on accountability as developed by the Swedish political scientist Erman (Erman, 2006). ${ }^{11}$ In her paper on accountability in the context of human rights, she is searching for ways of making global institutions dealing with human rights more accountable than they are today. Human rights play an important role in safeguarding the freedom of civilians against the power of states and global institutions. They provide the foundation for legal rules and legitimate preconditions for the exercise of power by these states and institutions. The universal and general character of human rights, however, makes it difficult to call these powerful states or organizations to account for the way they handle human rights. Considering the open character of these rights difficulties arise in trying to make these rights operational: how should they be interpreted and shaped in practice? Furthermore, different rights can be at odds with each other or conflict in an individual case. For instance, the freedom of speech can collide with the freedom of religion when people of a religious group are offended by the statements of another group concerning their object of devotion. How can such complex practices be accountable for the framing and shaping of human rights?

Erman discusses three 'logics' that can be used to design the accountability of states and global institutions for the way they handle their obligations concerning human rights (Erman, 2006).

First, in the logic of appropriateness, actors comply with rules and norms being convinced by their moral validity or the procedure, which led up to the norm in question.

Second, in the logic of consequentialism, actors conform to rules or procedures with a view on the result of the actions implicated by these rules procedures. Sanctions and incentives can be used to force actors to comply with rules and norms by manipulating their cost-benefit calculations, in order that they are convinced that compliance is in their own interest. In this logic, actors have considerable freedom for giving their personal interpretation of the rules and principles. In addition, bargaining plays an important role, since the main objective in this logic is to keep all stakeholders satisfied.

Third, in the logic of argumentation, deliberation and learning are the core elements. In the context of argumentation, maximalization of preferences and interests of the actors directly concerned is not the main purpose. Rather, the logic of argumentation concerns investigating and justifying the validity of the claims underlying these preferences and interests. Thus, the logic of argumentation offers actors the possibility to adjust their

11 Erman uses the term external'authority' in stead of external 'accountability. Here, however, we prefer the term 'accountability' in the context of our discussion. 
preferences or their interests to better arguments as possibly brought forward by other actors.

Based on the logic of argumentation, Erman takes a next step, namely to move from, what she calls, a dyadic model of accountability to a triadic model of accountability. The classical, dyadic model of accountability links political decisions towards citizens through representative institutions in the traditional liberal-democratic way. In a triadic model of accountability, actors deliberating about human rights have to give arguments, not only to the other actors but also in relation to a third party, constituting external accountability and constructing a 'virtual' voice for those who do not have the power to raise their voice. That is, deliberating about human rights with other actors by raising validity claims in relation to the externally acknowledged human rights - expressing a common source of shared values and norms. What is of relevance, are not interests and preferences that are antecedent to deliberation but goals, aims and ideals that survive deliberation. Only a triadic model, constructing a virtual voice and a logic of argumentation can yield accountability regarding the complex practices framing, interpreting and shaping human rights in a globalizing world.

\subsubsection{Transfer of Erman's logics model into a framework of accountability in the care for elderly people}

The aim of this section is to develop a new framework of accountability in the practice of health care for the elderly. Erman distinguishes three logics - the descriptive part of her political model -, but simultaneously makes a plea for extending the logic of argumentation in preference to the other two logics - the normative part (Erman, 2006).

It is instructive to shortly describe how accountability looks like according to these three logics in the care for elderly people. First, in the context of medical practice, the logic of appropriateness concerns physicians acting in accordance with legal rules and medicalprofessional guidelines, respecting general ethical principles. These rules and principles have been judged 'appropriate' beforehand. As long as physicians act according to these rules and norms, their actions will also be assessed 'appropriate'. A point of criticism regarding the logic of appropriateness is the rather strict approach in judging the physicians' actions. Little room is left for physicians to deviate from these rules for valid reasons or for providing a personal interpretation of these principles. Accordingly, in this logic, accountability in health care practices is to show that professional actions conform to a priori set of norms and rules and to respond to the official bodies maintaining these norms and rules.

Second, in transferring the logic of consequentialism to medical practice, physicians will strive for pragmatic decisions by way of negotiating and convincing other actors of their viewpoint. In comparison to the logic of appropriateness, generally accepted normative starting points play a more modest role. The logic of consequentialism offers physicians relatively much freedom to act and to decide according to their own discretion. But physicians are also given the opportunity to protect their own, professional interests and preferences, as long as patient (organizations) and other stakeholders are contented. Accordingly, in this logic, accountability in health care practices are regulated by norms and rules which are the outcome of bargaining and negotiating by the involved stakeholders and to respond to official bodies who supervise these negotiation processes.

Third, in the logic of argumentation, physicians are engaged in answering desirability questions regarding the care they need to deliver to patients. They strive for explicating value judgments relating their professional judgments to the empowering of the social 
position of the patients and their families they serve. This concerns investigating and justifying the validity of the claims underlying their preferences and interests. Thus, the logic of argumentation offers professionals and other stakeholders the possibility to adjust their preferences or their interests to better arguments as possibly brought forward by other actors.

These three logics can be distinguished analytically. In practice, the three logics are intermingled and intertwined. Although the first two logics are predominant in current practices of accountability in health care, it should be noted that aspects of the third logic of argumentation are present as well. Substantial arguments about value issues play their role in health care, e.g. in discussions about 'good death 'in euthanasia, 'good care' in palliative care, or 'useless medical care' in end-of-life decisions. However, there is an urgent need to push things much harder and to fully embrace the logic of argumentation and its attendant triadic infrastructure of tying stakeholder networks not only to official bodies and to their own and each other's interests, but also to the 'underlying party' giving it the voice it deserves.

However, it is a virtual voice, because physicians cannot claim to speak on behalf of the older patient. It is not about for whom they speak, but what kind of arguments they use to serve the older patient's situation. The logic of argumentation emphasizes the significance of having insight in which arguments are used by physicians. What is allowed and what is not is on the one hand not completely set up beforehand, but on the other side, not all is left to the discretion of the parties involved. Also, the logic of argumentation offers third parties or stakeholders, such as health care organizations, government, society, insurance companies and patient organizations an opportunity to comment on the arguments used and in that way, influence future decisions. For example, on the level of the physician-patient relationship, the regulations and directions of the management of the hospital he is working in bind a physician. These organizational rules can affect the way care is provided for an individual patient, as certain operations only take place in the morning or the waiting list for an MRI cannot be by-passed. These rules may also affect the relationships on the institutional level and the space for other stakeholders to influence the decision-making process on this level. For example, in the case where an individual patient or patient group believes that the consequences of a decision made on the level of the government or management of an institution is specifically unfair for certain patient groups. There is a two way process between the communicative and interactive level and the institutional level.

Erman's discussion of accountability in the context of human rights, however, cannot be transferred to the practice of taking care of older people without making some reservations. Older patients as a group are not like the people in need for human rights. Older people in western societies are citizens, protected by law and given the opportunity to be involved in political and social decision-making. Their situation is obviously not as harrowing as in the context of human rights worldwide. Nevertheless, there are some analogies as in medical practice much arguments remain invisible, and a voice in politics is not quite the same as a voice in a complex and opaque practice (see Chapter 2).

\subsubsection{Comparison of contract-based and deliberation-based framework of accountability}

By comparing our perspective on trust and accountability with a perspective based on the contract tradition, we are able to provide more insight in what this new framework of accountability entails (see table 1). As a contract between physician and patient and be- 
tween physician and the public is mainly focused on the rules shaping the agreement, the framework of accountability as we see it focuses in addition on the process of deliberation for reaching a decision and ultimately for reaching trust. In our perception, the emphasis is not on controlling physicians, but on reaching a more structurized and transparent decision-making process by enabling them to enter a learning process, which will help them to analyze their actions and decisions, and subsequently learn from their experiences. As a result individual physicians, the medical profession, patients, their families, and all the other stakeholders will be provided with an insight in various forms, in the decisionmaking process. What needs to be addressed specifically when offering transparency in this process is the role of the various medical and non-medical arguments that are used. It is imperative in this context to be truly transparent about the reasons, influences and considerations leading to a decision, which requires physicians to be open about and be receptive to the arguments of possible stakeholders that are influencing the decisionmaking process at the background. For instance, the patient's family who are very skeptical about a patient's ability to recover from an operation at home, or an older patient's general practitioner who has made a strong plea to ensure the treating physicians that only a month ago the patient was still very vital and alert. But it may also concern the physician's role as a partner in a partnership which confronts him with conflicting interests, or the hospital's management pushing him to do as much operations as possible, while he may prefer a more conservative treatment. But also the physician's own personal value judgments which may direct his decision-making in certain directions should be part of the communication process too.

Subsequently, the physician must be able to communicate these arguments with the patient involved. At best, if the patient is willing and able, this can result in a deliberation between patient and physician about the value of the various arguments used. In the context of the care for an older patient, the communication process will be specifically aimed at the desirability question, in which the arguments of the various stakeholders influencing medical decision-making concerning older people are represented. On the institutional level, the deliberation process can result in a discussion on the way the medical profession makes use of the rules and advices of protocols and guidelines, on preventing 'cookbook' health care, and on the consequences of medical actions, e.g. in terms of proportionality and overtreatment or under treatment of older patients as a group.

\begin{tabular}{l|l} 
Accountability in contract-based framework & Accountability in deliberation-based framework \\
\hline Control (external) & Learning process \\
\hline Performance indicators (transparency) & Insight in decision-making process \\
\hline Confidence & Arguments (medical and non-medical; transparency about) \\
\hline Mechanical/procedural & Communication \\
\hline Distrust (exemption from) & Deliberative trust
\end{tabular}

Table 4. Two perspectives on accountability: a contract-based and a deliberation-based framework 
The result is a new framework of accountability as a basis for trust in individual doctors and the medical profession. It concerns accountability to whom, that is to the individual patient and society as a whole, but also accountability for what, that is the arguments used in the decision-making process.

\subsection{Tying together professionalism, trust and accountability}

In this section we will tie the three central issues of this chapter together, that is medical professionalism and the role of value judgments, the Do's and Don'ts in medical decisionmaking, and trust and accountability in health care practices for the elderly.

A central element in the accountability framework as discussed above is the learning and training process of individual physicians and the medical profession as a whole to deal with the requirements resulting from this standard. Reaching trust based on a deliberative accountability, to be achieved on the basis of a discourse structure, requires that physicians get used to gaining and providing insight in their arguments and decisions in this manner. This is not self-evident to many doctors and medical students, since medical culture is strongly guided by an ethos of distinguishing between medical facts on the one hand and 'subjective' opinions on the other hand and the separation of facts and values as used according to the information model of the physician-patient relationship (see Chapters 1 and 2). This ethos is not conducive for a discussion of actual medical practice in which this distinction cannot be made so clearly, and where value judgments play an intrinsic role in the decision-making process (see Chapter 3). It is imperative to start the discourse process on the basis that both types of arguments influence the decision-making process concerning older people, as well as a mix of these and other kinds of arguments (Schermer, 2001). Realizing this is an important first step in reaching accountability. Trust and accountability should not only be embedded in and founded on rules of behavior and the consequences of acts and actions. A medical professional's accountability goes further than judging whether he acts according to the medical professional standards and respects the rights of the patients. In this context the process of reaching the decision, whether both medical and non-medical arguments are dealt with in a transparent manner, is imperative for judging the physician's trustworthiness and accountability. The physician's actions should be embedded in a process of deliberation. What matters is not just the result of the decision-making process or whether it complies with all rules and principles. It is imperative to be able to judge on the basis of which arguments this decision is reached in actual practice (procedural transparency) and to judge the validity of these arguments, from a medical, ethical, legal, ethical, and social perspective (material or substantive transparency).

A new accountability framework leads to a new concept of trust. Both personal and public trust in doctors is generated based on the way the decision-making process takes place and the validity of the arguments used in this process. A triadic model of accountability leads to a triadic model of trust: trust on a relational level in the physician as a representative of the medical profession, in his medical expertise, and in his ability to be open about and communicate about the arguments used to reach a decision. But also, trust on an institutional level in the way the medical profession shapes the responsibilities of physicians and their different roles, as well as trust in the fulfilling of an exemplary and leading role, in enhancing the new accountability framework.

Furthermore, the discourse structure itself presupposes a certain kind of complexity and 
uncertainty in the decision-making process, which is also found in the care for older people. Part of this presupposition is that there can be no fixed criteria or standards to be formulated in advance. In being open and accountable about the arguments used to reach a decision, physicians have to be open about the need to characterize their arguments in the process too. In the communication with patients and with their colleagues and medical professional organizations, the various arguments and their value can be given more shape. What we do not want is a kind of check off list, consisting of different types of arguments to be used and to be accountable for, because that would ignore the purpose of the accountability framework as we see it: openness about, reflection on, and communication about arguments, about the way they are used, in the context of a discussion of the desirability of a treatment or procedure with an older patient. The normative activity we require from physicians is not a punishment or instrument to control the medical profession from the outside, but a means to break open the decision-making process and provide the medical profession an opportunity to prove their trustworthiness. The Do's and Don'ts as discussed above can be helpful in providing some handles to shape this accountability in practice.

\subsection{Final considerations}

Throughout this thesis, we argued that value judgments represent an intrinsic part of the decision-making process for older people. Because of the personal, partly subjective and often hidden nature of these value judgments, they are often considered as not belonging in medical practice. In agreement with the information model, medical professionals generally consider the decision process as a more or less technical process, based on objective evidence from scientific research and previous diagnostics. Values play a role here, but only as part of the assessment of the wishes and desires of the patient and the quality of life after treatment. We want to put value judgments in the spotlight because they do influence the decision-making process and more insight is needed in which way arguments are used, whether they are justified and how they are influencing this process. This need not result in unfair or biased decisions, though, and we therefore do not suggest banning these value judgments from medical practice as medicine is performed by people for people, and therefore naturally involving personal views and opinions. What we do suggest is transparency about and an explicit reflection on these arguments and about the way these value judgments influence the decision-making process.

Accountability about the way these arguments influence the decision-process is a complex and delicate process. The discourse structure of the accountability framework already assumes that it is a process, which is complicated and uncertain. In the context of the care for older people, all arguments potentially relevant and influencing the decision process have to be brought above board. The individual nature of every medical decision and treatment prevents us to formulate a list of justified arguments to be used by physicians in everyday medical practice. However, physicians are obviously still expected to act according to general agreed ethical principles as equality, honesty, beneficence, non-maleficence, informed consent, privacy and the medical professional standard. The discourse structure emphasizes, however, that within the medical, ethical, legal and social boundaries of medical conduct, it cannot be set in advance which arguments medical or non-medical, from which stakeholder, will be decisive. In so far, everything is still open for discussion. In this context, if we want to provide an answer to the question whether good 
care is provided on a relational as well as on an institutional level between physician and society, we need to gain in-depth knowledge about what has been said, how is it been said, in which context etc. Comparable to Checkland's proposal, we do not just want transparency about the information that is given to the patient and which decision has been made, but we need insight in the arguments underneath, resulting in a particular decision (Checkland, Marshall, \& Harrison, 2004). Only in the context of a deliberation process between physician and patient and physicians and health care institutions it can become obvious which argument is justifiable and which argument is not acceptable. We propose a mutual discussion of values and preferences between physician and patient and physicians and health care institutions. Furthermore, this process of mutual provision of insight should not only take place if a patient wishes to leave the decision-making process to the physician, but every time the desirability question is addressed in the context of the care for an older patient. Recognition of the deliberation process between doctor and patient as the starting point opens the door for additional arguments from other stakeholders to play a role in future medical decision-making. These arguments are found on both the relational and the institutional level, for example, patient and physician, society, as well as for-profit industries and opinion leaders and other parties like the government, the patient's family, employers, professional organizations, patient groups representatives and institutional management.

The decision-making process can perhaps best be compared to a quest: which arguments are relevant cannot be decided beforehand, but has to be assessed during the process, in the relationship between physician and patient. The physician's and the medical professional organization's accountability is therefore directed at the quality of the arguments that are made transparent and in how the decision process has taken place. Medical professional responsibility is transformed from a dyadic model, accountability between parties involved, to a triadic model, accountability for the arguments used, as Erman argues (Erman, 2006). We are interested in the doubts, uncertainties, and ambivalences in reaching a decision. Thus, we will gain real insight in what happens in the decision-making process, while not interfering with the medical technical aspects of this process and at the same time being able to form a normative judgment about the trustworthiness of the medical profession.

Throughout the thesis we followed a track of analysis and, increasingly, of construction. Starting from the debate on age rationing and age as a criterion in medical decision-making, we suspected that values and norms regarding old age went into hiding in medical practice. For the strict and wide denial of age-based rationing in health care, both by medical professionals and (the majority of the) medical ethicists, - however much ethically justified or not -, cannot avoid the issue that values regarding old age do play their role. Thus, our first goal was to investigate in-depth whether, and if so, how value judgments creep into the practice of medical decision-making and health care delivery concerning elderly people.

For this reason, we conducted empirical studies of medical practice regarding older people. On the one hand, we interviewed key professionals inside medical practice but also working at strategic sites such as bodies, organizations, and institutes developing guidelines and protocols, and policies at different societal levels, as well as representatives of stakeholders such as representative organizations for older patients or more generally the elderly. On the other hand we investigated various disciplinary fields of medicine and health care by using practice descriptions in an academic hospital setting. 
We are aware of the weaknesses of the used methods, that is a qualitative study has its limitations in terms of coverage and representation of the object studied. The weakness not only concerns the 'quantitative' aspect of our research, but also the 'qualitative' aspect. For we could have chosen more intensive, anthropological methods such as fieldwork and (participatory) observation. Considering the fact that not much research has been done on the role of values in the health care delivery of the elderly, we preferred the methodology we have chosen. For the weakness as indicated above is also its strength. We presumed to find a reasonable balance between covering broad areas of care for the elderly and in-depth analysis of medical practice elucidating the role of values regarding old age in medical decision-making. For this reason we used analytic methods such as grounded theory (see Chapters 2 and 4) as well as analytical models such as the information model (Chapter 1 and 2) and Toulmin's model of practical reasoning (Toulmin, 1958 and Chapter 3). Thus, we combined data-intensive analysis methods and theory, or more precise, model driven analysis methods in our study.

The use of models has a dual structure. On the one hand we use models as a way of describing medical practice, e.g. the information model (Chapter 1 and 2) and Toulmin's model of practical reasoning (Toulmin, 1958 and Chapter 3). Obviously, models have limitative character in describing their object. Like geographical charts models grasp, in an abstract way, only some kind of essential features, e.g. describing the road network in terms of highways and local roadways. But they describe important features. In this respect, we attempted to complement the bottom-up, intensive data analysis methods used in this study with a top-down, model driven analysis.

This use of models does not exclude certain limitations. For example, it might be argued that the information model as presented by Emanuel and Emanuel (Emanuel \& Emanuel, 1992), does not adequately describe medical practice. In fact, Emanuel and Emanuel proposed four models of communication and interaction in the physician-patient relationship. Thus, following this line of argument, four models are needed to describe medical reality - with again all the limitations related to models, that is describing essential features, but leaving out details and local contingencies, such as in the case of geographical charts: road blocks by accidents, road reparation activities, and traffic jamming. However, in our study this is not the case. For the three models - information, interpretation, and deliberation - propose different visions in how to relate medical-technical actions to the values, preferences and desires held by patients, whereas in our study we particularly focused on the role of values and norms held by health care professionals. The fourth, paternalistic model proposes the 'doctor knows best' model, which in fact occurs in practice in various situations of acute medical problems, e.g. in first aid care, emergency medicine and intensive care. However, the paternalistic model is not adequate for our object of study, because then the doctor not only knows but also tells what is best. Our studies show that in practice physicians do not always explicitly tell older patients what they think is best, but that they go into hiding regarding the use of ageist, value-laden arguments. This hiding is disguised in following the information model (see Chapter 2).

The other side of the model coin is that we use the models also in a normative sense. That is as a way of improving transparency and accountability of health care practices. This is not to say that the models do have an open-ended character. For example, Toulmin's model does not prescribe what values should be used, but it uncovers the various layers of medical practical reasoning, proposing how to explicate the values and norms used in practice (Toulmin, 1958). Thus, we increasingly used models in a constructive way that 
is as ways of showing how to generate and shape health care practices in order to build trust. In this respect Chapter 6 is prominent, criticizing the most dominant model of accountability - the contract-based framework - and, by using the work of Erman (Erman, 2006), proposing a new framework of accountability and trust.

Simultaneously, we argued merely to sketch the horizon and contours of building new practices of accountability and trust in health care delivery for the elderly. To really build a practice is not a philosopher's task. It is the task for the health care professionals and involved stakeholders to build their own practices. However, we hope to have shown interesting horizons and avenues for doing so.

Our contrasting way of opposing the contract-based framework and the deliberationbased framework of accountability and trust, might suggest a black-and-white picture. The one is bad the other is good. This is not our view. In proposing a new framework, we do not want to throw away the baby with the bathwater. In several cases and settings, certainly in cases of conflict, we think that informed consent as presumed in the contractbased framework, has its function as a safe harbor, as a reservoir setting of openly dealing with and deciding on infringements of patient's rights, including the rights of the elderly. Thus, we consider both frameworks of accountability and trust as complementary. In addition the Erman model of the three logics presupposes a gradient between the more classical, contract-based and the new deliberation-based frameworks (Erman, 2006).

The Erman logics model provides a three-step procedure for strengthening the position of the elderly in policy making and health care practice (Erman, 2006). In the context of the logic of appropriateness, the first step implies setting laws, rules and regulations, which give the elderly their due. In the context of the logic of consequentialism, the second step implies ways of empowering bodies and organizations representing the elderly, as patients and as citizens, enabling them entering on a foot of equality the bargaining and negotiating processes in stakeholder's - or governance - networks. In the context of the logic of argumentation, the third step implies that the stakeholders take responsibility for the public affairs, exceeding their own interests and preferences, and be accountable for addressing value issues regarding the care for the elderly. Thus, trust in individual physicians and the medical profession as a whole is shaped on the basis of the way they use the arguments from multiple stakeholders trying to influence medical practice and on the appropriateness of these arguments. Physicians are held accountable for the procedural and material/substantive quality of their decisions. Accordingly, in this logic, accountability in health care practices are regulated by the norms and rules which are the outcome of giving good arguments to protect the rights and entitlements of the groups of patients and citizens they serve, and to respond to citizens without a voice. In this respect we propose that the deliberation-based framework on accountability and trust implies a radical and paradigmatic shift: not controlling but shaping practices in health care which may deserve trustworthiness.

\section{Acknowledgments}

We would like to thank Dr. Wybo Dondorp, Prof. Guido de Wert and Prof. Ruud ter Meulen for their valuable and detailed comments on the various versions of this chapter. 


\section{References}

Baier, A. C. (1986). Trust and Antitrust. Ethics, 96, 231-260.

Baier, A. C. (1994). Moral prejudices: essays on ethics. Cambridge: Harvard University Press. Bruhn, J. G. (2005). The Lost Art of the Covenant. Trust as a Commodity in Health Care. The Health Care Manager, 24, 311-319.

Checkland, K., Marshall, M., \& Harrison, S. (2004). Re-thinking accountability: trust versus confidence in medical practice. Quality and Safety in Health Care, 13, 130-135.

Childress, J. F. (1982). Who Should Decide? Paternalism in Health Care. New York/Oxford: Oxford University Press.

Davies, H. T. O., \& Lampel, J. (1998). Trust in performance indicators? Quality in Health Care, 7, 159-162.

Donaldson, L. J. (2001). Professional accountability in a changing world. Postgraduate Medical Journal, 77, 65-67.

Durante, C. (2009). Bioethics in a pluralistic society: bioethical methodology in lieu of moral diversity. Medicine, Health Care and Philosophy, 12, 35-47.

Emanuel, E. J., \& Emanuel, L. L. (1992). Four Models of the Physician-Patient Relationship. Journal of the American Medical Association, 267(16), 2221-2226.

Erman, E. (2006). Rethinking accountability in the context of human rights. Res Publica, 12, 249-275.

Harrison, S., \& Smith, C. (2004). Trust and moral motivation: redundant resources in health and social care? Policy \& Politics, 32(3), 371-386.

Katz, J. (2002). The Silent World of Doctor and Patient. Baltimore: The Johns Hopkins University Press.

Luhmann, K. (1979). Trust and Power. Two works by Niklas Luhmann. Chichester/New York/ Brisbane/Toronto: John Wiley \& Sons.

Netherlands Health Council/Council for Public Health and Health Care. (2006). Confidence in responsible care? The effects of performance indicators and moral issues associated with their use (No. 2006/1). The Hague: Centre for Ethics and Health.

O'Neill, O. (2002). A Question of Trust. Cambridge: Cambridge University Press.

O'Neill, O. (2004). Accountability, trust and informed consent in medical practice and research. Clinical Medicine, 4(3), 269-276.

Pellegrino, E. D., \& Thomasma, D. C. (1993). The virtues in medical practice. New York/Oxford: Oxford University Press.

Peter, E., \& Morgan, K. P. (2000). Explorations of a trust approach for nursing ethics. Nursing Inquiry, 8(3-10).

Pettersen, I. J. (2009). Trust-based or performance-based management-a study of employments contracting in hospitals. International Journal of Health Planning and Management, DOI: 10.1002/hpm.1981.

Power, M. (1997). The audit society: rituals of verification. Oxford: Oxford University Press.

Schermer, M. H. N. (2001). The different faces of autonomy. A study on patient autonomy in ethical theory and hospital practice. Amsterdam: University of Amsterdam.

Slevin, M. L., Plant, H., Lynch, D., Drinkwater, J., \& Gregory, W. M. (1988). Who should measure quality of life, the doctor or the patient? British Journal of Cancer, 57(109-112).

Thompson, L. G., \& Davis, P. M. (2008). Best medical practices in social accountability and continuing professional development: A survey and literature review. Journal of Interprofessional Care, 22, 30-39. 
Toulmin, S. E. (1958). The Uses of Argument. Cambridge: University Press.

Tronto, J. C. (2009). Consent as a grant of authority. A care ethics reading of informed consent. In H. Lindemann, M. Verkerk \& M. U. Walker (Eds.), Naturalized bioethics. Toward a responsible knowing and practice (pp. 182-198). New York: Cambridge University Press.

Zaner, R. M. (1991). The Phenomenon of Trust and the Patient-Physician Relationship. In E. D. Pellegrino, R. M. Veatch \& J. P. Langan (Eds.), Ethics, Trust, and The Professions. Philosophical and Cultural Aspects (pp. 45-67). Washington D.C.: Georgetown University Press. 
Epilogue 
W hen I first started this thesis, I was a lawyer with specific ideas on decisionmaking, medical practice and informed consent. Based on the knowledge I had gathered during my studies, I had a clear-cut idea on how I would be fighting for the rights of older people in health care and how I would be improving their social position. On my travel a map, called informed consent, would direct me, providing a solid framework for advocating the rights of older people.

Now, a few years later, at the end of my travel, my perspective has changed profoundly. I still believe in informed consent as a valuable starting point and beacon for shaping medical practice and the communication between physician and patient. But there is so much more. So many parties influencing everyday medical practice in several ways and on various levels, so many varieties in the utilization of the rules of informed consent, numerous dilemma's in selecting and communicating treatment options, so many ways of respecting the older patient and countless manners of providing good care. In my teaching work, I encountered many cases of routine high tech medical interventions, including extensive surgery, on patients deep into their eighties and sometimes nineties. One of the most important lessons for me as a freshly graduated lawyer was that not all people have to be rescued and not all doctors treat older patients badly. Medical practice concerning older people is not either black or white, but instead can best be described as consisting of many shades of grey. It is difficult to judge a practice as right or wrong.

This obviously does not mean that there is nothing left to say about this practice. We need to remain aware of the still existing risk of evolving into a practice in which the older patient is not respected and his rights are being violated or in which an older patient is treated at the will of the individual doctor. The framework we developed, concerning accountability and trust, is a valuable tool in this context. An important role in this framework is reserved for the professionals involved in the care for older people. This thesis is written with several groups of professionals in mind, working with older people or involved in their care. For instance, physicians and other health care workers, but also patients, managers, medical professional organizations, representative organizations for older people, insurers, and policy makers. All these people are the stakeholders that are needed for building a medical practice based on trust and the framework of accountability as presented here in this thesis. Now, it is their move.

So, what does this mean, this changed perspective on informed consent? In this context the distinction between analogous reality and digital abstraction, as made by the Dutch sociologist of law, Schuyt (Schuyt, 1982), is relevant. By talking about informed consent as the patient's right and the physician's duty, by focusing on the rules and boundaries as provided by law, and by only concentrating on informed consent as the outcome of a process, to be judged as right or wrong in specific cases on the level of the physicianpatient relationship, informed consent is transformed into a digital abstraction, and thus the subtle nuances of reality of, in our case the decision-making process concerning older people, are lost. To be sure, at a certain level this digital abstraction is required and should be maintained, for example when conflicts arise concerning the information and decisionmaking process between physician and patient.

But, the decision-making process is so much more than mere informed consent. To make use of the roads that have been mapped in this thesis, to employ the opportunities provided by these roads, a change in the perspective on informed consent is needed, from a digital abstraction to an analogous reality. Thus, new medical decision-making practices 
can be built and shaped, based on trust and accountability of physicians. Accountability for the medical and non-medical arguments used in the decision process, for the way these arguments are communicated, and for the outcome, the decision that has been made. Thus, the building blocks for shaping this practice are the discussions on what it means to provide good care to older people (what arguments play a role here and how are they communicated) and on being transparent about the various value judgments from the diverse stakeholders influencing the decision process. Subsequently, trust in doctors is shaped based on the way physicians use the building blocks needed for building and shaping an accountable practice.

The prime focus of this study is the role and impact of value laden judgments on the decisions being made in medical practice concerning older people. These judgments influence the decision-making process from the onset. This position of value judgments is generally not recognized as such by medical professionals. According to doctors, the decision-making process concerning older people is primarily based on objective evidence gathered based on medical research. After the objective evidence has been individualized according to the subjective needs of the patients, values and value laden arguments come into play by way of the wishes and desires of the patient concerning treatment, non-treatment, fears and anxieties, and quality of life. This is, however, a too simplistic perspective on how the decision-making process really takes place, and too one-dimensional regarding which arguments are influencing this process at what time.

In this context, informed consent is also one of the building blocks for shaping this practice. What needs to be accomplished is that physicians have the knowledge, motivation and competencies required for reaching a decision based on the rules of informed consent, and in addition reflect on why informed consent is important and valuable. It is not enough if physicians follow the rules of informed consent because everybody knows that is what should be done. It is not satisfactory if physicians inform patients because that is considered to be good practice, turning informed consent into a mere constraint for medical decisions: as long as they comply with informed consent, they are all right.

What is aspired in this thesis is that physicians realize that they cannot only focus on the outcome of the decision-making process in terms of informed consent. Before this final step is reached, a practice is shaped in which informed consent is one of the building blocks. Physicians need to take an active role in shaping a decision-making practice in which they are held accountable for the way they communicate the value-laden arguments in the decision-making process with their patients. In this practice, the process, the prerequisites regarding the process on both the institutional and relational level, and the outcome form important building blocks, in addition to informed consent.

Thus, a practice is shaped concerning the care for older people in which the analogous reality, that is the uncertainties and complexities indentifying this care, is not lost to a digital abstraction of rules and regulations. What is aspired is that physicians consider the arguments for judging informed consent as valuable. By holding medical professionals accountable for the way they communicate the value laden arguments in the decision-making process with their patients, informed consent becomes more than a simple outcome. What has been showed in this thesis is that for the medical profession to demonstrate itself as trustworthy, consisting of trustworthy professionals, it needs to take action. First, it has to acknowledge that value judgments influence the decision-making process from the start. Second, these value-laden arguments have many sources. That is, it is not just the patient bringing these arguments to the fore, but physicians themselves also are guided, 
knowingly and unknowingly, by these judgments from various stakeholders on both the relational and institutional level such as managers, insurance companies, and supervising authority bodies and second opinion arrangements. Third, physicians have to reflect on these personal judgments and whether they can be judged as 'good' arguments. Subsequently, physicians are held accountable for communicating these judgments. By being transparent about the various arguments influencing the decision-making process, patients and other stakeholders are given the opportunity to judge whether the arguments used are acceptable.

Finally, the Erman logics model provides a three-step procedure for strengthening the position of older people in policymaking and health care practice. The first step involves providing safeguards for respecting the rights of older people (Erman, 2006). This implies setting laws, rules and regulations, which give the elderly their due. The second step involves building a structure on this rules-based foundation in which institutional mechanisms, such as organizations representing the elderly, supervising bodies and guideline developers, are embodied. The interests of the older patient need to be built into these institutional arrangements, thus protecting these interests in the negotiation and bargaining process. Based on these first two steps, we have now given shape to the legal en institutional preconditions for strengthening the position of older people. However, one final step has to be taken, as the preconditions we have identified have to be filled in with what actually happens in medical practice concerning older people, on the relational level. In this context, the third step implies that the stakeholders, physicians, insurers, patient organizations, policy makers, etc, take responsibility and be accountable for addressing value issues regarding the care for older patients. On this level, the stakeholders involved have to be aware of the role and impact of the value judgments influencing their discretionary freedom and their and other stakeholder's actions in each of the three steps, thus influencing the care provided to older people. For, every direct relationship between each of the stakeholders on both levels is imbued with value laden arguments.

So, what are the consequences of these three steps for the relationship and communication process between physician and older patient? In this relationship, the patient's and the physician's values play their part, but also the value laden arguments of the stakeholders involved, underlying their guidelines, protocols, instructions, or policies. But also, these arguments have their impact on each of the previous steps, as they influence the stakeholders' interest and may change the policies and regulations on a national, regional or local level. In other words, although we distinguish three separate steps, each step is linked to the other in two directions, influencing each other back and forth. Thus, the significance of preserving the deliberation process becomes clear: it cannot be set in advance which arguments can be considered appropriate and justified, but has to be judged every time a decision is made.

If we assume that in the care for older people, these three steps are identified and respected, then we will be able to trust individual physicians and the medical profession as a whole, dependent on the way they use the arguments from multiple stakeholders trying to influence medical practice and on the appropriateness of these arguments. Physicians are held accountable for the procedural and substantive quality of their decisions. Accordingly, accountability in health care practices is regulated by the norms and rules, which are the outcome of giving good arguments to protect the rights and entitlements of older patients, in other words, by giving the elderly a virtual voice: physicians are held accountable for the kind of arguments they use to serve the older patient's situation. In this respect, 
we propose that the deliberation-based framework on accountability and trust implies a radical and paradigmatic shift: not controlling but shaping practices in health care, which may deserve trustworthiness. Thus, we will move from a practice of setting limits to shaping practices in the care for older people.

\section{References}

Erman, E. (2006). Rethinking accountability in the context of human rights. Res Publica, 12, 249-275.

Schuyt, C. J. M. (1982). Ongergeld heden: naar een theorie van wetgeving in de verzorgingsstaat. Inaugurele rede Rijksuniversiteit Leiden. Alphen aan de Rijn: Samsom. 


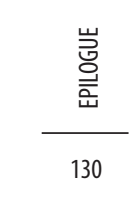


Summary 
T his thesis has to be viewed against the background of the debate on the role of age in medical decision-making as it was initiated in the 1980's. The focus in this debate is provided by the question whether it is justified to ration care based on age. Although the various proposals in this context never really made headway on a policy level, some of the questions that were raised in this discussion, are still relevant today. Three issues are at stake. First, the role of scarcity in the provision of care for older people. Second, the influence and consequences of ageism in the care for older people. And third, what does it mean to provide good care to older people? In this thesis we will address these issues. It is, however not our purpose to set limits, but to promote elderly sensitive medicine, including an awareness that more health care is not always better. Also, we want to place our discussion on the societal level, but again not in the context of setting limits. To be able to do that, we will develop a framework on accountability and trust in the care for older people.

\section{Chapter 1}

In the first chapter, the debate on the role of age forms the starting point for further analysis. The debate on the role of age has resulted in two established views on medical decision-making for older people. First, age-based-rationing is generally rejected as a tool in deciding what care to provide to older people, both at the policy level and in the consultation room of the physician. Secondly, age can only be accepted as part of a strictly medical-technical assessment for decision-making on the level of the physicianpatient relationship. Only if age serves as a true medical criterion, physicians are allowed to use age as part of the decision-making process concerning the delivery of care to older people. However, this starting point is surrounded by many uncertainties and continuously raises many questions and discussions. The basic issue is, what is a medical or clinical criterion and how can age be part of a strictly technical assessment? Does this imply that value judgments regarding old age are excluded from medical decision-making? And if not, how do value judgments play their role and how can these be accounted for? This paper aims to address these basic views and to elucidate how views on old age work out in health care practice.

We performed interviews with key professionals in clinical practice and policy making in health care to get a deeper understanding of their perspectives on the practice of medical decision-making for older people. By way of an analysis of the interviews, three ways in which the various respondents discuss this issue are identified: age as a criterion: yes or no, age-based-rationing and age in the clinical encounter. The respondents point out that age and age-based-rationing still influence the actions of professionals working with older people, albeit in an unaccounted way. This raises concern about how patients and society should (re)consider the trust they put upon physicians in this context? To answer this question, a closer look at medical practice is needed. The interviewed experts provide valuable insights in the complex ways age plays its role in medical practice. A plea is made for further research into the dynamics and complexities of the decision-making process concerning older people.

\section{Chapter 2}

This chapter focuses on the interaction between physicians and older patients against the background of informed consent. Based on the analysis of medical practice cases discussed in clinical ethics meetings in an Academic Hospital setting we identified six 
role patterns concerning the older patient in the physician-patient relationship. These patterns represent a gradient varying from physicians respecting the patient's right of autonomy to examples in which this right is bypassed by physicians and/or the older patient's family. In this respect, we found significant variations in dealing with the principle of informed consent. Physicians should find ways to deal with the tension between values, e.g. respecting patient rights and fulfilling professional responsibility, e.g. dealing with specific medical characteristics of older patients and technical routines. In this context, we consider the deliberative model as described by Emanuel and Emanuel to be more helpful here than the informative model, which supports the view of age as a strictly medical criterion in physician's decision-making. To be able to trust physicians in taking care of older people transparency in the criteria and arguments influencing communication, informed consent and delivery of care in medical practice, is needed.

\section{Chapter 3}

The question whether old age should or should not play a role in medical decision-making regarding the elderly patient is regularly debated in ethics and medicine. In this chapter we investigate how exactly age influences the decision making process. To explore the normative argumentation in the decisions regarding an elderly patient we make use of the argumentation model advanced by Toulmin. By expanding the model in order to identify normative components in the argumentation process, it is possible to analyse the way age related value judgments influence the medical decision-making process. We apply the model to practice descriptions made by medical students after they attended consultations and meetings in medical practice during their clinical training. Our results show the pervasive character of age related value judgments. They influence the physician's decision in several ways and at several points in the decision-making process. Such explicit value judgments were not exclusively used for arguments against further diagnosis or treatment of older patients. We found no systematic 'ageist' pattern in the clinical decisions by physicians. Since age plays such an important, yet hidden role in the medical decision-making process, we make a plea for revealing such normative argumentation in order to gain transparency and accountability in this process. An explicit deliberative approach will make the medical decision-making process more transparent and improve the physician-patient relationship, creating confidence and trust, which are at the heart of medical practice.

\section{Chapter 4}

This chapter deals with the issue of public trust in decisions made by individual physicians, concerning older people, as perceived by various key professionals. While trust is a basic element in our health care service, it is at the same time a difficult phenomenon to conceptualize. This paper tries to contribute to a better understanding of what trust in medical practice entails, and what are the necessary conditions for a society to put trust in the medical profession. The focus is on care for older people under the condition of scarcity in health care resources. Our study has a qualitative design consisting of semistructured in-depth interviews with 24 key professionals focusing on decision-makers and those in line of professionally organizing or influencing the decision-making process. We found roughly three categories of trust: distrust, trust and qualified trust. In each category, we found different reasons to give or withhold trust and different views on how far the discretionary power of doctors should go. We recommend promoting trust by addressing 
the criteria or limits brought forward in the qualified trust category. The preconditions as identified in the qualified trust section provide the boundaries and marking points between which physicians have to move regarding the care for older people. The qualifications provide us insight in where and how to invest in trust under these and under different circumstances. An important conclusion is that trust is never finished: trust needs to be gained and negotiated in a continuous process of action and interaction.

\section{Chapter 5 and 6}

Chapter 5 and 6 have to be viewed as part of a diptych: In Chapter 5, preparatory activities are undertaken and insights are gathered by way of presenting important building blocks for shaping new medical practices in health care delivery for the elderly. These activities, insights and building blocks are needed to enable us to take the next step in Chapter 6, namely building a new framework based on accountability and trust in the care for older people.

In the previous chapters, we have discussed the role of age and age-based-rationing in the decision-making and communication process concerning older people. The role and impact of value judgments and the consequences for trust in the medical professional form a Leitmotiv in these discussions. An important question returning in each chapter is what the consequences are for the patient's and public trust in medical professionals. What matters here is the distinction we made between physicians performing medical acts, in a comprehensive sense of the word medical, and physicians performing medical technical acts. The latter consists of those actions physicians themselves usually consider medical acts: collecting data about symptoms, signs and condition of the patient (anamnesis and physical examination), the construing of the (differential) diagnosis and the provision of therapy or prevention (Chapter 1): a rather objective process of gathering evidence and providing treatment. However, medical practice is not only about these technical assessments of the patient's condition. Various normative, value laden judgments play, and should play a role in medical decision-making. Medical technical acts are therefore one version of medical acts. In chapter 5, we will take a closer look on the role and impact of the value laden judgments in the decision-making process concerning older people. In this context, we will use the call for more accountable and trustworthy professionals as a starting point. First, we will take a closer look on what is discussed in the context of trust by medical professional organizations in the United Kingdom, USA, Canada, and the Netherlands. Today, the charters on medical professionalism of the national medical associations attempt to define what patients and the public can expect from doctors. Also they define their focus in the context of both patient and public trust and accountability. Subsequently, we will provide a more detailed description of what we believe trust and accountability entail in the context of the care for older patients. We conceptualize this as building new practices, for we will present a set of important building blocks in the form of what medical professional should (Do's) and what they should not do (Don'ts). To illustrate this practice building endeavor we will use the model of the Royal Dutch Medical Association (KNMG) concerning the physician's roles and responsibilities.

In chapter 6 we will further go into what the influence and role of value judgments mean for patients' and public trust in doctors. We will provide a detailed description of a new framework of accountability of physicians as a foundation for trust in physicians. Here also our focus will be on the decision-making for older patients. 
Samenvatting 


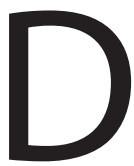

it proefschrift moet worden gezien tegen de achtergrond van het debat over de rol van leeftijd in medische besluitvorming, dat is begonnen in de jaren tachtig van de vorige eeuw. De kern van het debat is de vraag of het gerechtvaardigd is om zorg te rantsoeneren op basis van leeftijd. Hoewel de verschillende voorstellen in dit verband nooit echt voet aan de grond hebben gekregen op politiek niveau, is een aantal vragen uit deze discussie nog steeds relevant.

Driekwestiesstaan ophetspel.In deeersteplaats, de rolvanschaarstein hetzorgaanbodvoor ouderen. In de tweede plaats, de invloed en gevolgen van leeftijdsdiscriminatie op de zorg voor ouderen. En in de derde plaats, wat betekent het om goedezorg te bieden aan ouderen? In dit proefschrift zullen we deze kwesties verder onderzoeken. Ons doel is echter niet het stellen van grenzen, maar het bevorderen van een ouderen-gevoelige-geneeskunde, waaronder we mede verstaan het bewustzijn dat meer gezondheidszorg niet altijd beter is. Ook willen we onze discussie op een maatschappelijk niveau plaatsen, maar ook hier wederom niet in de context van het stellen van grenzen. Om dat te kunnen doen, zullen we een kader ontwikkelen ten aanzien van accountability en trust in de zorg voor ouderen.

\section{Hoofdstuk 1}

In het eerste hoofdstuk vormt het zojuist genoemde debat over de rol van leeftijd het uitgangspunt voor verdere analyse. Het debat over de rol van leeftijd heeft geleid tot het ontstaan van twee standaard opvattingen over medische besluitvorming voor oudere mensen. In de eerste plaats, wordt rantsoenering op basis van leeftijd in het algemeen afgewezen als een hulpmiddel bij de beslissing welke zorg te bieden aan ouderen, zowel op beleidsniveau als in de spreekkamer van de arts. In de tweede plaats, is leeftijd alleen aanvaardbaar als onderdeel van een strikt medisch-technische beoordeling in de besluitvorming op het niveau van de arts-patiënt relatie. Alleen indien de leeftijd fungeert als een puur medisch criterium, is het toegestaan om leeftijd te gebruiken als onderdeel van de besluitvorming met betrekking tot oudere patiënten. Echter, dit uitgangspunt kent vele onzekerheden en roept voortdurend vele vragen en discussies op. De fundamentele vraag is wat een medisch of klinisch criterium is en hoe leeftijd deel kan uitmaken van een strikt technische beoordeling. Betekent dit dat waardeoordelen over ouderdom zijn uitgesloten van medische besluitvorming? En zo nee, hoe spelen waardeoordelen dan hun rol en hoe kunnen deze worden verantwoord? Dit hoofdstuk heeft tot doel deze cruciale standpunten nader te onderzoeken en te verduidelijken hoe opvattingen over ouderdom hun uitwerking vinden in de praktijk van de gezondheidszorg.

Om inzicht te krijgen in de opvattingen van professionals in een sleutelrol in de klinische praktijk, hebben we een aantal interviews afgenomen. We hebben hen gevraagd naar hun opvattingen op het gebied van de klinische praktijk en de beleidsontwikkeling in de gezondheidszorg ten aanzien van de praktijk van medische besluitvorming bij oudere mensen. Op basis van de analyse van de interviews, hebben we drie manieren waarop respondenten dit onderwerp bespreken, geïdentificeerd: leeftijd als criterium; rantsoenering op basis van leeftijd; leeftijd in de spreekkamer. De respondenten wijzen erop dat leeftijd en rantsoenering op basis van leeftijd nog steeds van invloed zijn op de acties van professionals die werken met ouderen, zij het zonder dat ze daarvoor accountable zijn. Dit leidt tot bezorgdheid over hoe patiënten en de samenleving over het vertrouwen in artsen moeten denken. Om deze vraag te beantwoorden, is een kijkje in de medische praktijk nodig. De ondervraagde experts geven waardevolle inzichten in de complexe manieren waarop leeftijd een rol speelt in de medische praktijk. 
We pleiten voor verder onderzoek naar de dynamiek en complexiteit van de besluitvorming met betrekking tot oudere mensen.

\section{Hoofdstuk 2}

Dit hoofdstuk richt zich op de interactie tussen artsen en oudere patiënten tegen de achtergrond van informed consent. Op basis van de analyse van casus uit de medische praktijk zoals besproken in klinische ethiek bijeenkomsten in een academisch ziekenhuis, zijn zes patronen geïdentificeerd met betrekking tot de rol van de oudere patiënt in de arts-patiënt relatie. Deze patronen vormen een gradiënt variërend van artsen die het recht op autonomie van de oudere patiënt respecteren, tot voorbeelden waarbij dit recht wordt genegeerd door artsen en / of de familie van de oudere patiënt. In dit opzicht vonden we significante verschillen in de manier van omgaan met het beginsel van informed consent. Artsen moeten een manier vinden om te gaan met de spanning tussen waarden en professioneel verantwoordelijk handelen. Een voorbeeld van een dergelijke spanning is de eerbiediging van de rechten van patiënten aan de ene kant en rekening houden met specifieke medische kenmerken van oudere patiënten en technische vaardigheden aan de andere kant. In deze context, beschouwen we het deliberatieve of overleg model zoals beschreven door Emanuel en Emanuel beter bruikbaar dan het informatieve model, waarin de visie dat leeftijd als een strikt medisch criterium de besluitvorming van de arts kan beïnvloeden, wordt onderschreven. Om artsen te kunnen vertrouwen met betrekking tot de zorg aan ouderen, hebben we behoefte aan transparantie in de criteria en argumenten die de communicatie, het informed consentproces en de levering van zorg in de medische praktijk beïnvloeden.

\section{Hoofdstuk 3}

De vraag of ouderdom wel of niet een rol mag spelen in de medische besluitvorming met betrekking tot de oudere patiënt, wordt regelmatig bediscussieerd in de ethiek en de geneeskunde. In dit hoofdstuk onderzoeken we hoe leeftijd precies van invloed is op de besluitvorming. Om de normatieve argumentatie in de besluitvorming met betrekking tot een oudere patiënt te verkennen, maken we gebruik van het argumentatiemodel van Toulmin. Door het model uit te breiden, kunnen we de normatieve componenten identificeren in het argumentatieproces. Op deze manier is het mogelijk om te analyseren op welke manier leeftijdsgebonden waardeoordelen het medische besluitvormingsproces beïnvloeden. We passen het model toe op de casusbeschrijvingen van medische studenten op basis van de praktijkervaring die ze hebben opgedaan tijdens hun opleiding. Onze resultaten tonen het doordringende karakter van leeftijdsgebonden waardeoordelen aan. Ze beïnvloeden de beslissingen van de arts op verschillende manieren en op verschillende punten in het besluitvormingsproces. Deze expliciete waardeoordelen worden niet uitsluitend gebruikt als argumenten tegen verdere diagnose of behandeling van oudere patiënten. We vonden geen systematisch'ageist' patroon in de klinische beslissingen door artsen. Omdat leeftijd een zo belangrijke, maar verborgen rol speelt in de medische besluitvorming, houden we een pleidooi voor het openbaar maken van dergelijke normatieve argumentatiepatronen. Op deze manier willen we meer transparantie en accountability krijgen in het besluitvormingproces. Een benadering volgens het overlegmodel zal de medische besluitvorming transparanter maken en de arts-patiënt relatie verbeteren, hetgeen leidt tot vertrouwen, en juist vertrouwen vormt het hart van de medische praktijk. 


\section{Hoofdstuk 4}

In dit hoofdstuk behandelen we de kwestie van het maatschappelijke vertrouwen in de beslissingen van individuele artsen met betrekking tot oudere mensen, zoals geïnterpreteerd door verschillende professionals in een sleutelrol in de klinische praktijk. Hoewel vertrouwen een basiselement is in onze gezondheidszorg, is het tegelijkertijd een moeilijk fenomeen om onder woorden te brengen. Dit hoofdstuk probeert bij te dragen aan een beter begrip van wat het vertrouwen in de medische praktijk inhoudt en wat de noodzakelijke voorwaarden zijn voor een samenleving om de medische professie te kunnen vertrouwen. De nadruk ligt op zorg voor ouderen tegen de achtergrond van de schaarste aan middelen in de gezondheidszorg. Ons onderzoek heeft een kwalitatieve opzet, bestaande uit semigestructureerde diepte-interviews met 24 professionals, met de nadruk op besluitvormers en professionals die het besluitvormingsproces organiseren of beïnvloeden. We hebben bij benadering drie categorieën van vertrouwen geïdentificeerd: wantrouwen, vertrouwen en gekwalificeerd vertrouwen. In elke categorie hebben we verschillende redenen gevonden voor het geven of weigeren van vertrouwen en verschillende visies op hoe ver de discretionaire bevoegdheid van artsen moet gaan.

Wij adviseren het vertrouwen te bevorderen door de criteria of grenzen zoals naar voren gebracht in de gekwalificeerd vertrouwencategorie, als uitgangspunt te nemen. De voorwaarden zoals aangegeven in deze categorie, bieden de grenzen en de markeringspunten waartussen de artsen zich moeten bewegen met betrekking tot de zorg aan ouderen. De kwalificaties geven ons inzicht in waar en hoe te investeren in vertrouwen onder verschillende omstandigheden. Een belangrijke conclusie is, dat vertrouwen nooit voltooid is: vertrouwen moet worden verdiend en onderhandeld in een continu proces van actie en interactie.

\section{Hoofdstuk 5 en 6}

Hoofdstuk 5 en 6 vormen onderdelen van een tweeluik: in hoofdstuk 5 worden voorbereidende activiteiten verricht en inzichten vergaard door middel van de introductie van belangrijke bouwstenen voor het vormen van nieuwe medische praktijken in de gezondheidszorg voor ouderen. Deze activiteiten, inzichten en bouwstenen zijn nodig om ons in staat stellen om de volgende stap te nemen in hoofdstuk 6, namelijk de bouw van een nieuw kader op basis van accountability en trust in de zorg voor ouderen. In de voorgaande hoofdstukken hebben we gesproken over de rol van leeftijd en rantsoenering op basis van leeftijd in het besluitvormings- en communicatieproces met betrekking tot oudere mensen. De rol en impact van waardeoordelen en de gevolgen voor het vertrouwen in de medische professional vormen een rode draad in deze discussies. Een belangrijke vraag die in elk hoofdstuk terugkomt, is wat de gevolgen zijn voor het vertrouwen van de patiënt en de maatschappij in de medische professionals. Waar het hier om gaat, is het onderscheid dat we hebben gemaakt tussen de artsen die medische handelingen uitvoeren, in de uitgebreide zin van het woord medisch, en artsen die medisch-technische handelingen uitvoeren. Deze laatste bestaan uit acties die artsen zelf meestal als medische handeling benoemen. Zij verstaan hieronder het verzamelen van gegevens over symptomen, aanwijzingen en conditie van de patiënt (anamnese en lichamelijk onderzoek), het construeren van de (differentiaal) diagnose en het aanbieden van therapie of preventie (Hoofdstuk 1). Dit is een tamelijk objectief proces van verzamelen van bewijzen en het bieden van een behandeling. Maar, in de medische praktijk draait het niet alleen om deze technische beoordeling van de toestand van de patiënt. Verschillende normatieve beslis- 
singen, op basis van waardeoordelen spelen een rol, en moeten een rol spelen in de medische besluitvorming. Medisch-technische handelingen zijn dus slechts één versie van medische handelingen. In hoofdstuk 5, onderwerpen we de rol en impact van de waardegeladen beslissingen in het besluitvormingsproces met betrekking tot oudere mensen aan een nadere beschouwing. In deze context, nemen we als uitgangspunt de vraag naar professionals die meer accountable en betrouwbaar zijn. Eerst nemen we een kijkje bij wat betreft vertrouwen naar voren wordt gebracht door medische professionele organisaties in het Verenigd Koninkrijk, de Verenigde Staten, Canada en Nederland. De huidige charters over medische professionaliteit van de nationale medische verenigingen proberen te definiëren wat de patiënten en de maatschappij kunnen verwachten van artsen. Daarnaast geven ze bijzondere aandacht aan zowel het vertrouwen van patiënt en samenleving, als aan de verantwoordingsplicht. Vervolgens zullen we een meer gedetailleerde beschrijving geven van wat volgens ons het vertrouwen en de accountability omvatten in het kader van de zorg voor oudere patiënten. We omschrijven dit als het bouwen van nieuwe praktijken, waarvoor wij een aantal belangrijke bouwstenen leveren in de vorm van wat de medische professional moet (Do's) en wat zij niet moeten doen (Don'ts). We nemen het model van de Koninklijke Nederlandse Maatschappij tot bevordering der Geneeskunst (KNMG)over de rollen en verantwoordelijkheden van de arts als illustratie voor onze bouwactiviteiten.

In hoofdstuk 6 zullen we verder ingaan op wat de invloed en de rol van waardeoordelen betekenen voor het vertrouwen van patiënten en van de maatschappij in artsen. Wij bieden een gedetailleerde beschrijving van een nieuw kader van accountability van artsen als een basis voor het vertrouwen in artsen. Ook hier zal onze focus liggen op de besluitvorming voor oudere patiënten. 
$\frac{\underline{\underline{\underline{\underline{y}}}}}{10}$ 


\section{Dankwoord}


n nu maar hopen, dat ik niemand vergeet.

ledereen die zowel Rob Houtepen als mij, of alleen Rob kent, zal niet verbaasd zijn dat hij als eerste wordt genoemd in dit dankwoord. Rob is de meest oprechte persoon die ik ken. Rob, je bent uniek in je soort: neurotisch, echt geïnteresseerd, integer en zeer behulpzaam. Jouw enthousiasme, kennis, intelligentie, eerlijkheid en betrouwbaarheid zijn de echte building blocks van dit proefschrift. Voor mij, ben je de ruggengraat van de vakgroep. En voor de DE koffiecorner, ben je de omzet van de Heavenly Hazels met slagroom.

Rein Vos is bij mijn onderzoek betrokken geraakt door me ervan te overtuigen dat het de moeite waard was om er mee door te gaan. De opdrachten die ik voor jou toen heb moeten maken, Rein, hebben me ontzettend veel over mezelf geleerd. lets waarvoor ik je nog steeds zeer dankbaar ben. Van het vertrouwen dat jij in mij uitsprak, pluk ik nog steeds de vruchten. Je nuchtere, maar vaak ook passionele benadering en eerlijkheid, zijn verfrissend en motiverend. Je was er iedere keer als ik je nodig had, je bracht me iedere keer een stap verder en vooral bracht je ook de rust die onmisbaar was om het project succesvol af te ronden

Rob en Rein, ik kan met volle overtuiging zeggen, dat dit proefschrift er niet was geweest als ik jullie niet had gehad. Ontzettend veel dank daarvoor. Voor mij zijn en blijven jullie ontzettend waardevol.

Ruud ter Meulen is mijn promotor van het eerste uur. Eerst vanuit Maastricht en later op afstand vanuit Bristol. Het contact werd toen minder intensief, maar in noodgevallen bleef je bereikbaar. Ik ben je nog steeds dankbaar voor de kans die je me hebt gegeven.

Ook Trudy van der Weijden is al vanaf het begin bij het project betrokken. Van haar kwaliteiten als arts en onderzoeker heb ik dankbaar gebruik kunnen maken. We blijven elkaar op onverwachte momenten tegen het lijf lopen en ik vind het heerlijk om dan even een stand-van-zaken te geven en snel over te gaan op het onderwerp kinderen. Ik hoop je nog vaak tegen te komen.

Wybo Dondorp en Guido de Wert, jullie zijn voor mij een apart tweetal binnen de vakgroep en daarom noem ik jullie hier samen. Wybo, je wist altijd precies de vinger op de zere plek te leggen en hebt me daardoor vaak gedwongen net even wat langer over bepaalde dingen na te denken, waardoor de teksten waar je bij betrokken bent geweest gewoon beter werden, net dat beetje meer kregen. Guido, jou ken ik al lang: van IGE' er tot uiteindelijk vakgroepvoorzitter. Aan het einde van het traject ben je bijzonder waardevol voor me geweest toen de omstandigheden daarom vroegen, zowel op inhoudelijk als praktisch gebied. Dank daarvoor.

Ron Berghmans, mijn tweede vader hier op de vakgroep. Nuchter, betrokken en met een hondje. Ik mis je hier op de vakgroep. Onze klaagzangen over de artsen van tegenwoordig, over de kassameisjes bij de Plus, over het slechte weer en gewoon over de lucht, de mensheid, werken en collega's in het algemeen. Bedankt ook voor je (soms iets te vergaande) relativeringsvermogen. Ik houd je in de gaten vanuit mijn keukenraam.

Ireen Proot, we zitten al lang niet meer naast elkaar op de gang, maar de basis was gelukkig al gelegd. Je onmetelijk positieve instelling, nuchterheid en analytisch vermogen heb ik altijd bewonderd. De steun en vooral ook het vertrouwen dat je me in dit hele proces hebt gegeven, zijn me dierbaar. Wellicht een beetje uit het oog, maar zeker niet uit het hart.

Patricia Jaspers en Bart Penders, it's the end of an era: ik ben klaar! Waar moeten we het nu 
straks over hebben? Het moge duidelijk zijn dat jullie, als kamergenoten, een belangrijke rol hebben gespeeld in dit hele proces. Bart, je haalde me al snel in en ook nog op een manier die menigeen versteld heeft doen staan. Ik heb zeer dankbaar gebruik gemaakt van je praktische en soms strategische tips om dit hele project tot een goed einde te brengen. Patricia, we hebben heel veel gedeeld de afgelopen jaren. Frustraties en promotieperikelen, maar ook en vooral mooie en geheime wensen en plannen. We delen zoveel meer dan enkel een kamer. Door je carrièremove ben ik al min of meer gedwongen om te wennen aan een kamer zonder jou, maar ik hoop dat we elkaar nog lang en vaak zullen tegenkomen.

Halime Celik, Vivianne Bauer en Christi Nierse, de bewoners van de 'troostkamer'. Jullie zijn stuk voor stuk lieve en warme mensen die altijd voor me klaar hebben gestaan. Halime, nog steeds als ik je zie of spreek, is het een drukte van jewelste. Van jou heb ik geleerd om vasthoudend te zijn. Ik mis onze bijkletsmomenten en het uitwisselen van de ervaringsverhalen met betrekking tot de kinderen. Ons contact is minder intensief, maar zal niet verloren gaan.

Vivianne, met je gevoel voor mode en stijl. Een frisse wind hier op de vakgroep. Heel erg lang ken ik je eigenlijk nog niet, maar ik ben je in die korte tijd enorm gaan waarderen om je mooie karakter en warme persoonlijkheid.

Christi, jou ken ik het langst. Je begon als student-assistent en kwam bij mij op de kamer terecht. Mijn moedergevoelens kon ik vervolgens meteen al in praktijk brengen (wat overigens meer aan mij lag dan aan jou). En ik heb nog steeds het gevoel dat ik je moet beschermen. Ik vind je een heerlijk persoon, grappig, nuchter en lekker zelfstandig. We moeten elkaar vaker proberen te spreken.

Lieve dames, alle drie bedankt voor jullie steun en voor alle gezelligheid!

En dan natuurlijk al mijn collega's en oud-collega's bij Metamedica. Jullie zorgen allemaal voor de nodige afwisseling en gezelligheid in het keukentje en natuurlijk voor de broodnodige horizonverbreding: dank daarvoor. Omdat ik hier zo lang heb rondgelopen, wil ik een aantal van jullie even apart noemen. Om te beginnen Ingrid Lathouwer en Hellen Heutz: Ingrid die ik dankzij mijn onderwijstaken goed heb leren kennen en Hellen die het hoofd koel houdt en zich staande wist te houden in de hectiek van de brieven en administratie aan het einde van het traject. Dank jullie wel voor de broodnodige ondersteuning! En Agnes Meershoek en Anja Krumeich: ook jullie blijken gewoon aardige mensen te zijn... want wat was ik onder de indruk van jullie toen ik hier net begon. Ik zal jullie oprechte interesse tijdens en na de zwangerschap van Kes niet vergeten. Annelien Bredenoord en Erik Aarden, ook jullie wil ik even apart bedanken voor de praktische en zeer nuttige tips ten aanzien van de afronding van het boek en de voorbereiding van de verdediging. En Ada van Bruchem, mijn oude kamergenote. Ik denk dat we in veel opzichten niet meer van elkaar kunnen verschillen. Enkele overeenkomsten zijn er gelukkig wel, die ervoor hebben gezorgd dat we het vaak heel gezellig hebben gehad.

Mijn lieve vriendinnen Catelijne Leenen en Wendy Kieboom, we delen dezelfde achtergrond, maar eigenlijk vooral eenzelfde levenshouding. Niks laadt me iedere keer weer zo op als een avondje met jullie. Altijd te kort, want er valt nog zo veel te bespreken. Wij raken, denk ik, nooit uitgepraat. Maar we hoeven het straks niet meer over mijn proefschrift te hebben!

Mijn paranimfen, Angelique Heijnen en Janneke Moust. Lieve, warme en bijzondere Angelique, wat ga ik jou missen! Het klikt tussen ons vanaf het begin. Vanaf het begin ben je ook al mijn paranimf. Collega voor nu, maar vriendin voor het leven. 
Lief zusje. Het gaat zo lekker vanzelf als we samen zijn. Ik hoef niks uit te leggen en ik hoef me niet te verantwoorden. Het idee dat jij er gewoon altijd bent, is geruststellend en vertrouwd. Want zusjes blijven we altijd. Love you.

Angelique en Janneke, natuurlijk zijn jullie mijn paranimfen!

Papa en mama. Wat zou ik zonder jullie moeten beginnen? In de periode van het werken aan mijn proefschrift hebben jullie met $z$ 'n tweeën maar ook wij als gezin samen met Arjen en Janneke, flink wat voor de kiezen gehad. Maar we zijn er allemaal nog en allemaal nog bij elkaar.

Lieve mama, dankjewel voor het iedere keer weer klaarstaan als ik je nodig heb. Op praktisch gebied als lieve oma en opvang voor Kes en Dex en op emotioneel gebied als mijn moeder. Bedankt ook voor het me iedere keer weer herinneren aan wat er echt belangrijk is in de wereld.

En lieve papa, wat lijken wij eigenlijk op elkaar, he? Je kunt nu gerust ademhalen: ik heb mijn proefschrift afgemaakt. Je speelt een hele belangrijke rol in mijn leven en ik hoop dat je weet dat ik je enorm waardeer als vader, raadgever en opa.

Dank jullie beiden voor mijn fijne en warme jeugd, die de basis vormt van wie ik nu ben. Ik houd van jullie.

Lieve Maria, met jou luiden we al jaren het weekend in. Ik hoop dat we dat nog lang blijven doen. Als Kes of Dex bij jou zijn, weet ik dat ik me geen zorgen hoef te maken. Bedankt voor het zijn van een lieve en betrouwbare oma en schoonmoeder.

Kes en Dex, jullie zijn nog zo klein, maar o zo belangrijk voor me. Wat is er heerlijker dan iedere ochtend wakker te worden met het idee dat jullie er zijn! Er is niks mooier dan moeder te zijn van jullie. Ik houd van jullie met heel mijn hart.

Iwan. De liefde van mijn leven. Mijn steun en toeverlaat. Mijn rots in de branding. Wat heb je veel moeten aanhoren de laatste jaren. Over het proefschrift hoeven we het nu niet meer te hebben. Ik wil je bedanken voor alles wat je bent: lief en zorgzaam, een goede papa, betrouwbaar en eerlijk, mooi en sterk en vooral voor het zijn van mijn man. Ik houd van je, onvoorwaardelijk en ontzettend veel.

Tenslotte, dank aan iedereen die op de een of andere manier heeft bijgedragen aan het voltooien van dit proefschrift. 
Curriculum Vitae 
osy Ubachs-Moust werd geboren op 17 november 1975 te Houthem-Valkenburg. Zij behaalde haar HAVO en VWO diploma in respectievelijk 1994 en 1996 aan het Sint-Maartenscollege te Maastricht. Zij volgde van september 1996 tot september 2001 de studie Nederlands Recht aan Maastricht University. Vervolgens werkte zij als docent bij de vakgroep Gezondheidsrecht aan de Faculty of Health, Medicine and Life Sciences van Maastricht University. In september 2002 is zij als aio begonnen aan haar promotie-onderzoek bij de vakgroep Health, Ethics \& Society. Vanaf 2006 heeft zij haar onderzoekswerkzaamheden gecombineerd met een docentschap bij dezelfde vakgroep.

Josy is in 2004 getrouwd met Iwan Ubachs. In 2005 werd zij moeder van Kes en in 2010 van Dex. 